\title{
Les artefacts importés dans un contexte de carrières : la techno-économie des industries lithiques du Témiscouata (Québec) durant le Sylvicole et la période de Contact
}

\author{
Patrick Eid \\ Université de Montréal, Montréal, Canada. Email: patrick.eid@artefactuel.ca
}

\begin{abstract}
Résumé :
Cet article présente les données relatives à la techno-économie de chasseurs-cueilleurs nomades du Témiscouata (Québec, Canada) durant les périodes du Sylvicole moyen tardif (1500-1000 AA), le Sylvicole supérieur (1000-450 AA) et la période de Contact (450-250 AA). Cette région, située dans l'extrémité nord du bassin versant du la rivière Saint-Jean (Maine, Nouveau-Brunswick, Québec), offre une importante source de matière première, le chert Touladi, qui a été fortement exploitée durant la préhistoire et même durant la période historique par les Premières Nations amérindiennes. Les chaînes opératoires lithiques de cinq sites archéologiques du Témiscouata ont été analysées via l'approche technologique afin d'en reconstituer les schèmes techno-économiques. Deux chaînes opératoires principales sont présentes dans les assemblages, soit la taille bifaciale et le débitage de nucléus à éclats. Une troisième chaîne opératoire est occasionnellement présente et correspond à l'utilisation de pièces esquillées, processus qui génère indirectement des supports potentiellement utilisables pour en faire des outils. D’abord réalisée sur la matière locale, l'analyse a ensuite porté son regard sur les matériaux exogènes afin de voir si la gestion des chaînes opératoire différait lorsque les groupes nomades étaient éloignés des carrières de chert Touladi. Les artefacts en matériaux allochtones, même s'ils comptent pour une part minime des assemblages lithiques, permettent d'entrevoir les stratégies adoptées préalablement à l'occupation du Témiscouata, dans un contexte de rareté en matières premières lithiques de bonne qualité.
\end{abstract}

Mots-clés : technologie lithique; techno-économie; chaîne opératoire; matières premières exogènes; Québec; Premières Nations; préhistoire; archéologie

\section{Introduction}

Le Nord-est américain est un territoire possédant de nombreuses sources de matières lithiques qui ont été exploitées par les communautés amérindiennes durant la préhistoire et même durant la période historique. Ces contextes d'abondance en matières premières sont habituellement accompagnés de nombreux sites voués à la taille de ces roches dures, mais où se déroulent aussi d'autres activités de natures économique, technique ou domestique. Dans les sites archéologiques situés à proximité d'une source de pierre siliceuse de bonne qualité, la part de matières allochtones au sein des assemblages est bien évidemment modeste en

Published by the School of History, Classics and Archaeology, University of Edinburgh ISSN: 2055-0472. URL: http://journals.ed.ac.uk/lithicstudies/

This work is licensed under a Creative Commons Attribution 2.5 UK: Scotland License. 
comparaison. Dans le Nord-est américain, si les archéologues se sont beaucoup intéressés à la typologie des outils et la caractérisation de la matière première de ces objets importés, ils se sont généralement moins attardés à leur technologie de fabrication et aux mécanismes économiques qui ont mené à leur transport, leur utilisation et leur abandon loin de leur source d’origine. Il était donc intéressant de réaliser une recherche visant à mieux comprendre les stratégies de gestion des industries lithiques en dehors des zones riches en ressources lithiques. Cependant, plutôt que d'analyser directement de tels contextes, notre intérêt était de vérifier comment ces stratégies économiques peuvent se traduire matériellement sur les sites à proximité de carrières de pierres. Cet article se penche sur cette question et l'aborde à travers les résultats d'une thèse de doctorat (Eid 2017) portant sur l'analyse techno-économique d'assemblages lithiques du Témiscouata, une région du Québec (Canada) où l'on retrouve une source de pierre siliceuse de bonne qualité : le chert Touladi (Figure 1).

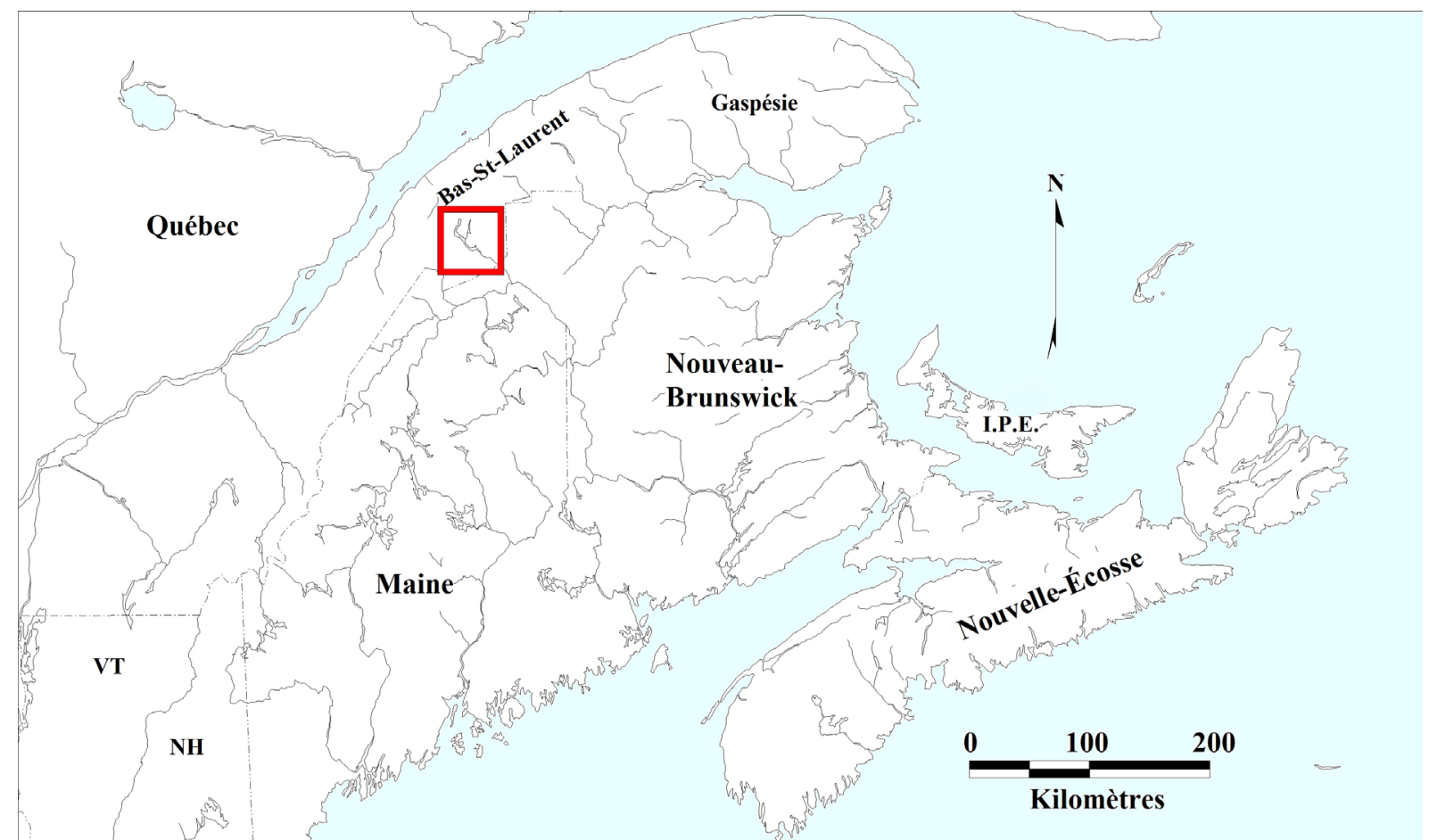

Figure 1. Carte de localisation générale du Témiscouata (encadré rouge) dans la Péninsule maritime (cartographie : Adrian Burke).

Figure 1. Map of general location of Témiscouata (red box) in the Maritime Peninsula (cartography: Adrian Burke).

\subsection{La techno-économie}

La techno-économie est la branche des études technologiques qui s’intéresse particulièrement aux modes de gestion et d'organisation des chaînes opératoires (voir par exemple : Boëda 1991; Boëda et al. 1990; Brenet 2011; Geneste 2010; Inizan 1976; 1980; Lhomme \& Connet 2001; Perlès 1980; 1991b; Porraz 2005). Les productions d'outils en pierre taillée demandent une certaine organisation relativement à l'approvisionnement en matériaux, la fabrication, l'utilisation, l'entretien et l'abandon des outils, ainsi qu'au transport de pièces lithiques durant les phases de déplacements. Elles sont donc très révélatrices d'intentions, de choix, de comportements et de stratégies de gestion sur le plan économique.

Le premier objectif d'une analyse économique des industries lithiques est d'élucider la nature des stratégies mise en œuvre sur les sites où les activités se sont déroulées (échelle locale). Ensuite, il est possible d'aborder les modalités de gestion à l'échelle du territoire, notamment via l'étude de la segmentation des processus dans le temps et l'espace. La 
présence et l'absence de maillons des chaînes opératoires sont autant d'éléments significatifs qui amènent à s'interroger sur les raisons de ces portions manquantes. Si les technologies mises en œuvre sur la matière première locale (chert Touladi) révèlent les processus économiques qui ont eu lieu au Témiscouata, ils annoncent aussi ce qui était prévu après le départ des groupes de la région. Les objets en matières allochtones abandonnés au Témiscouata nous renseignent quant à eux sur les stratégies de gestion qui avaient cours avant d'atteindre la région, lorsque les groupes avaient accès à d'autres sources lithiques ou lorsqu'ils ne pouvaient compter que sur les réserves qu'ils transportaient avec eux. L'adoption de stratégies de gestion constitue donc un mécanisme important pour l'adaptation des chasseurs-cueilleurs à leur environnement et il est sujet à s'adapter en fonction des besoins et des contextes rencontrés au cours d'un cycle de nomadisme (Brenet 2011: 30; Geneste 2010: 429-435; Lhomme \& Connet 2001; Porraz 2005: 19-20; Soressi 2002: 136-140).

Par la suite, la reconstitution des schèmes techno-économiques amène à explorer les raisons qui ont mené à leur adoption. Cette seconde partie du problème est plus complexe puisqu'elle ne se résume pas forcément en une simple relation de cause à effet entre deux variables. À un même problème, il peut exister diverses solutions envisageables qui vont être puisées à travers un compromis entre les possibilités et les contraintes. Ces dernières, peuvent être autant internes (connaissances, savoir-faire, traditions techniques, compétences, anticipation des besoins, etc.) qu'externes (disponibilité et qualité des matériaux, schèmes de mobilité, économie de subsistance, besoins spécifiques, relations avec ses voisins, capacités de transport, disponibilité en temps, aléas historiques, etc.) à l'individu et à son groupe (Boëda 1991; Geneste 2010; Lemonnier 1986; Perlès 1991b; Porraz 2005: 49).

\subsection{Le Témiscouata}

Situé dans l'hinterland de la région du Bas-Saint-Laurent au Québec (Canada), le Témiscouata se trouve, dans la Péninsule maritime, à la frontière de la province du NouveauBrunswick et de l'État américain du Maine (Figure 1). Placé au cœur de la chaîne des monts Notre-Dame, une extension du massif appalachien, le paysage de la région est parsemé de montagnes, de vallées, de plateaux et de collines à travers lesquels coule un vaste réseau hydrographique. Les nombreux lacs et rivières ont joué un rôle capital dans l'occupation du Témiscouata qui se situe dans une position intermédiaire entre la vallée du fleuve SaintLaurent au nord et la côte Atlantique au sud (baie de Fundy et golfe du Maine). Le carrefour de voies navigables du Témiscouata en a fait un lieu de passage privilégié durant la préhistoire permettant ainsi la connexion avec de nombreuses autres régions. De par sa position géographique, le Témiscouata peut être considéré comme faisant partie de la haute vallée de la rivière Saint-Jean qui se jette dans la baie de Fundy au sud (Burke 2001; 2009; Chalifoux \& Burke 1995: 237; Chalifoux et al. 1998: 25-29; Dumais et al. 1998; MarieVictorin 1918; Robitaille \& Saucier 1998: 111).

Avant le contact européen, la région du Témiscouata était surtout fréquentée par des chasseurs-cueilleurs nomades exploitant une variété de niches écologiques et confrontés à une grande saisonnalité des ressources. Outre l'exploitation des richesses animales et végétales provenant des forêts et des milieux aquatiques, les groupes autochtones y venaient aussi pour extraire une ressource minérale de choix, le chert Touladi, dont deux carrières sont connues à ce jour (CkEe-26 et CkEe-28). En position primaire, cette variété de pierre siliceuse se présente sous la forme de lits affleurants ou enterrés sous la surface du sol et se détachant en blocs et plaquettes de dimensions variées, mais souvent limitées par la présence de failles et diaclases. On la retrouve aussi en dépôt secondaire, sous la forme de galets disséminés notamment le long des lacs et rivières de la région (Burke 2000: 169-185; 2007; 2009; Burke 
\& Chalifoux 1998; Chalifoux \& Burke 1995; Chalifoux et al. 1998; Chapdelaine 1991; Gauthier et al. 2012; Leclerc 2009: 67-73; Morin 1988).

Si la plus ancienne occupation humaine du Témiscouata remonte à la fin de la période paléoindienne, entre 9000 et 9500 ans avant aujourd'hui (AA) (Dumais \& Rousseau 2002), la majorité de celles retrouvées et fouillées à ce jour sont plutôt datées de la préhistoire récente (Sylvicole : 3000 à $450 \mathrm{AA}$ ) et de la période de Contact avec les premiers Européens (450-250 AA). À l'arrivée de ces derniers, c'est la Première Nation Malécite (Wolastoqiyiks) qui occupe de manière privilégiée le Témiscouata et le reste du bassin versant de la rivière Saint-Jean. La continuité culturelle observée pendant les trois derniers millénaires par l'archéologie tend d'ailleurs à démontrer l'ancienneté de l'occupation de ce territoire par les ancêtres des Malécites. Le portrait tracé par l'archéologie, l'ethnologie et l'ethnohistoire montre que les chasseurs-cueilleurs fréquentant le Témiscouata avaient adopté une économie de subsistance basée principalement sur une exploitation généraliste des ressources, dont la disponibilité évoluait fortement au cours des saisons et selon les différentes niches écologiques exploitées. Ce mode de vie imposait à ces communautés une grande mobilité, surtout durant la saison froide, lorsque les ressources se faisaient beaucoup plus rares et qu'elles étaient plus difficiles d'accès (Burke 2000: 58-64, 72-83, 94-100, 333-340; 2009; Burke \& Chalifoux 1998; Burke \& Richard 2010; Chalifoux et al. 1998; Sanger 2008).

Les sites du Sylvicole et de la période de Contacts découverts à ce jour n’ont pas révélé de stratification culturelle et aucune structure d'habitation n'a été clairement identifiée. En effet, les traces de poteaux sont absentes et les structures mises au jour se résument habituellement à une ou plusieurs aires de combustion, parfois accompagnées de fosses discrètes. Les établissements sont habituellement situés sur de basses terrasses à proximité des principaux lacs et rivières de la région et les vestiges sont normalement enfouis sur une faible profondeur (Burke 2000: 100, 160-161; 2003; 2009; Chalifoux et al. 1998: 61-128).

\section{3. État de la recherche en technologie lithique au Témiscouata}

À ce jour, les analyses technologiques de tradition française n’ont que rarement été appliquées sur des collections lithiques du Nord-est américain. L’étude des technologies lithiques a donc été abordée avant tout via des analyses de tradition anglo-saxonne (reduction sequence analysis) regroupant diverses méthodologies de recherche. Au Témiscouata, l'application de ces approches a permis de révéler les grandes lignes de ces industries depuis la collecte de la matière première aux carrières de chert jusqu'à l'abandon des outils (Burke 2000; 2007; Burke \& Chalifoux 1998; Chalifoux et al. 1998: 129-143). Ces recherches ont révélé des industries dominées par la production d'outils bifaciaux (bifaces, pointes de projectiles) et sur éclats, ces derniers se traduisant la plupart du temps par des outils ad hoc (éclats retouchés et utilisés bruts), des grattoirs et, dans une moindre mesure, par des pièces esquillées. Les nucléus sont exclusivement à éclats et la matière première locale a été surtout extraite des carrières plutôt qu'en position secondaire via les galets. Les analyses spécialisées qui ont été réalisées jusqu'alors sur le matériel lithique concernaient essentiellement les matières premières, ce qui a permis de mieux caractériser le chert Touladi, mais aussi les matériaux issus des autres sources des régions environnantes, notamment celles du bassin versant de la rivière Saint-Jean (cherts Munsungun, Tobique, Washademoak, etc.) (Figure 2). Ces analyses ont aussi mené à une meilleure compréhension des territoires d'exploitation des groupes nomades et des réseaux d'échanges qui prévalaient durant la préhistoire (Burke 2000; Gauthier et al. 2012; Leclerc 2009).

Ces recherches passées ont grandement contribué à une meilleure connaissance des occupations préhistoriques du Témiscouata, de son histoire culturelle et des interrelations avec les groupes des régions limitrophes. Néanmoins, les approches méthodologiques mises 
en œuvre jusqu’à récemment avaient atteint une certaine limite dans la production de données inédites et il devenait alors pertinent d'explorer de nouvelles avenues de recherche. C'est dans ce contexte que l'auteur de cet article a entrepris une thèse de doctorat (Eid 2017) basée sur l'approche technologique héritée de la tradition française. Cette recherche avait pour problématique de reconstituer les chaînes opératoires lithiques au Témiscouata, du Sylvicole moyen tardif (1500 à $1000 \mathrm{AA}$ ) à la période de Contact (450-250 AA), selon une perspective régionale et diachronique, afin de reconnaître les schèmes techno-économiques adoptés et leur implication dans les modes de vie des chasseurs-cueilleurs. Pour répondre à cette problématique, cinq collections lithiques, issues d'autant de sites archéologiques, ont été analysées.

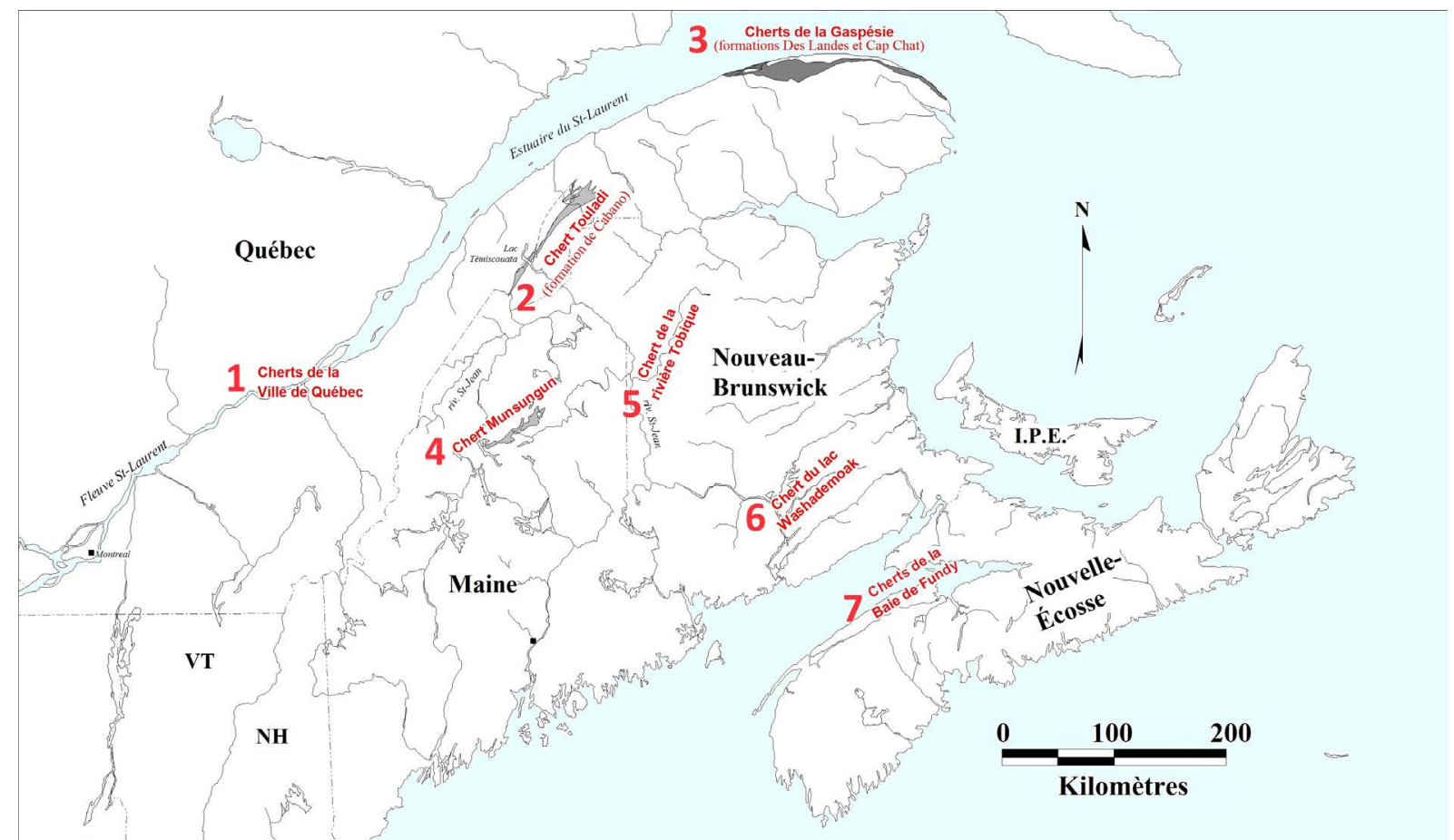

Figure 2. Carte localisant les principales sources lithiques de la Péninsule maritime : 1- cherts de la Ville de Québec; 2- chert Touladi; 3- cherts de la Gaspésie; 4- chert Munsungun; 5- chert de la rivière Tobique; 6- chert du lac Washademoak; 7- cherts de la baie de Fundy (cartographie : Adrian Burke).

Figure 2. Map locating the main lithic sources of the Maritime Peninsula : 1- Québec City cherts; 2- Touladi chert; 3- Gaspésie cherts; 4- Munsungun chert; 5- Tobique river chert; 6- Washademoak lake chert; 7- Bay of Fundy cherts (cartography: Adrian Burke).

Cet article ne traite cependant que d'une facette de cette recherche, soit le traitement des matières siliceuses exogènes par les tailleurs du Témiscouata. Nous avons choisi de nous attarder plus particulièrement sur ces artefacts importés, puisqu'ils sont présents dans la plupart des assemblages retrouvés à proximité de carrières lithiques, mais ils demeurent souvent dans l'ombre de la masse imposante d'artefacts produits sur la matière locale. Ils sont néanmoins révélateurs de comportements qui ont prévalu avant leur abandon, notamment dans les zones pauvres en ressources lithiques. L'objectif de cet article est donc de présenter les données technologiques associées aux artefacts importés et de voir dans quelle mesure elles nous permettent une meilleure compréhension des stratégies de gestion qui ont eu cours avant que les groupes n’atteignent le Témiscouata. 


\subsection{Présentation des sites de l'étude}

Les cinq sites archéologiques du Témiscouata abordés dans cette thèse sont : CkEe-12, CkEe-22, CkEe-9, CkEe-2 et CjEd-5 (Tableau 1; Figures 3 et 4). Ils comptent tous plusieurs aires de fouilles ayant révélé chacune des contextes différents (nature de l'occupation, datation, assemblage lithique, structures découvertes, superficie excavée, etc.). Cependant, une seule aire a été sélectionnée pour chaque établissement dans l'optique d'analyser des assemblages aussi homogènes que possible.

CkEe-12 se situe sur une pointe de terre sur la rive ouest du Petit lac Touladi. Dans le cadre de cette recherche, nous nous sommes concentrés sur l'aire 5 qui a été fouillée sur une superficie de 18,5 $\mathrm{m}^{2}$. Elle a révélé la présence d'un foyer déstructuré autour duquel se sont accumulés 4500 artefacts en pierre taillée. Le charbon récolté a été daté à $950 \pm 60$ AA (calibré entre 980 et 1220 de notre ère) ce qui positionne cette occupation à la fin du Sylvicole moyen tardif et au début du Sylvicole supérieur. L’assemblage lithique est intéressant notamment par son nombre relativement important de nucléus $(n=38)$ et sa faible proportion d'outils bifaciaux ( $n=7)$ et sur éclats $(n=14)$ (Tableau 2). L'aire 5 a été initialement interprétée comme le reste d'une occupation temporaire spécialisée dans la taille de pierre (Chalifoux et al. 1998: 90-96; Jost 1995: 72-76).

Tableau 1 : Présentation des sites de l'étude. EC - ère commune.

Table 1. Presentation of the study sites. EC - common era.

\begin{tabular}{|c|c|c|c|c|}
\hline Sites & Aires & Périodes chronologiques & $\begin{array}{l}\text { Datations } \\
\text { radiocarbones } \\
\text { calibrées }\end{array}$ & Fonction(s) présumée(s) \\
\hline CkEe-12 & $\begin{array}{l}\text { Aire } 5 \\
\left(18,5 \mathrm{~m}^{2}\right)\end{array}$ & $\begin{array}{l}\text { Fin du Sylvicole moyen tardif - } \\
\text { début du Sylvicole supérieur }\end{array}$ & 980 à $1220 \mathrm{EC}$ & Atelier de taille spécialisé \\
\hline CkEe-22 & $\begin{array}{l}\text { Aire } 1 \\
\left(16,5 \mathrm{~m}^{2}\right)\end{array}$ & $\begin{array}{l}\text { Fin du Sylvicole moyen tardif - } \\
\text { début du Sylvicole supérieur }\end{array}$ & 980 à 1276 EC & $\begin{array}{l}\text { Atelier de taille et campement } \\
\text { résidentiel }\end{array}$ \\
\hline CkEe-9 & $\begin{array}{l}\text { Aire } 2 \\
\left(22 \mathrm{~m}^{2}\right)\end{array}$ & $\begin{array}{l}\text { Sylvicole supérieur - période de } \\
\text { Contact }\end{array}$ & 1430 et $1660 \mathrm{EC}$ & $\begin{array}{l}\text { Atelier de taille et campement } \\
\text { résidentiel }\end{array}$ \\
\hline CkEe-2 & $\begin{array}{l}\text { Aire C } \\
\left(22 \mathrm{~m}^{2}\right)\end{array}$ & $\begin{array}{l}\text { Sylvicole supérieur - période de } \\
\text { Contact }\end{array}$ & - & $\begin{array}{l}\text { Atelier de taille et camp de } \\
\text { base }\end{array}$ \\
\hline CjEd-5 & $\begin{array}{l}\text { Structure } 7 \\
\left(6 \mathrm{~m}^{2}\right)\end{array}$ & Sylvicole moyen tardif & 680 à $1050 \mathrm{EC}$ & $\begin{array}{l}\text { Atelier de taille, campement } \\
\text { résidentiel et lieu de pratiques } \\
\text { rituelles }\end{array}$ \\
\hline
\end{tabular}

Tableau 2. Effectifs généraux des collections lithiques étudiées.

Table 2. Details of the artefacts found in each collection studied.

\begin{tabular}{|c|c|c|c|c|c|c|c|c|c|}
\hline$\stackrel{\varrho}{ \pm}$ & 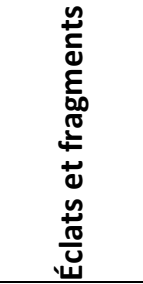 & $\frac{\stackrel{n}{\partial}}{\frac{.0}{U}}$ & 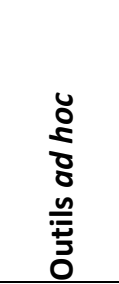 & $\begin{array}{l}\frac{n}{0} \\
\frac{1}{0} \\
\frac{\pi}{0}\end{array}$ & 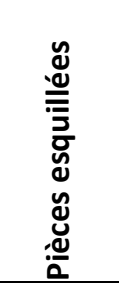 & 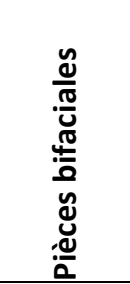 & 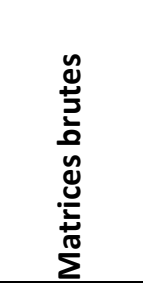 & 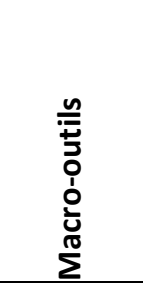 & 胥 \\
\hline CkEe-12 & 4441 & 37 & 10 & 4 & & 7 & 1 & & $4500(16,0 \%)$ \\
\hline CkEe-22 & 9236 & 7 & 72 & 26 & & 25 & 2 & 7 & $9375(33,3 \%)$ \\
\hline CkEe-9 & 87 & 81 & 137 & 126 & 186 & 194 & & 1 & $812(2,9 \%)$ \\
\hline CkEe-2 & 5605 & 8 & 65 & 14 & 90 & 46 & & 2 & $5830(20,7 \%)$ \\
\hline CjEd-5 & 7564 & 6 & 26 & 7 & 1 & 9 & & 1 & $7614(27,1 \%)$ \\
\hline Total & $\begin{array}{c}26933 \\
(95,7 \%)\end{array}$ & $\begin{array}{c}139 \\
(0,5 \%)\end{array}$ & $\begin{array}{c}310 \\
(1,1 \%)\end{array}$ & $\begin{array}{c}177 \\
(0,6 \%)\end{array}$ & $\begin{array}{c}277 \\
(1,0 \%)\end{array}$ & $\begin{array}{c}281 \\
(1,0 \%)\end{array}$ & $\begin{array}{c}3 \\
(0,01 \%)\end{array}$ & $\begin{array}{c}11 \\
(0,04 \%)\end{array}$ & $\begin{array}{c}28131 \\
(100 \%)\end{array}$ \\
\hline
\end{tabular}




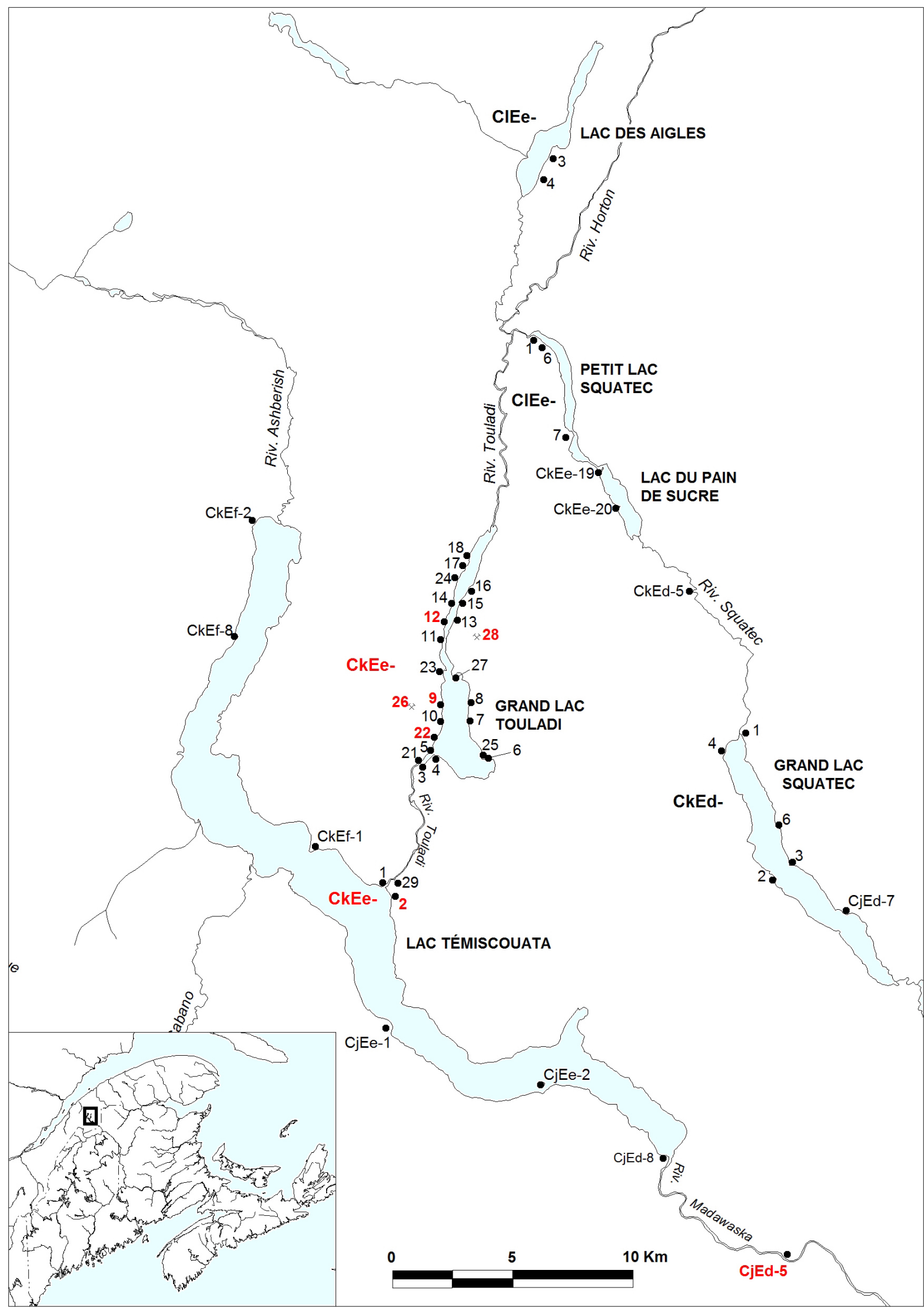

Figure 3. Carte du Témiscouata et des sites préhistoriques de la région. On voit en rouge, les sites de l'étude et les deux carrières de chert Touladi (CkEe-26 et CkEe-28) (cartographie : Adrian Burke).

Figure 3. Map of Témiscouata showing de main archaeological sites in the region. In red, the sites studied in this article and the two chert quarries (CkEe-26 et CkEe-28) (cartography : Adrian Burke). 


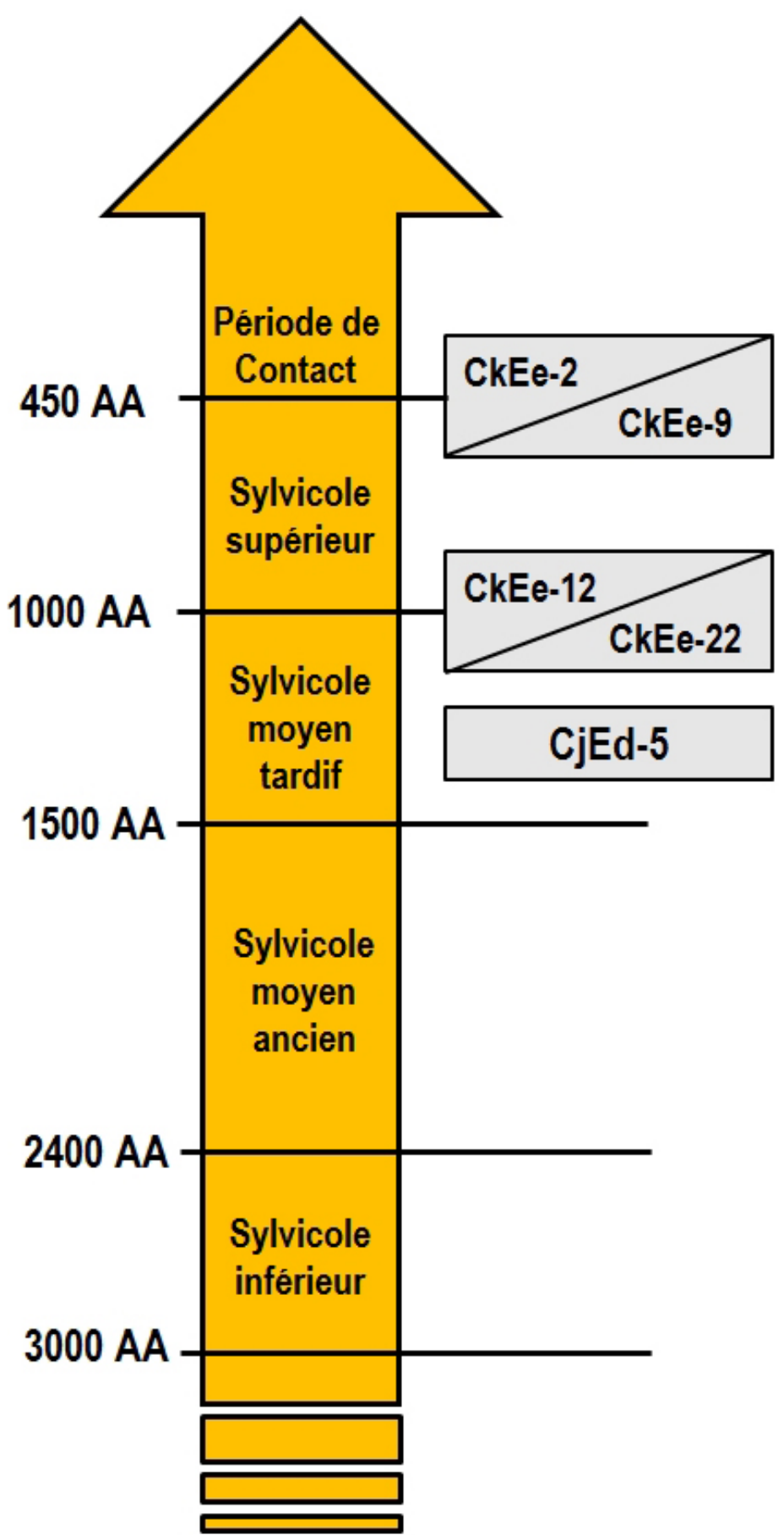

Figure 4. Ligne du temps montrant le positionnement chronologique de l'aire sélectionnée sur chacun des sites archéologiques de l'étude.

Figure 4. Timeline showing the chronological positioning of the selected area on each of the archaeological sites in the study.

CkEe-22 se trouve sur la rive ouest du Grand lac Touladi et la collection analysée provient de l'aire $1\left(16,5 \mathrm{~m}^{2}\right)$. C'est à cet endroit que la majorité des outils de ce site ont été retrouvés $(n=123)$ et ce secteur compte aussi une proportion relativement forte d'artefacts en matériaux exogènes $(n=485)$ (Tableau 2). De plus, même si aucune structure formelle n’a été identifiée sur l’aire 1, un échantillon de charbon a été daté à $910 \pm 80$ AA (calibré entre 980 à 1276 de notre ère), situant ainsi l'occupation vers la fin du Sylvicole moyen tardif et le début du Sylvicole supérieur. CkEe-22 a été initialement interprété comme les restes d’une 
occupation de courte durée et assez circonscrite, correspondant peut-être en un camp de chasse où des activités de taille de la pierre auraient été menées (Chalifoux et al. 1998: 103).

Le site CkEe-9 se situe lui aussi sur la rive ouest du Grand lac Touladi et notre analyse a porté sur l'aire $2\left(22 \mathrm{~m}^{2}\right)$ qui a révélé une structure de combustion datée à $340 \pm 60 \mathrm{AA}$ (calibrée entre 1430 et 1660 de notre ère). La découverte d'une perle de verre à proximité du foyer tend à confirmer que l'occupation se situe au tout début de la période historique, puisque l'analyse typologique de cet artefact indique une datation probable du XVI ${ }^{\mathrm{e}}$ siècle (Delmas 2016: 97-98; Loewen 2016: 271). L'aire 2 a livré une très forte densité en matériel lithique et c'est la collection la plus riche de notre corpus, toutes classes d'artefacts confondues ( $n=67$ 701). Cependant, les éclats de taille en chert Touladi n’ont pas été analysés et la recherche s'est limitée aux nucléus et aux outils de cette matière, ainsi qu'aux éclats en matériaux exogènes. Les artefacts analysés pour ce site sont donc au nombre de 812 (Tableau 2). L'aire 2 de CkEe-9 a été interprétée comme le reste d'une ou plusieurs occupations de courtes durées prenant la forme d'un campement, possiblement familial, où se sont déroulées des activités de taille intensives, mais aussi des tâches de nature domestique, comme l'indiquent notamment les restes osseux, la poterie et les nombreux outils sur éclats utilisés sur place (Burke 1993: 53-92; Chalifoux et al. 1998: 75-82).

Le site CkEe-2 est situé sur la rive est du lac Témiscouata et il occupe une position stratégique permettant d'exploiter les ressources de ce vaste plan d'eau et celles de la rivière Touladi, laquelle donnait accès aux lacs du même nom et aux carrières de chert. Notre analyse s'est concentrée sur l'aire C qui a été fouillée sur près de 237,5 pieds carrés, soit environ 22 $\mathrm{m}^{2}$. Elle a livré une aire de combustion, ainsi qu'une importante collection d'artefacts lithiques ( $\mathrm{n}=5830)$ (Tableau 2). L’assemblage lithique a notamment la particularité de montrer très peu de nucléus et une forte proportion de pièces esquillées. L'aire $\mathrm{C}$ a été interprétée initialement comme un petit camp de base occupé vers la fin du Sylvicole supérieur et le début de la période de Contact (Bisson 1990; Chalifoux et al. 1998: 62-70).

Enfin, le site CjEd-5 est situé sur la rive nord de la rivière Madawaska, sur une pointe de terre à l'embouchure de la rivière aux Bouleaux et à environ 9 km en aval du lac Témiscouata. C'est le site de notre corpus le plus éloigné des carrières de chert Touladi (entre 27,5 et $29 \mathrm{~km}$ ), bien qu'il demeure tout de même dans une zone d'approvisionnement direct. Nous nous sommes concentrés sur la collection d'artefacts retrouvée en association à la structure 7. Cette dernière correspond à une vaste aire de combustion fouillée sur une superficie de $6 \mathrm{~m}^{2}$ et associée à 13591 restes osseux et 7615 artefacts en pierre taillée. La datation radiométrique étalonnée situe l'occupation vers $1020 \pm 100$ AA (calibrée entre 680 et 1050 de notre ère), ce qui correspond à la période du Sylvicole moyen tardif. Ce secteur présente un contexte particulier où se seraient déroulées des activités rituelles. En effet, deux bifaces en quartzite de Ramah, une matière rarement rencontrée dans la région, ont été intentionnellement fracturés et les fragments ont ensuite été brûlés dans le foyer. Le "sacrifice » présumé de ces deux bifaces a été accompagné de ce qui semble être un festin composé d'au moins six castors, d’un porc-épic et peut-être un artiodactyle (Burke 2005; 2006).

\section{Les chaînes opératoires sur le chert Touladi}

Nous présentons ici brièvement les résultats de l'analyse techno-économique des chaînes opératoires sur le chert Touladi, afin de bien contextualiser les données relativement aux matériaux importés. Trois chaînes opératoires ont été reconnues pour la matière première locale : la production bifaciale, le débitage de nucléus et l'utilisation de pièces esquillées. Ces trois processus techniques ont généré des éclats qui ont potentiellement pu servir ensuite à la production d'outils. 


\subsection{La chaîne opératoire bifaciale (chert Touladi)}

La fabrication de pièces bifaciales en chert Touladi s'est révélée être l'activité de taille dominante sur chaque site et celle qui a généré le plus d'éclats. Les collections étudiées ont livré 265 pièces bifaciales abandonnées selon différents stades de productions (Tableau 3). Aux fins de l'analyse technologique, le processus de taille de bifaces a été séparé en différentes phases et sous-phases à travers lesquelles les éclats diagnostiqués ont été associés (Tableau 4, Figures 5 à 10). Sauf quelques exceptions, la majorité des pièces bifaciale a été façonnée directement sur des matrices brutes, le plus souvent sur des plaquettes de chert dont la forme tabulaire se prêterait naturellement bien à cette activité. De gros éclats, probablement issus de nucléus, ont aussi occasionnellement servi de supports pour l'industrie bifaciale. Quant aux galets de chert prélevés en position secondaire, ils n’ont été employés que de manière anecdotique.

Tableau 3. Les types de pièces bifaciales en chert Touladi.

Table 3. Bifacial tools types made with Touladi chert.

\begin{tabular}{lllllll}
\hline Types de pièces bifaciales & CkEe-12 & CkEe-22 & CkEe-9 & CkEe-2 & CjEd-5 & Total \\
\hline Ébauche (phase 1) & 6 & 10 & 74 & 23 & 5 & $118(44,5 \%)$ \\
Préforme (phase 2) & & 3 & 39 & 9 & & $51(19,2 \%)$ \\
Biface (phase 3) & 1 & 4 & 44 & 5 & & $54(20,4 \%)$ \\
Biface (phase 4) & & 1 & 19 & 8 & 1 & $29(10,9 \%)$ \\
Pointe de projectile (phase 4) & & 1 & 12 & & & $13(4,9 \%)$ \\
\hline Total & $\mathbf{7}$ & $\mathbf{1 9}$ & $\mathbf{1 8 8}$ & $\mathbf{4 5}$ & $\mathbf{6}$ & $\mathbf{2 6 5 ( 1 0 0 \% )}$ \\
\hline
\end{tabular}

Si on ne se fie qu'aux pièces bifaciales elles-mêmes, l'amont de cette chaîne opératoire semble beaucoup plus représenté que son aval. Il faut toutefois tenir compte du fait que la majorité des pièces bifaciales abandonnées in situ présentent des indices explicites de fractures ou de malfaçons. Les phases préliminaires seraient à ce propos plus susceptibles d'être l'objet de tels problèmes, notamment à cause des nombreuses failles présentes dans la matière et qui sont souvent imperceptibles avant le début de la taille. Également, car l'étape de mise en forme initiale des plaquettes de chert est une opération délicate où il faut retirer les angles naturels de ces matrices pour y aménager à la place les plans d'équilibres bifaciaux et bilatéraux, opération qui semble avoir généré beaucoup de ratés. Ajoutons à cela que les spécimens taillés avec succès semblent avoir été préférentiellement exportés des ateliers de taille pour une utilisation différée (sans pour autant exclure une utilisation in situ préalable).

Les modalités d'abandons différentielles des pièces bifaciales selon leur état d'avancement ont pour effet de fausser le portrait des activités de taille associées à cette chaîne opératoire si on ne s'attarde qu'à ces artefacts. Pour avoir une image plus juste de la réalité qui prévalait, il est alors nécessaire de se tourner vers l'analyse des éclats issus de chaque phase de production. Ces derniers sont présents en grande quantité et sont donc plus représentatifs des étapes de production qui ont eu cours sur chaque site. Les données générées par l'étude des éclats révèlent que l'industrie bifaciale a été segmentée dans le temps et dans l'espace de manière différente pour chaque site. En effet, chaque collection montre un profil différent quant à la proportion des phases de production qui se sont déroulées in situ. Si un site montre que l'ensemble du processus s'est déroulé sur place, la plupart des autres révèlent plutôt une fragmentation de la chaîne opératoire dans le temps et dans l'espace. Tantôt c'est l'amont qui est dominant, révélant ainsi que les outils taillés étaient exportés dans un état inachevé. Tantôt c'est plutôt l'aval qui prévaut, montrant que les pièces bifaciales ont été introduites sous forme d'ébauches, de préformes ou même de pièces de phases postérieures (Figures 11 à 14). 
Tableau 4. Description des phases de production bifaciale et de leurs produits respectifs.

Table 4. Description of the bifacial stages and their respective products.

\begin{tabular}{|c|c|}
\hline $\begin{array}{l}\text { Phase de production } \\
\text { bifaciale }\end{array}$ & Caractéristiques générales de la pièce bifaciale et des éclats détachés \\
\hline Ébauchage initial & $\begin{array}{l}\text { Pièce bifaciale : très grossière; épaisseur prononcée; contours irréguliers; les } \\
\text { plans d'équilibre bifacial et bilatéral ne sont pas ou peu établis; cortex et }\end{array}$ \\
\hline $\begin{array}{l}\text { Phase 1a } \\
\text { (Étape préliminaire) }\end{array}$ & $\begin{array}{l}\text { surfaces naturelles encore très présents; lorsqu'aménagée sur une } \\
\text { plaquette de chert, il y a présence de bords naturels angulaires plutôt } \\
\text { qu'aménagés en biseau. } \\
\text { Éclats : ils sont de formes très variées et plutôt difficiles à distinguer de ceux }\end{array}$ \\
\hline Outil = ébauche & $\begin{array}{l}\text { produits par les nucléus. Ils peuvent être de dimensions variables, souvent } \\
\text { assez épais, mais parfois assez minces aussi. Le talon a tendance à être lisse, } \\
\text { cortical ou facetté. L'angle de chasse n'est souvent pas très incliné, surtout } \\
\text { si l'ébauche est taillée à partir d'une plaquette. L'abrasion de l'angle de } \\
\text { chasse est possible, mais plutôt rare. Le cortex et les surfaces naturelles de } \\
\text { diaclase sont abondants sur la face supérieure des éclats. La technique de } \\
\text { percussion directe au percuteur dur est plus fréquente que celle par } \\
\text { percuteur tendre. }\end{array}$ \\
\hline Ébauchage avancé & $\begin{array}{l}\text { Pièce bifaciale : moins grossière; épaisseur encore prononcée; contours } \\
\text { moins irréguliers; les plans d'équilibre bifacial et bilatéral sont mieux }\end{array}$ \\
\hline $\begin{array}{l}\text { Phase } 1 \mathrm{~b} \\
\text { (Étape préliminaire) }\end{array}$ & $\begin{array}{l}\text { établis; présence occasionnelle de cortex; présence occasionnelle, mais } \\
\text { localisée, de bords naturels angulaires lorsqu'aménagée sur une plaquette } \\
\text { de chert. } \\
\text { Éclats : ils tendent à se régulariser un peu, mais sont encore assez variables }\end{array}$ \\
\hline Outil = ébauche & $\begin{array}{l}\text { en dimensions. Le cortex ou les surfaces naturelles de diaclases sont moins } \\
\text { prédominants, mais tout de même présents. Le talon est souvent incliné et } \\
\text { facetté et tend parfois à être éversé légèrement. L'abrasion de l'angle de } \\
\text { chasse est plus fréquente qu'à la phase initiale. Les techniques de } \\
\text { percussions directes dure et tendre sont présentes. }\end{array}$ \\
\hline Préformage & $\begin{array}{l}\text { Pièce bifaciale } \text { : les plans d'équilibre bifacial et bilatéral sont assez bien } \\
\text { établis; épaisseur encore relativement prononcée; les contours se }\end{array}$ \\
\hline Phase 2 & $\begin{array}{l}\text { régularisent; la préforme est habituellement entièrement couverte par les } \\
\text { négatifs d'enlèvements (aucun cortex ni bord naturel angulaire). }\end{array}$ \\
\hline (Étape préliminaire) & $\begin{array}{l}\text { Éclats: ils ne portent habituellement pas de cortex, ils tendent à être moins } \\
\text { épais que la phase précédente et à présenter une certaine courbure du }\end{array}$ \\
\hline Outil = préforme & $\begin{array}{l}\text { profil. Le talon est habituellement éversé et facetté sur les deux versants, } \\
\text { mais l'angle de chasse n'est pas aussi aigu qu'aux phases suivantes. L'angle } \\
\text { de chasse est habituellement abrasé. La technique de percussion directe } \\
\text { tendre est exclusive. }\end{array}$ \\
\hline Façonnage initial & $\begin{array}{l}\text { Pièce bifaciale : les plans d'équilibre bifacial et bilatéral atteignent leur état } \\
\text { définitif; la pièce est grandement amincie durant cette étape; les contours }\end{array}$ \\
\hline Phase 3a & $\begin{array}{l}\text { sont régularisés; le biface peut être utilisé dès ce stade, mais peut subir } \\
\text { encore beaucoup de transformations. }\end{array}$ \\
\hline (Étape intermédiaire) & $\begin{array}{l}\text { Éclats : ils sont assez minces et potentiellement de grande dimension, } \\
\text { quoique différents modules soient possibles. On voit souvent une courbure }\end{array}$ \\
\hline Outil = biface & $\begin{array}{l}\text { légère dans le profil de l'éclat. Le talon est éversé et facetté sur les deux } \\
\text { versants, l'angle de chasse est aigu et il est systématiquement abrasé. La } \\
\text { technique de percussion directe tendre est exclusive. }\end{array}$ \\
\hline
\end{tabular}




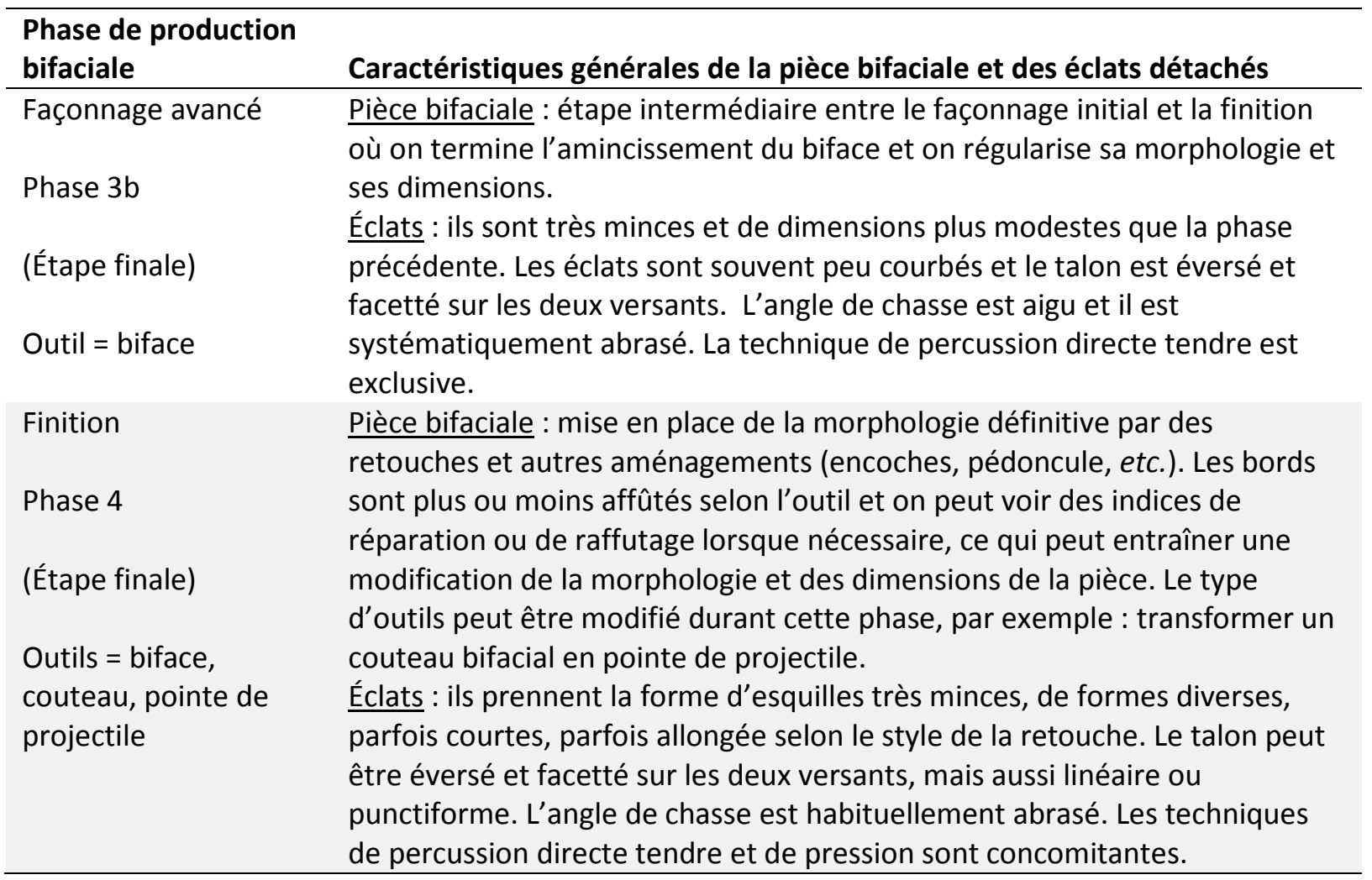
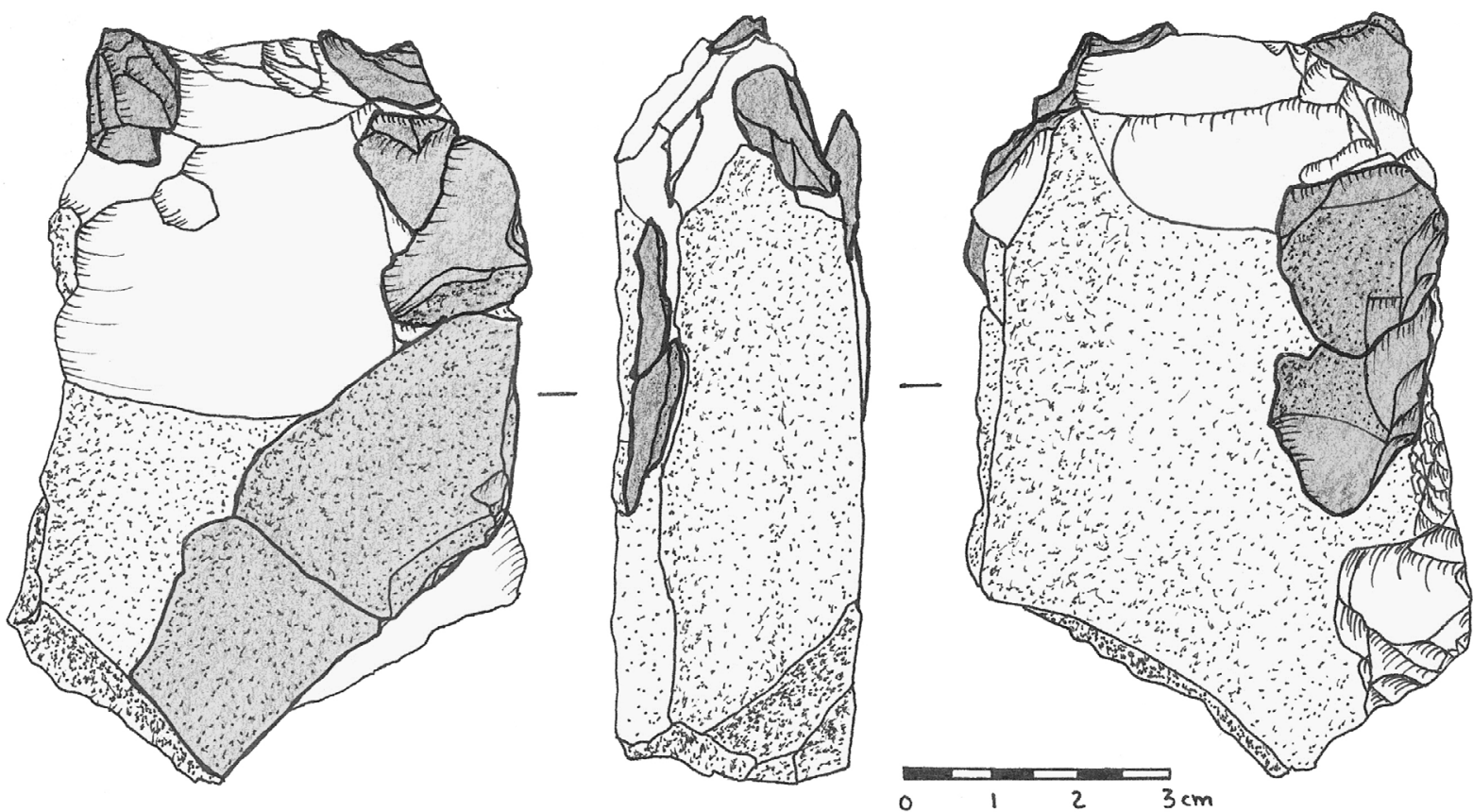

Figure 5. Ébauche en chert Touladi et les éclats qui lui sont remontés (en foncé). L'ébauche est ici très préliminaire, on distingue sur la vue de profil l'aménagement sommaire d'un seul bord biseauté (CjEd-5.467; dessin : Marianne-Marilou Leclerc).

Figure 5. Partially refitted bifacial rough-out in an early stage made with Touladi chert (CjEd-5.467; drawing: Marianne-Marilou Leclerc). 


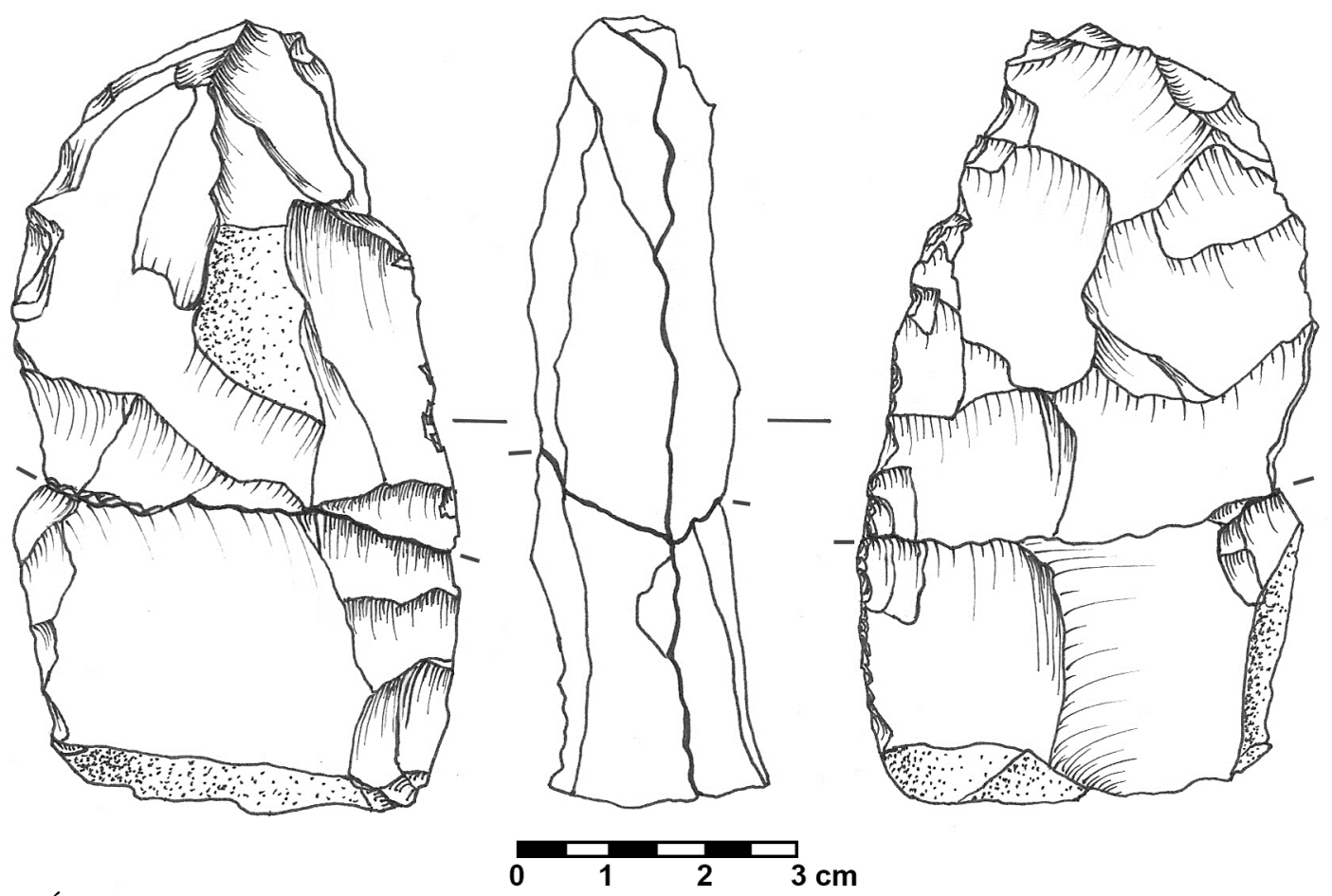

Figure 6. Ébauche en chert Touladi. L’ébauche est ici plus avancée que la précédente, car la majorité des bords a été aménagée en biseau (CkEe-9.881; dessin : Marianne-Marilou Leclerc).

Figure 6. Bifacial rough-out made with Touladi chert. This one is slightly more advanced than the previous one (CkEe-9.881; drawing: Marianne-Marilou Leclerc).
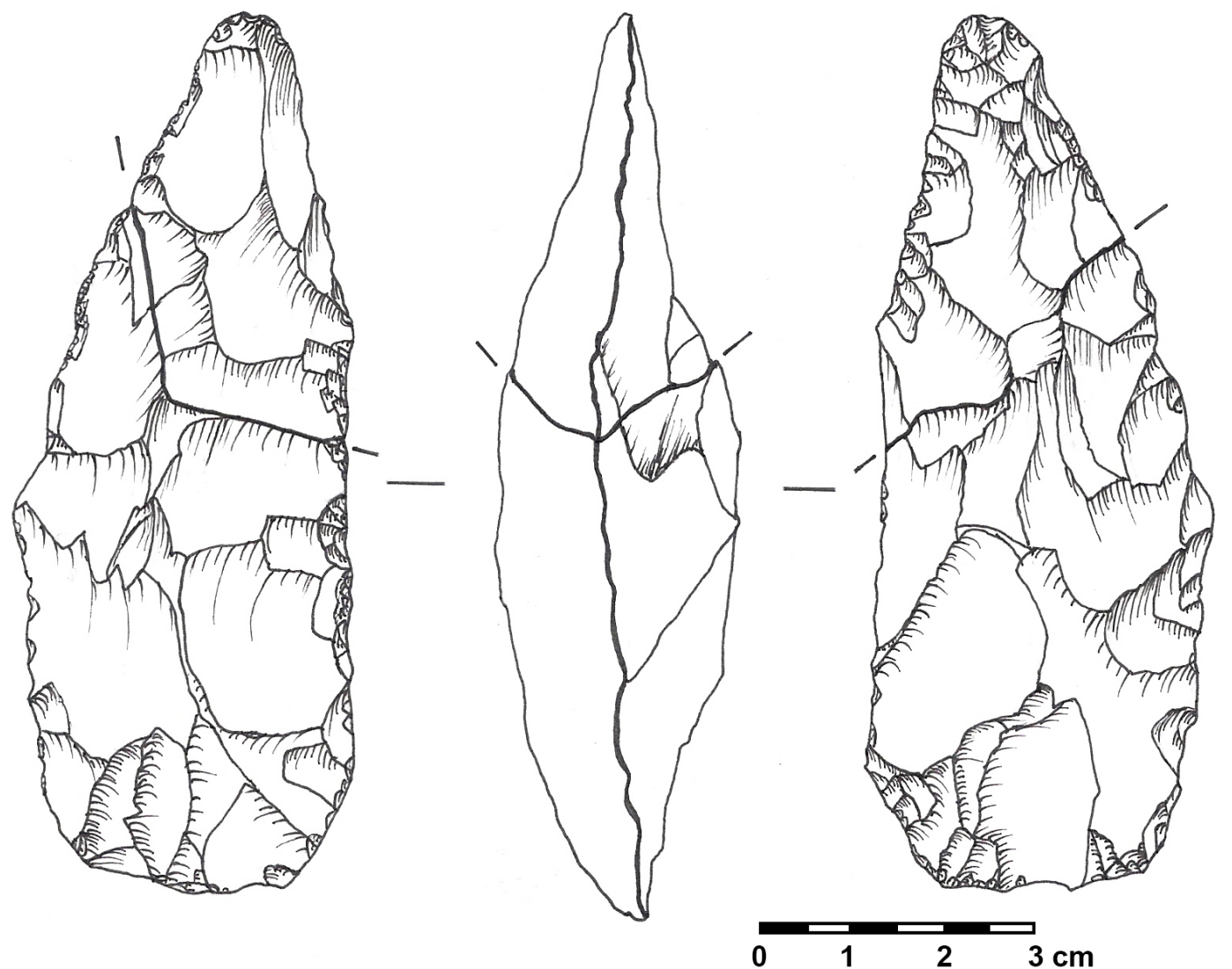

Figure 7. Préforme bifaciale (phase 2) en chert Touladi (CkEe-9.572-647; dessin : Marianne-Marilou Leclerc). Figure 7. Bifacial preform (stage 2) made with Touladi chert (CkEe-9.572-647; drawing: Marianne-Marilou Leclerc). 


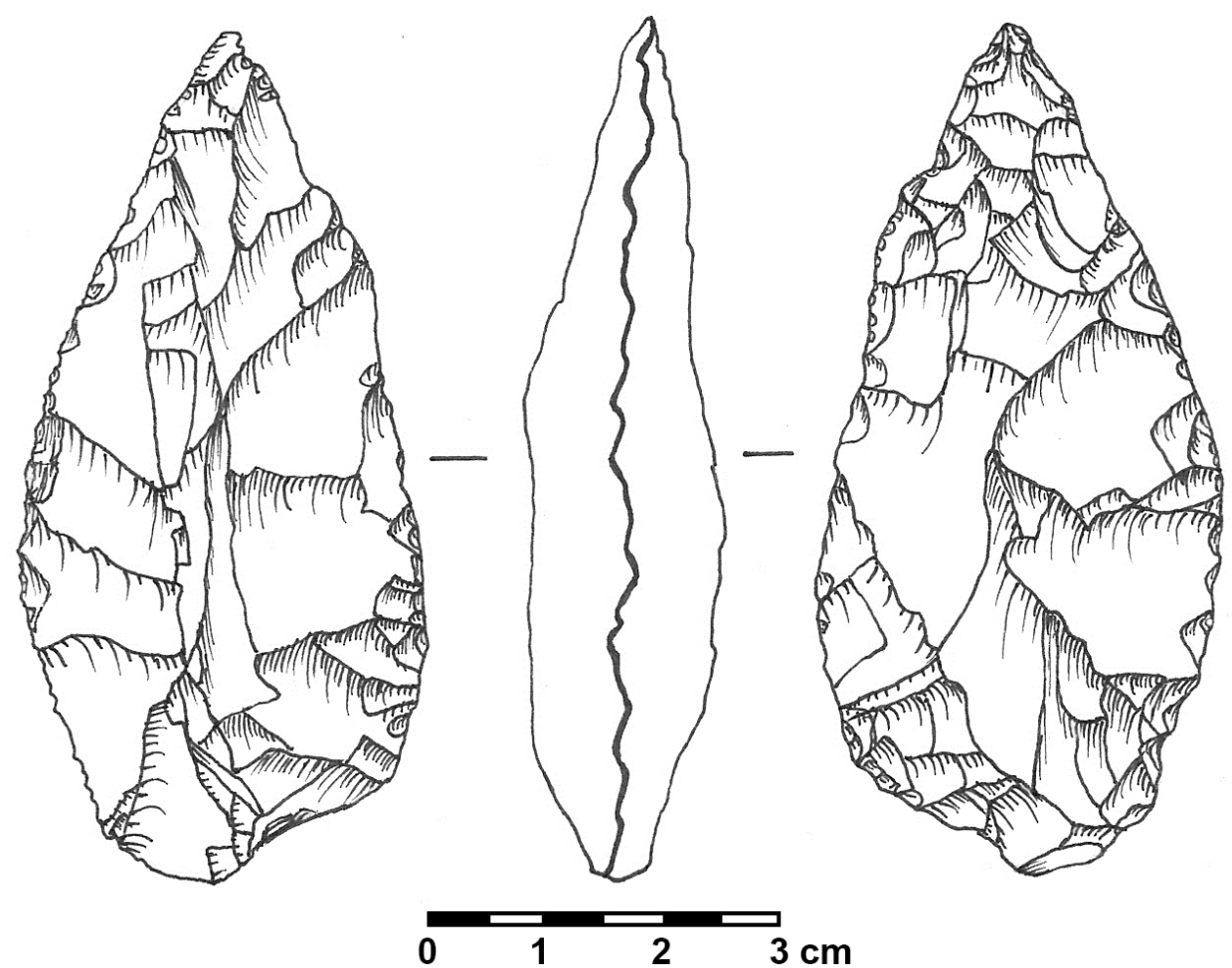

Figure 8. Biface de phase 3 en chert Touladi (CkEe-9.658; dessin : Marianne-Marilou Leclerc).

Figure 8. Stage 3 biface made with Touladi chert (CkEe-9.658; drawing: Marianne-Marilou Leclerc).
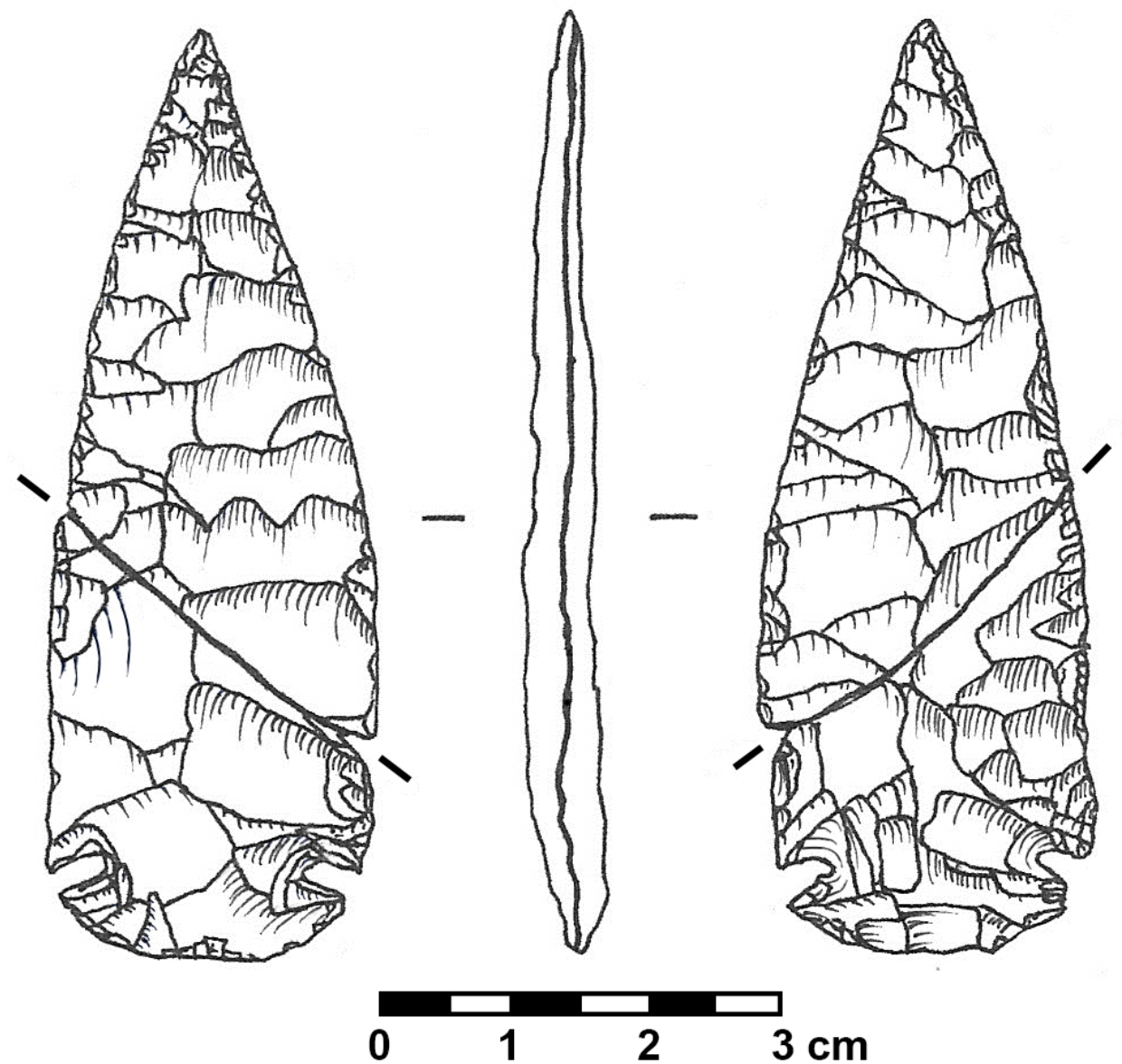

1

\section{2}

\section{$3 \mathrm{~cm}$}

Figure 9. Pointe de projectile (phase 4) en chert Touladi (CkEe-9.670-671; dessin : Marianne-Marilou Leclerc). Figure 9. Projectile point (Stage 4) made with Touladi chert (CkEe-9.670-671; drawing: Marianne-Marilou Leclerc). 
Ébauchage initial (phase 1a)

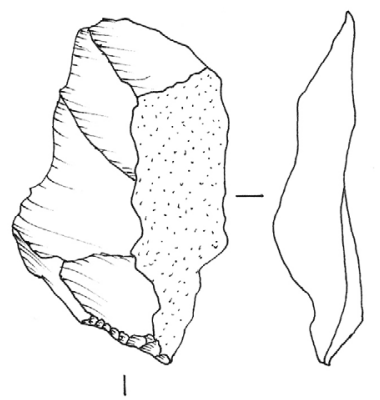

r

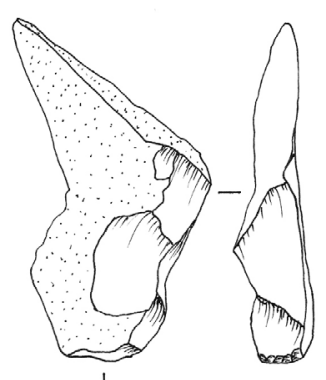

1

s
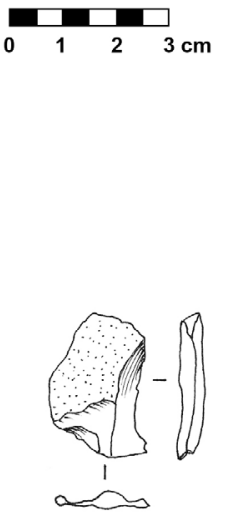

Ébauchage avancé (phase 1b)

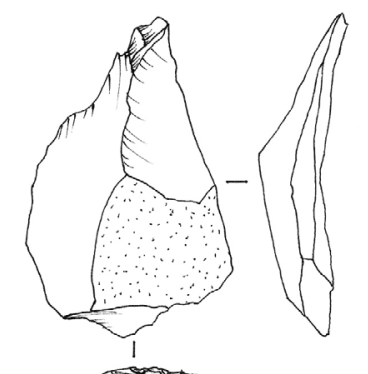

$\longrightarrow$

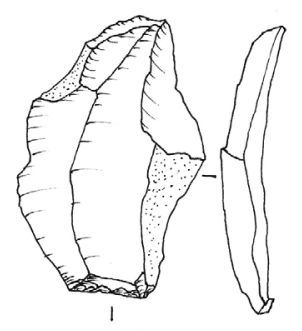

ans

\section{Préformage (phase 2)}
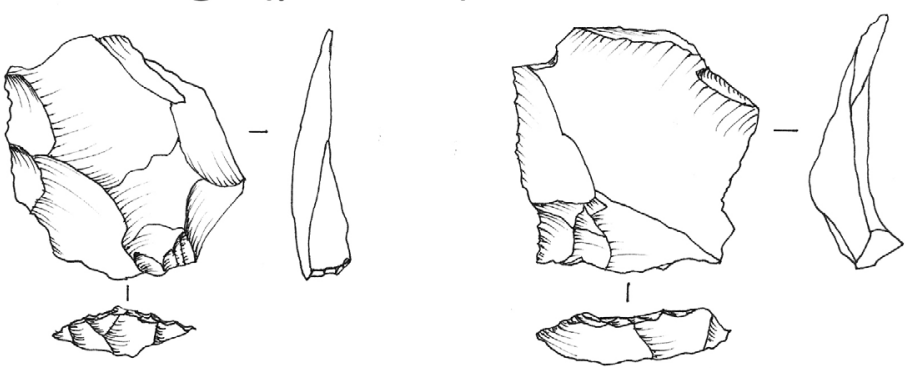

Façonnage initial (phase 3a)

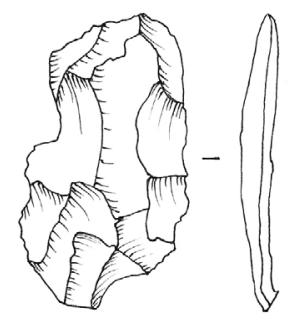

1

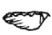

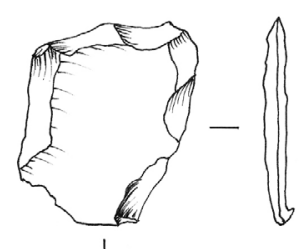

$\Leftrightarrow$
Façonnage avancé (phase 3b)

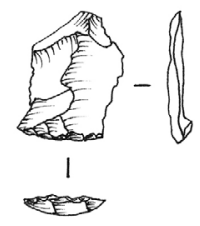

Figure 10. Échantillon d’éclats typiquement associés à chaque phase de production bifaciale (dessin : MarianneMarilou Leclerc).

Figure 10. Sample of typical flakes from each bifacial production stages (drawing: Marianne-Marilou Leclerc). 


\section{CkEe-12 - Phases de production bifaciale}

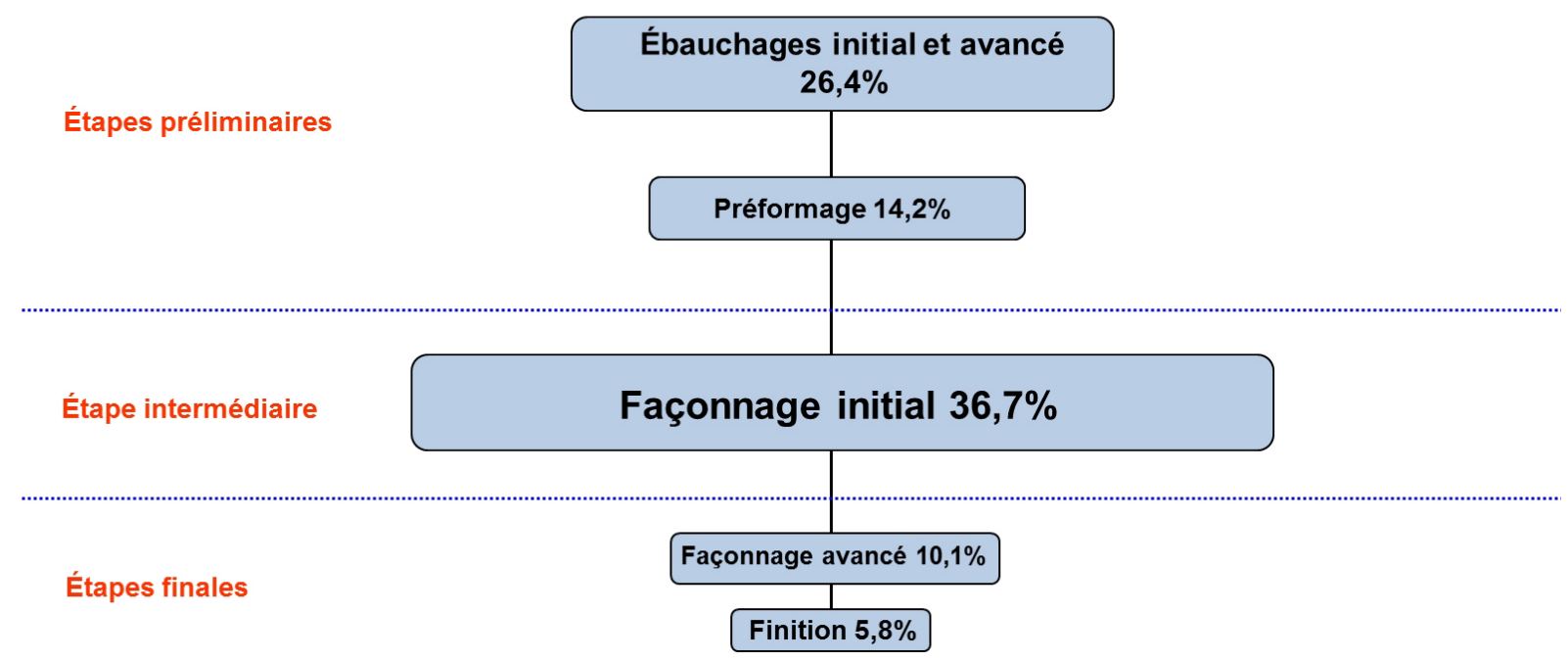

Figure 11. Schématisation des phases de production bifaciale visibles à travers les éclats du site CkEe-12. Figure 11. Schematization of the bifacial production stages visible through the flakes from CkEe-12 site.

\section{CkEe-22 - Phases de production bifaciale}

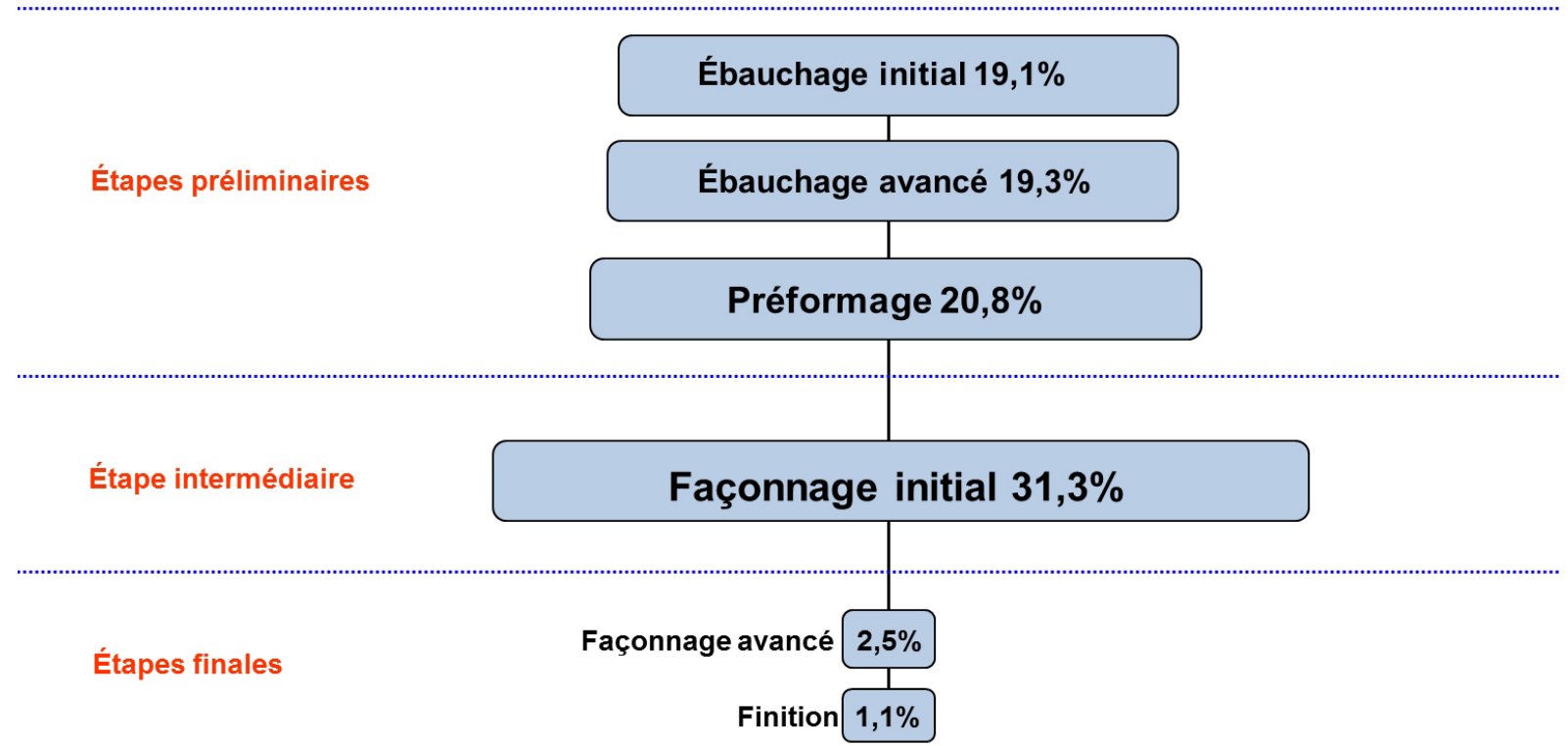

Figure 12. Schématisation des phases de production bifaciale visibles à travers les éclats du site CkEe-22. Figure 12. Schematization of the bifacial production stages visible through the flakes from CkEe-22 site.

Même si chaque site révèle ses particularités, les méthodes et techniques de fabrication de l'industrie bifaciale sont similaires sur tous les établissements. C'est donc plutôt les modalités de gestion des étapes de fabrication et d'utilisation, étalées sur le court, le moyen et peut-être même le long terme, qui se démarquent d'un site à l'autre. 


\section{CkEe-2 - Phases de production bifaciale}

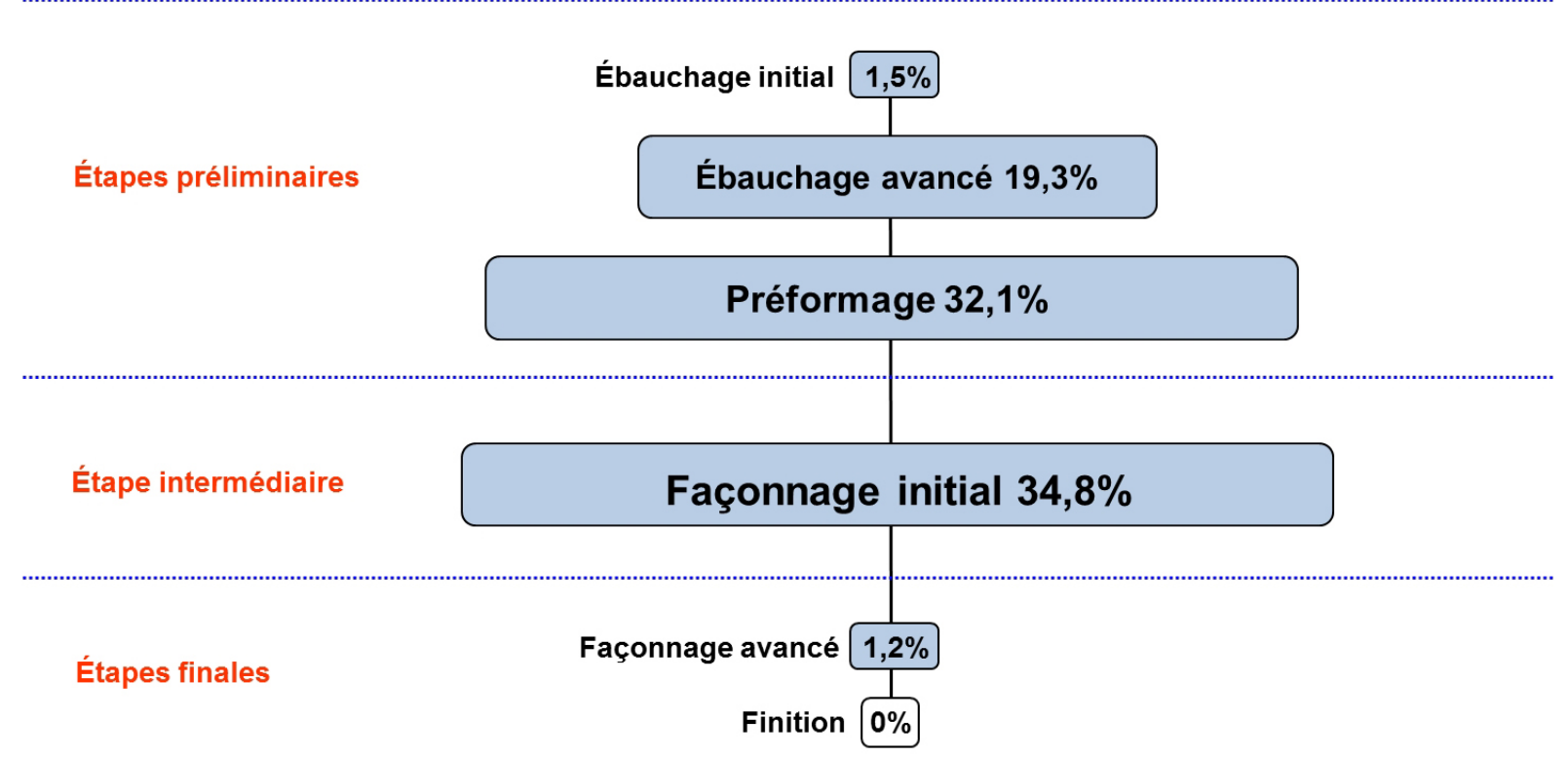

Figure 13. Schématisation des phases de production bifaciale visibles à travers les éclats du site CkEe-2.

Figure 13. Schematization of the bifacial production stages visible through the flakes from CkEe-2 site.

\section{CjEd-5 - Phases de production bifaciale}

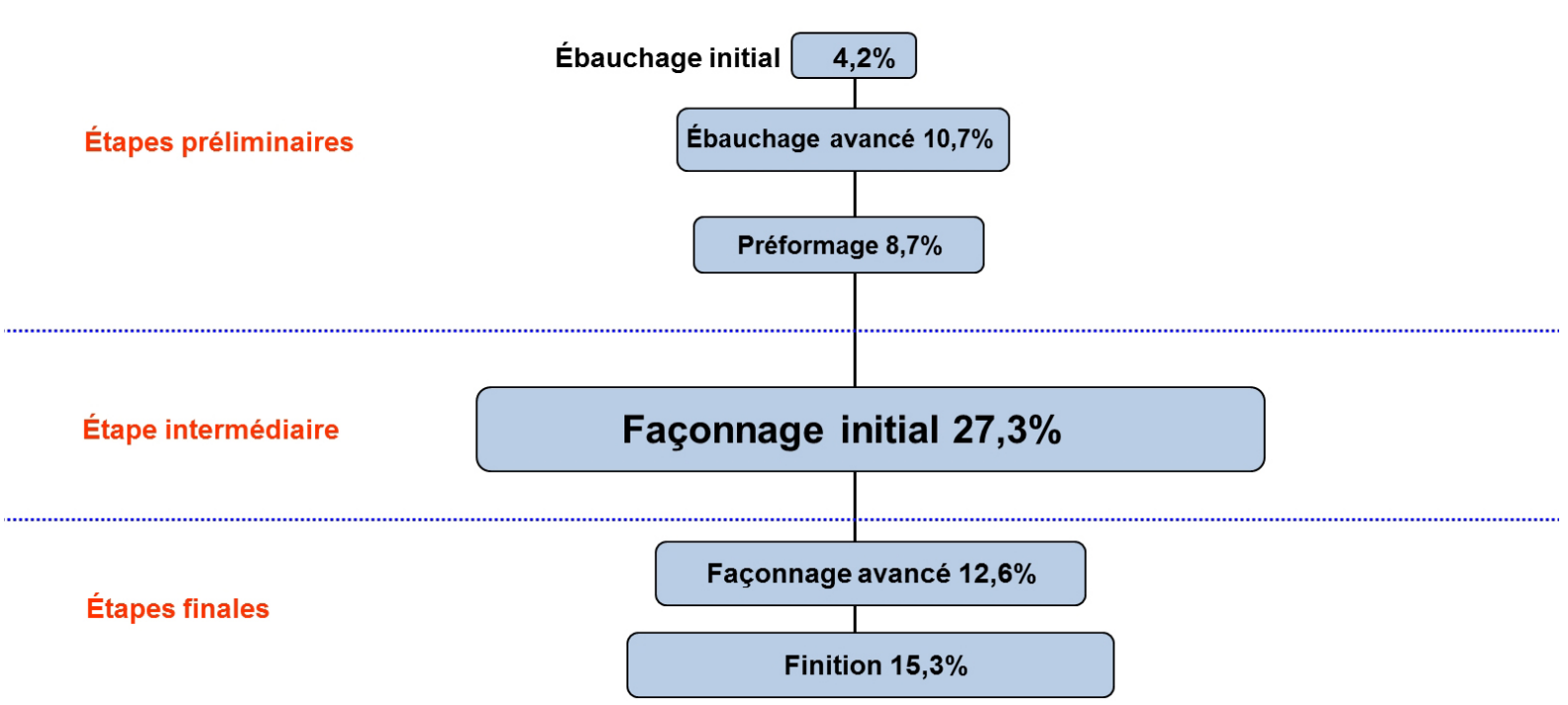

Figure 14. Schématisation des phases de production bifaciale visibles à travers les éclats du site CjEd-5. Figure 14. Schematization of the bifacial production stages visible through the flakes from CjEd-5 site.

\subsection{La chaîne opératoire de débitage des nucléus (chert Touladi)}

On dénombre 136 nucléus en chert Touladi sur les cinq collections analysées. Ces artefacts occupent une place relativement marginale dans la plupart des assemblages, sauf pour les sites CkEe-12 et CkEe-9 où ils sont plus nombreux (Tableau 5). La technologie des nucléus en chert Touladi est très simple et se résume en une méthode de taille informelle dite " ad hoc », c'est-à-dire un débitage qui ne montre aucun schéma opératoire particulier ou standardisé. On n’a identifié aucun indice de préparation des surfaces, ce qui aboutit en un 
débitage sans prédétermination, exploitant généralement peu la volumétrie des matrices de chert Touladi et produisant des supports non stéréotypés. La percussion directe dure est la seule technique rencontrée et les accidents de taille sont relativement fréquents et se rencontrent principalement sous la forme de réfléchissements (Figures 15 à 17).

Tableau 5. Effectif des nucléus en chert Touladi pour chaque site.

Table 5. Number of cores found in each site.

\begin{tabular}{llllll}
\hline CkEe-12 & CkEe-22 & CkEe-9 & CkEe-2 & CjEd-5 & Total \\
\hline $36(26,5 \%)$ & $7(5,1 \%)$ & $81(59,6 \%)$ & $8(5,9 \%)$ & $4(2,9 \%)$ & $136(100 \%)$ \\
\hline
\end{tabular}

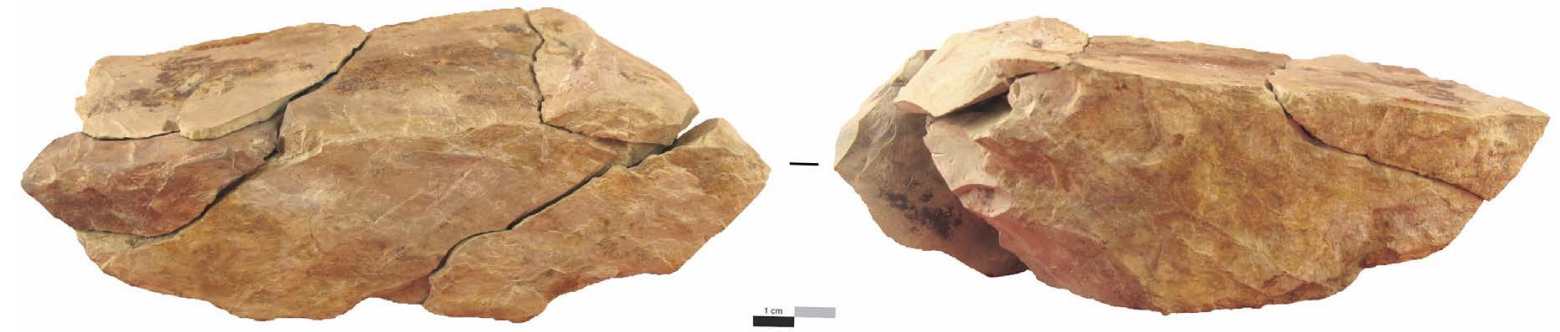

Figure 15. Nucléus en chert Touladi partiellement remonté (CkEe-12.327).

Figure 15. Partially refitted core made with Touladi chert (CkEe-12.327).
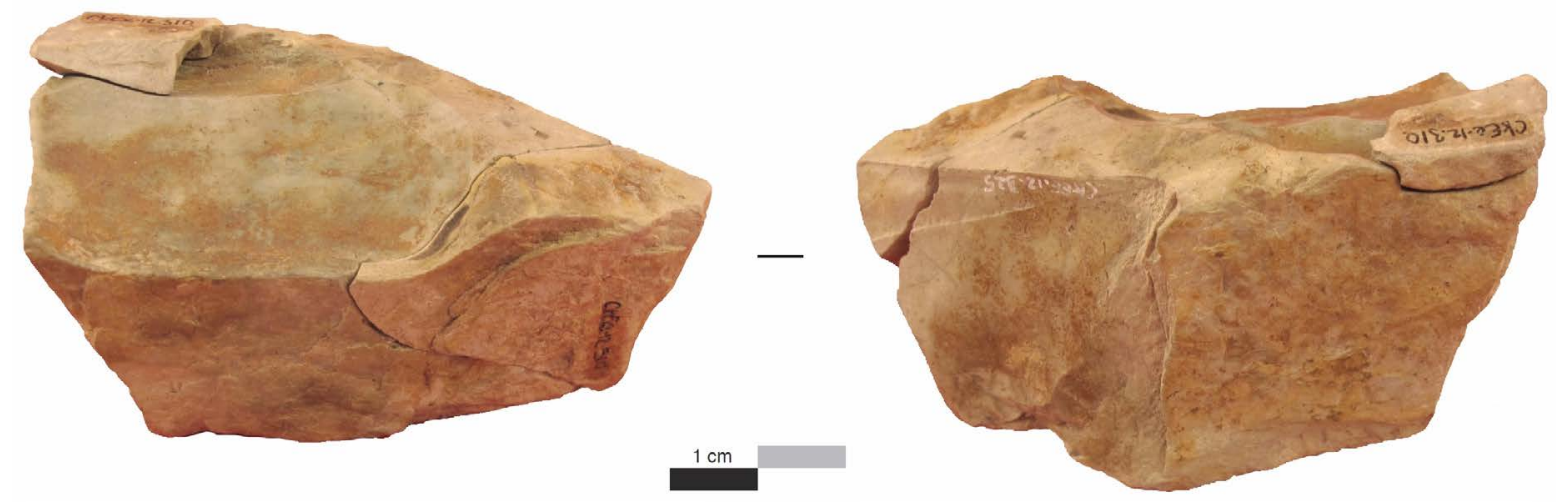

Figure 16. Nucléus en chert Touladi partiellement remonté (CkEe-12.325).

Figure 16. Partially refitted core made with Touladi chert (CkEe-12.325).

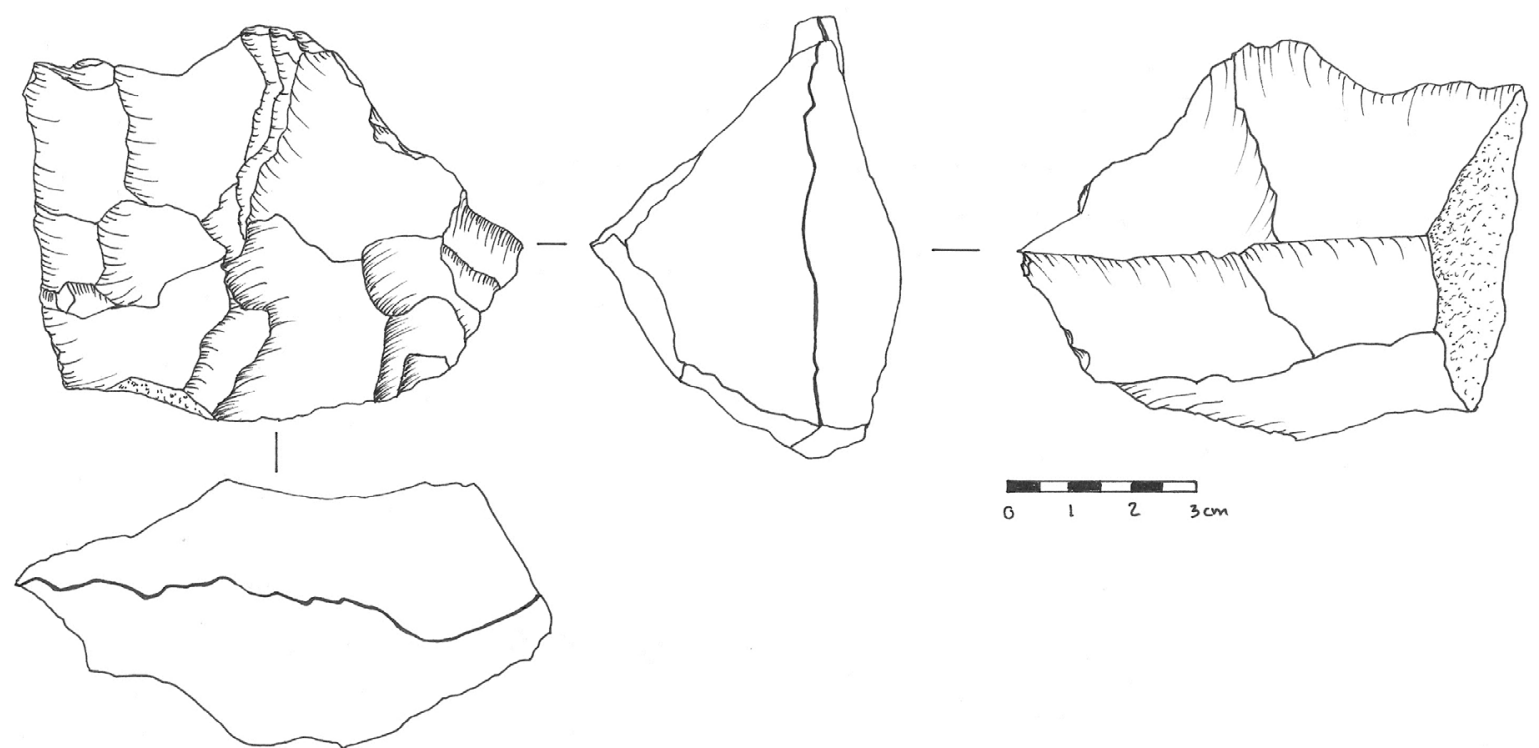

Figure 17. Nucléus en chert Touladi (CkEe-22.13; dessin : Marianne-Marilou Leclerc).

Figure 17. Core made with Touladi chert (CkEe-22.13; drawing: Marianne-Marilou Leclerc). 
On observe aussi que la majorité des nucléus ont eu un rendement relativement peu élevé quant à la production d'éclats-supports. Leur volumétrie initiale est souvent assez peu modifiée et il persiste alors encore beaucoup de plages corticales. Quant aux éclats débités, même s'ils ont une légère tendance à être plus volumineux que ceux issus de la taille des bifaces, ils affichent généralement des attributs morphométriques apparentés aux sousproduits bifaciaux, principalement ceux des phases préliminaires. Ils ne sont cependant pas standardisés et présentent une assez grande variabilité de formes et de modules. La ressemblance entre les produits des nucléus et ceux provenant de la taille d'ébauches bifaciales est d'ailleurs manifeste, rendant souvent très difficile la distinction de ces deux classes d'éclats. C'est donc essentiellement par la pratique de remontages d'éclats sur des nucléus qu'il a été possible d'identifier clairement les supports générés par cette industrie. Au total, 102 éclats en chert Touladi ont pu être associés à un débitage de nucléus. De ce nombre, 87 éclats et fragments ont été remontés sur 25 nucléus. Les remontages indiquent également qu'une forte proportion des supports débités a été abandonnée à l'état brut sans évidences tangibles d'utilisation. Ajoutons également qu'aucun des outils sur éclat analysés n'a pu être remonté sur un nucléus en chert Touladi, malgré d'insistantes tentatives en ce sens.

D’un point de vue morphométrique, il semble que les supports débités des nucléus n’offrent habituellement guère d'attributs qui les auraient rendus plus attractifs que ceux issus de la taille des pièces bifaciales, déjà très nombreux sur chaque site. Si on retrouve quelques éclats plus volumineux qui ont occasionnellement pu être transformés en bifaces ou en d'autres outils, la plupart des supports issus des nucléus seraient trop petits pour en faire des pièces bifaciales (Figure 18). En effet, si on se fie aux dimensions des spécimens analysés, les préférences des tailleurs étaient orientées surtout vers des modules plus volumineux pour ces outils. Enfin, même si les nucléus ont pu être testés près des carrières, l'ensemble de leur débitage s’est vraisemblablement déroulé sur les sites analysés, illustrant ainsi la faible propension à segmenter cette chaîne opératoire dans le temps et dans l'espace.

\subsection{La chaîne opératoire d'utilisation des pièces esquillées (chert Touladi)}

L’industrie des pièces esquillées est un processus différent des deux précédents, puisque les éclats générés par la percussion bipolaire sur enclume l’ont été essentiellement pendant l'utilisation d'outils plutôt que par des opérations de façonnage ou de débitage. On peut donc considérer que les supports produits l'ont été de manière non intentionnelle, ce qui n'exclut pas un réemploi a posteriori des éclats générés pour la fabrication d'outils. Une utilisation opportuniste des résidus de pièces esquillées ne fait pas d'elles des nucléus pour autant, mais cela constitue néanmoins un élément intéressant dans la gestion économique des industries lithiques.

La chaîne opératoire associée à l'utilisation des pièces esquillées ne se rencontre que sur deux des collections de l'étude, soit CkEe-9 et CkEe-2 (Figures 19 à 21). La plupart des sites du Témiscouata ne présentent d'ailleurs pas de tels outils et, lorsque présents, ils le sont en quantité négligeable (Chalifoux et al. 1998: 35, 83, 100, 108-114). Quant aux éclats associés à l'utilisation de pièces esquillées, leur étude s'est limitée à la collection du site CkEe-2 ( $n=149$ ), puisque la collection d'éclats en chert Touladi de CkEe-9 n’a pas été analysée. Les données recueillies sont donc plus modestes que pour les autres chaînes opératoires, mais quelques conclusions peuvent tout de même être avancées. D’abord, la réalisation de nombreux remontages d'éclats sur ces outils démontre que l'ensemble du processus d'utilisation des pièces esquillées était généralement mené in situ. Ensuite, malgré une assez grande variabilité dans la morphologie des résidus engendrés, leurs dimensions moyennes se rapprochent assez des sous-produits de l'industrie bifaciale. 

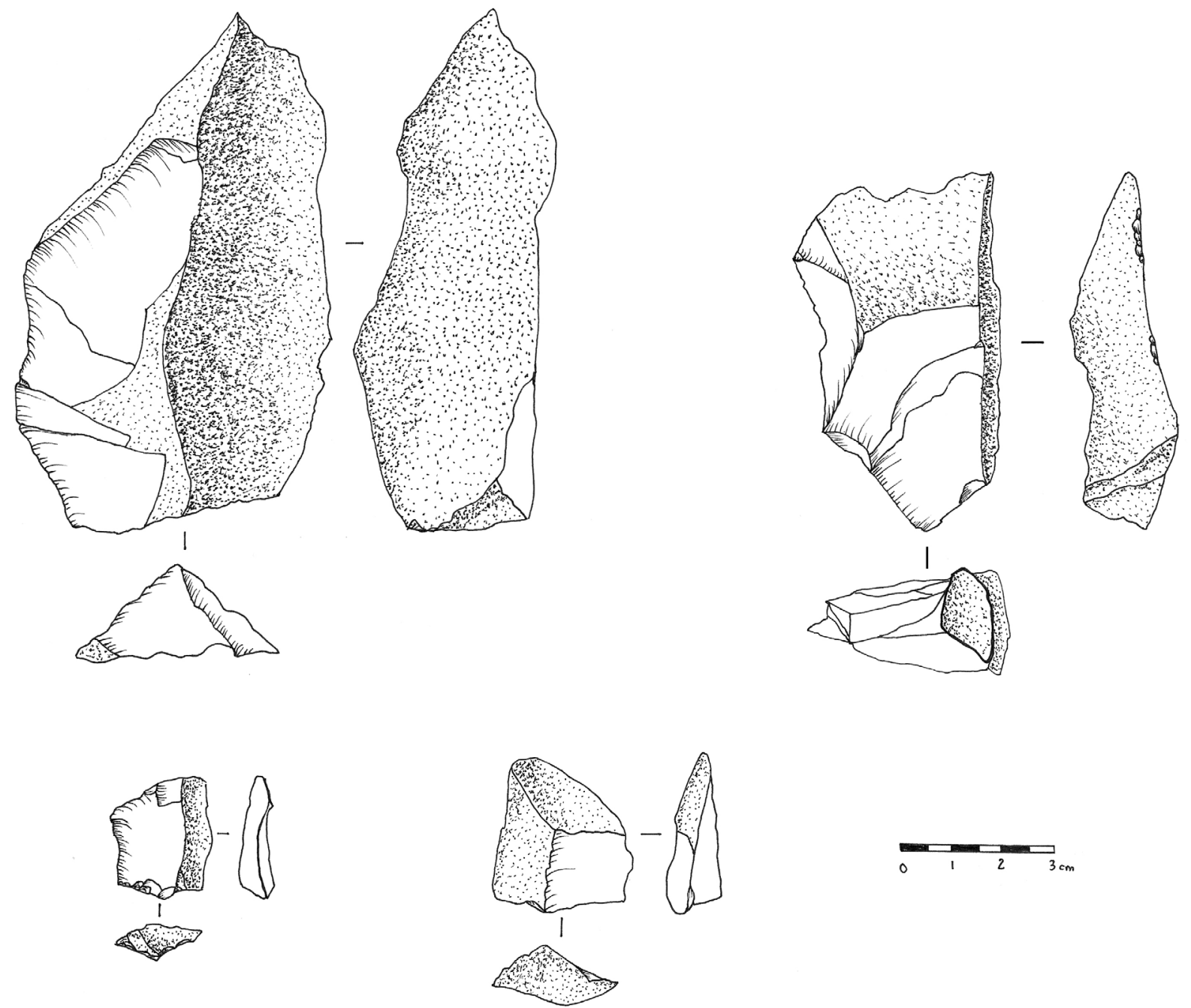

Figure 18. Échantillon d'éclats issus d’un débitage de nucléus et provenant tous de remontages faits sur des nucléus du site CkEe-12 (dessin : Marianne-Marilou Leclerc).

Figure 18. Sample of flakes from refitted cores from CkEe-12 site (drawing: Marianne-Marilou Leclerc).

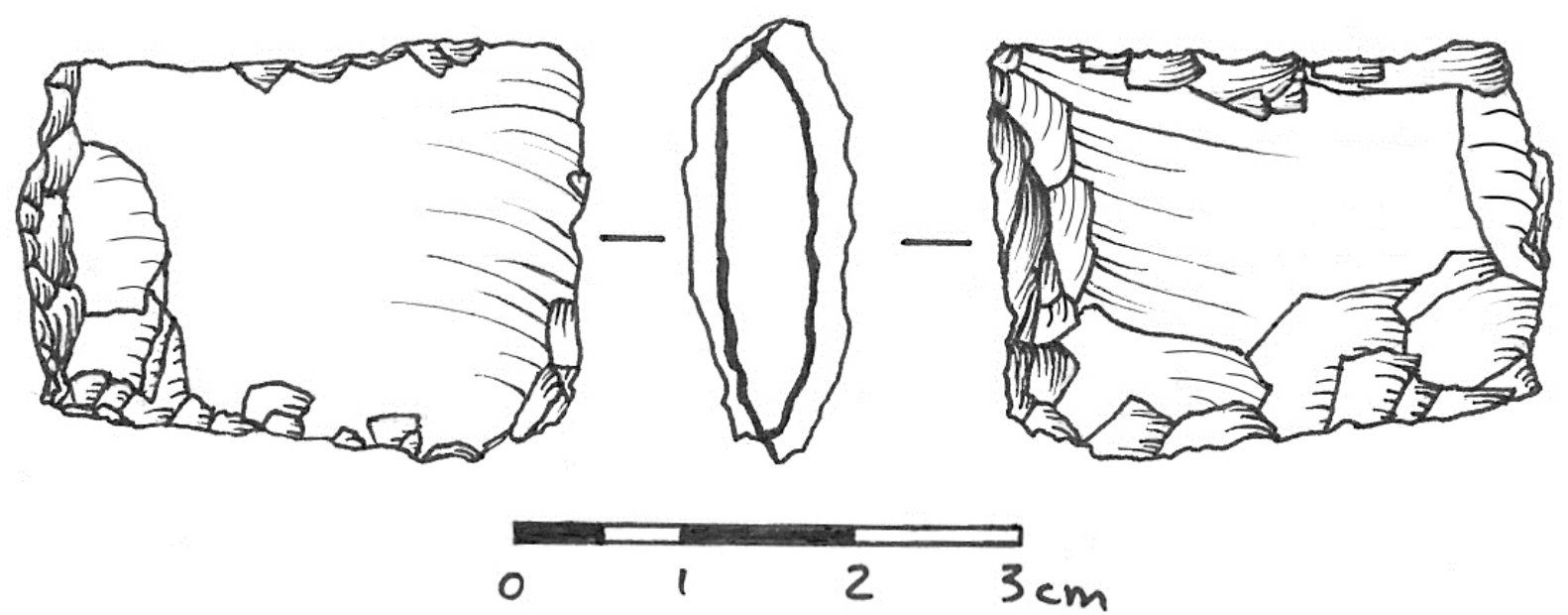

Figure 19. Pièce esquillée en chert Touladi ayant été utilisée sur deux axes perpendiculaires (CkEe-9.569; dessin : Marianne-Marilou Leclerc).

Figure 19. Pièce esquillée made from Touladi chert (CkEe-9.569; drawing: Marianne-Marilou Leclerc). 

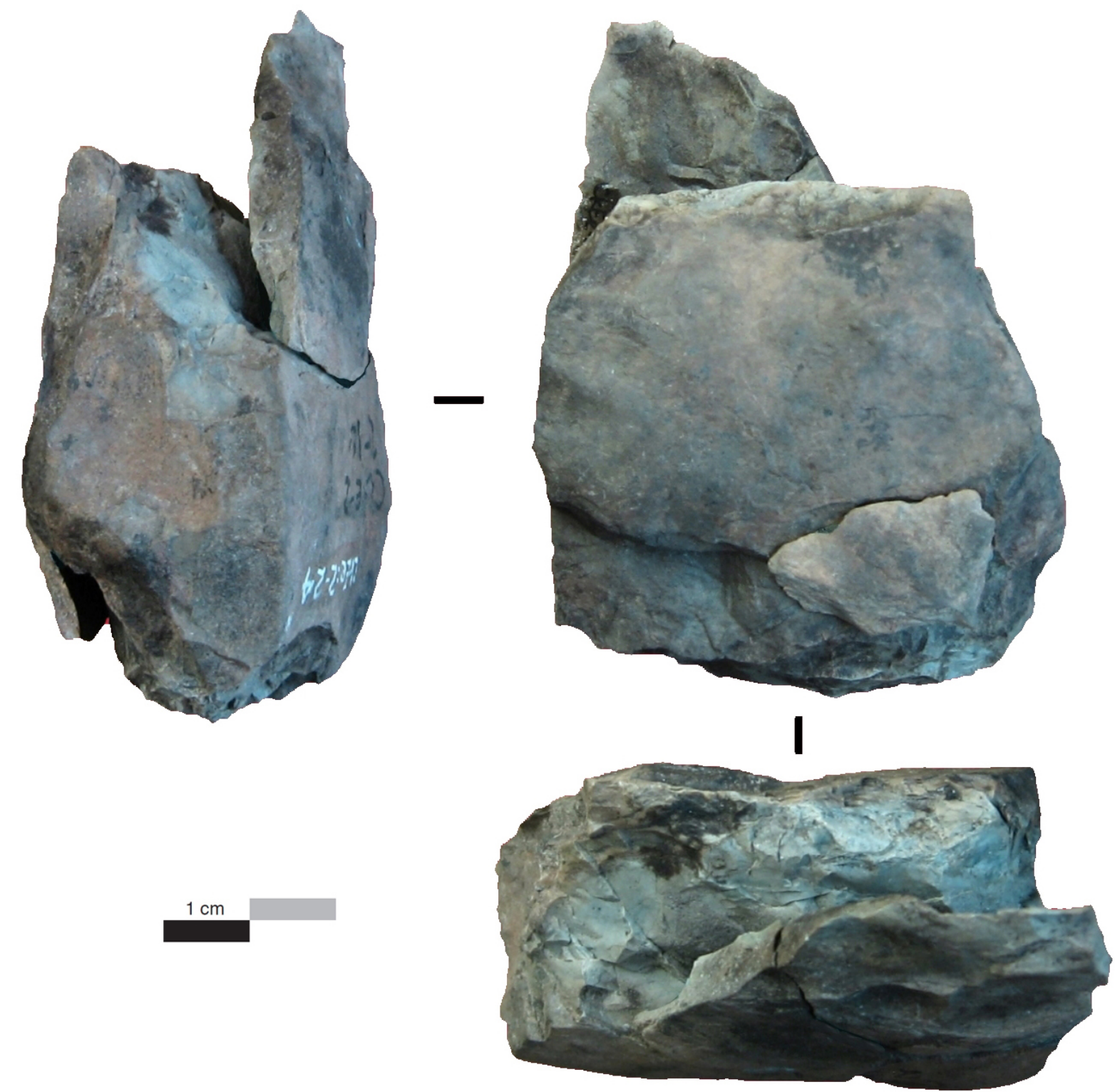

Figure 20. Pièce esquillée en chert Touladi partiellement remontée (CkEe-2.24).

Figure 20. Partially refitted Pièce esquillée made from Touladi chert (CkEe-2.24).

\subsection{L’outillage sur éclats}

Les trois chaînes opératoires reconnues dans les collections étudiées ont toutes généré des supports sous la forme d'éclats. En regard du nombre absolu d'éclats produits, c'est sans conteste le processus bifacial qui en a engendré le plus, les deux autres occupant une place nettement plus secondaire sous ce rapport.

Les outils sur éclats en chert Touladi sont au nombre de 666 et se déclinent en trois grands types : les outils ad hoc (éclats retouchés ou utilisés bruts sans morphologie ni attributs stéréotypés) (Figure 22), les grattoirs (Figures 23 et 24) et les pièces esquillées (Figures 19 à 21) (Tableau 6). La majorité de ceux dont l'affiliation technologique a pu être diagnostiquée avec un haut indice de certitude montre qu'ils proviennent de supports issus du processus bifacial $(n=84)$, ceux fabriqués sur des sous-produits de pièces esquillées venant en seconde place ( $\mathrm{n}=18)$, alors les outils faits sur des supports débités de nucléus finissent bons derniers $(\mathrm{n}=2)$ (Tableau 7). À noter que vingt spécimens ont été produits directement à partir de matrices brutes (bloc, plaquette ou galet). 


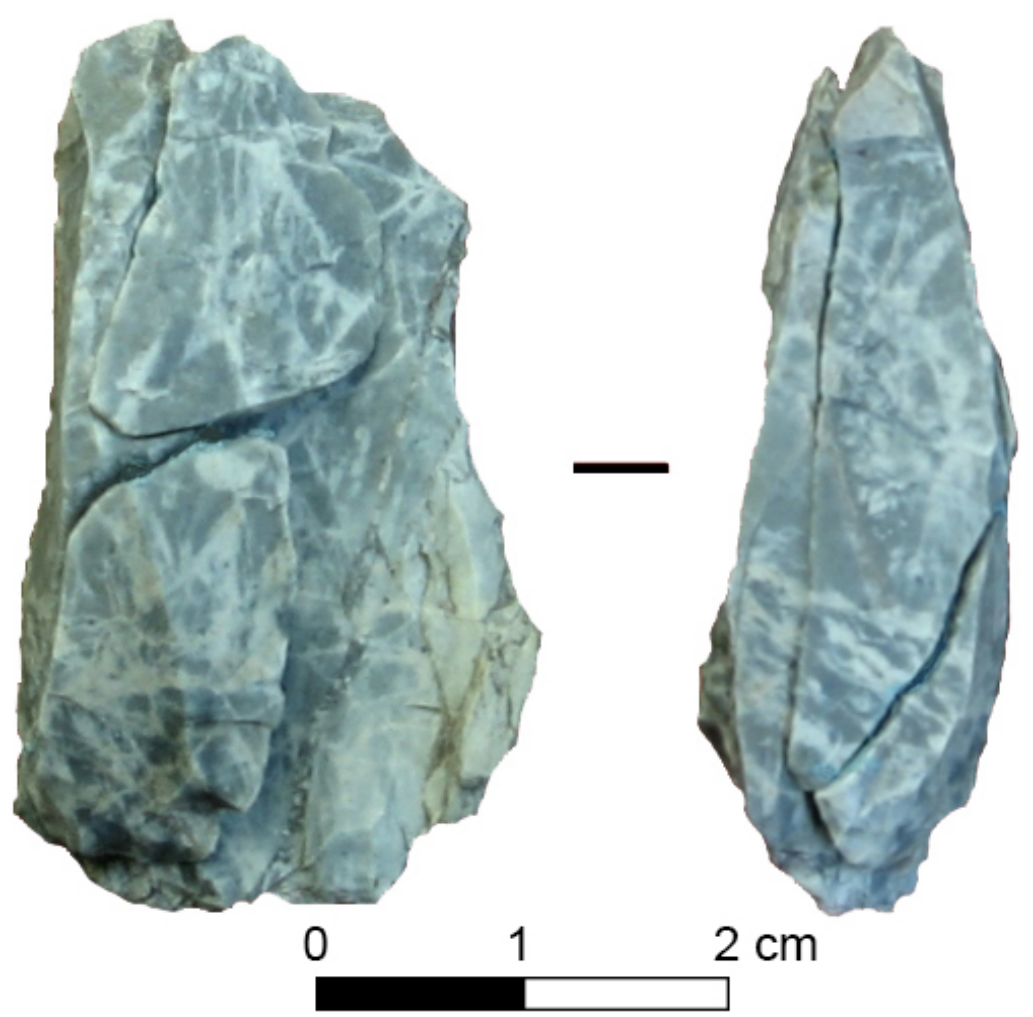

Figure 21. Pièce esquillée en chert Touladi partiellement remontée (CkEe-2.80). Figure 21. Partially refitted Pièce esquillée made from Touladi chert (CkEe-2.80).
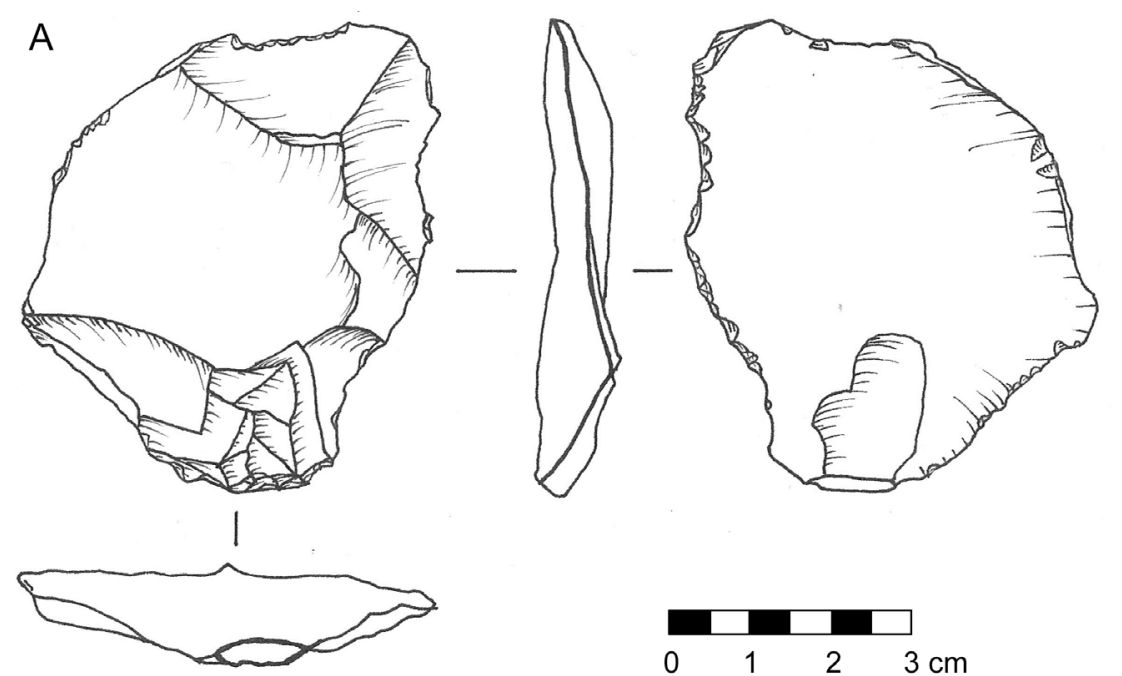

B
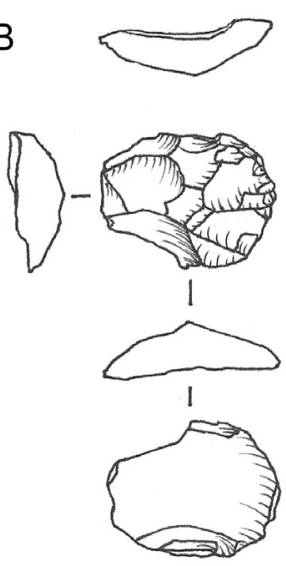

C
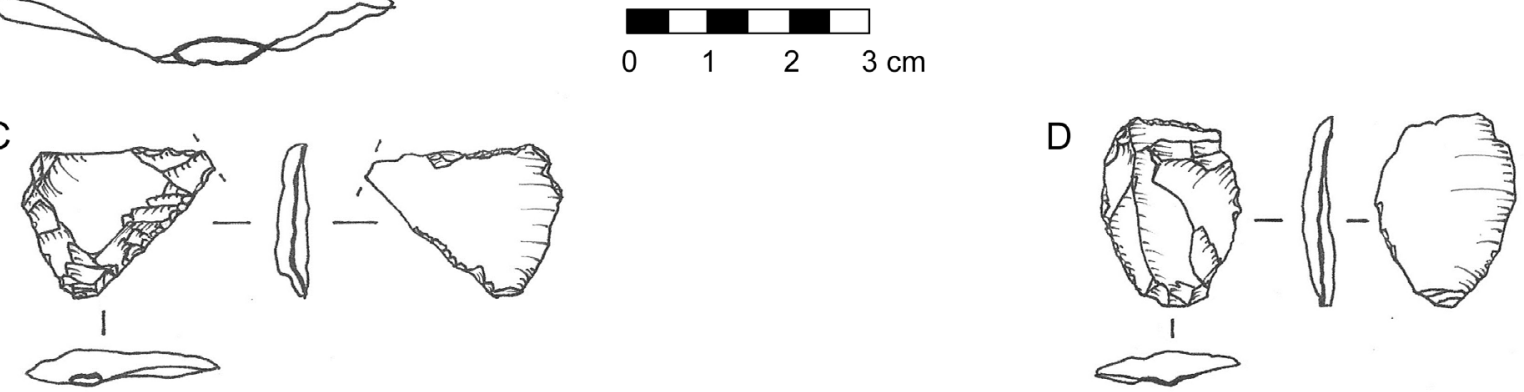

Figure 22. Échantillon d’outils sur éclats ad hoc : A - éclat utilisé brut (CkEe-22.97); B - éclat retouché (CkEe2.457); C - outil pointu (CkEe-12.334); D - éclat retouché (CkEe-2.459). L’outil en B est le seul en matériau exogène (chert Munsungun) et il a été taillé par percussion bipolaire sur enclume à partir d'une pièce esquillée ou d'un nucléus. Tous les autres ont été taillés par percussion directe tendre à partir de sous-produits de la chaîne opératoire bifaciale (dessin : Marianne-Marilou Leclerc).

Figure 22. Sample of informal flake tools: A - used flake (CkEe-22.97); B - retouched flake (CkEe-2.457); C pointed tool (CkEe-12.334); D - retouched flake (CkEe-2.459) (drawing: Marianne-Marilou Leclerc). 

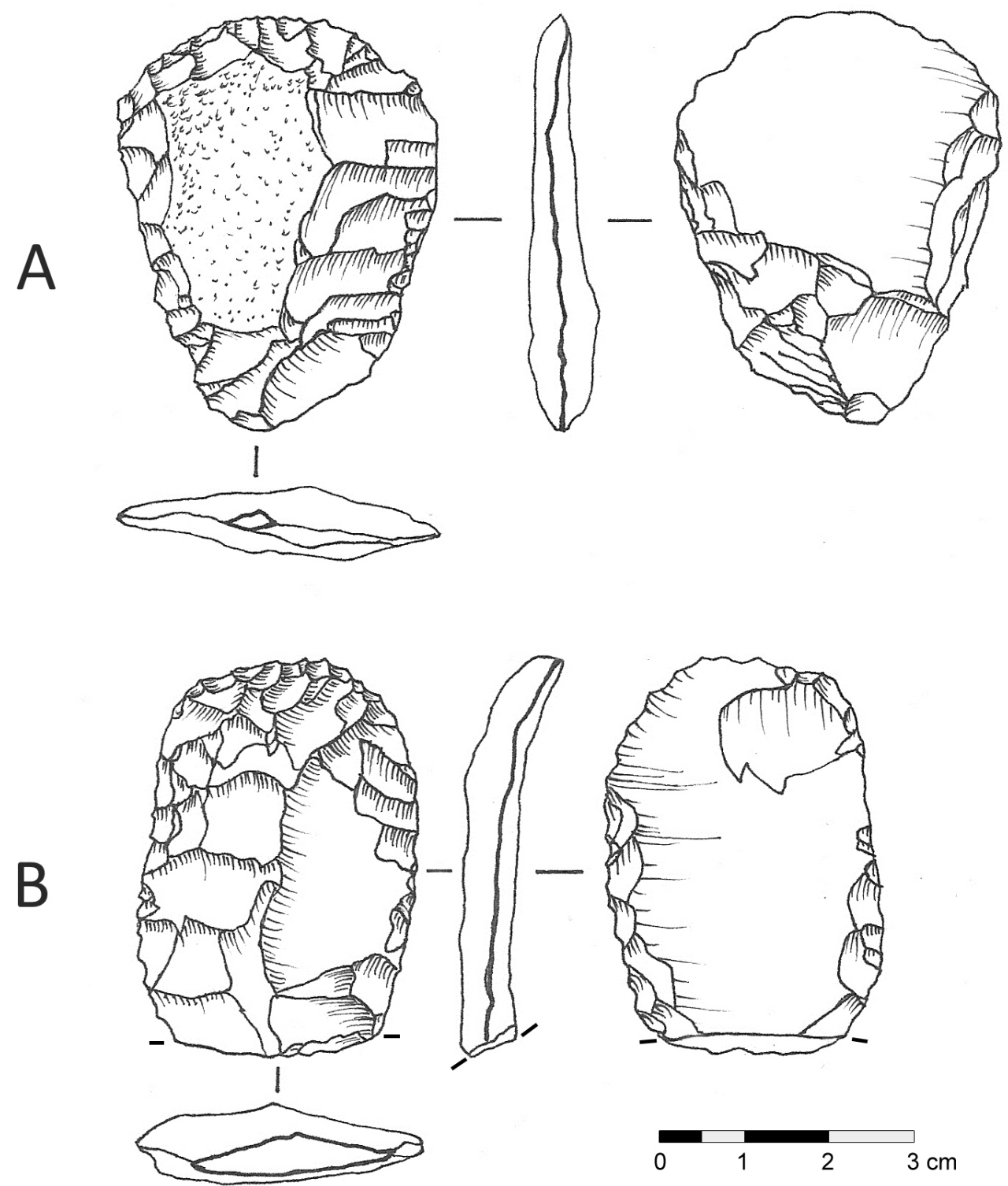

Figure 23. Deux grattoirs en chert Touladi affichant un aménagement plus élaboré que la plupart des autres grattoirs retrouvés au Témiscouata (A - CkEe-22.173; B - CkEe-22.169; dessin : Marianne-Marilou Leclerc).

Figure 23. Two endscrapers made with Touladi chert displaying a more elaborate layout than most other scrapers found in Témiscouata (A - CkEe-22.173; B - CkEe-22.169; drawing: Marianne-Marilou Leclerc).

Pour les différentes classes d'outils, les tailleurs se sont généralement contentés de supports aux formes et dimensions variées sans que l'on puisse discerner de volonté explicite de standardisation. Toutes proportions gardées, ce sont les grattoirs qui constituent la classe d'outils sur éclats la plus formalisée par l'aménagement systématique d'un front, bien que cet outil se décline tout de même en une assez grande variété de formes et de dimensions. Globalement, ils tendent cependant à être légèrement plus petits que les autres outils, mais cela serait possiblement dû au fait que ces artefacts auraient davantage fait l'objet d'un entretien de leurs bords actifs. Les outils ad hoc ne présentent généralement aucun signe d'entretien et semblent avoir généralement été abandonnés alors qu'ils affichaient peu de traces d'usure macroscopiques. Quant aux attributs morphométriques des pièces esquillées, ils sont continuellement modifiés de manière involontaire par leur utilisation en percussion bipolaire. 




Figure 24. Grattoir en chert Touladi ayant été cassé en deux parties. On constate que le front du segment de gauche a été retravaillé après la cassure (CkEe-9.511-901; dessin : Marianne-Marilou Leclerc).

Figure 24. Refitted endscraper made from Touladi chert. The left segment was reworked after the fracture of the tool (CkEe-9.511-901; drawing: Marianne-Marilou Leclerc).

Tableau 6. Les différentes classes d'outils sur éclats en chert Touladi.

Table 6. The various classes of flake tools made from Touladi chert.

\begin{tabular}{lcccccc}
\hline Classe d'outil & CkEe-12 & CkEe-22 & CkEe-9 & CkEe-2 & CjEd-5 & Total \\
\hline Outils ad hoc & 9 & 66 & 125 & 60 & 19 & $279(41,9 \%)$ \\
Grattoirs & 1 & 15 & 103 & 5 & 4 & $128(19,2 \%)$ \\
Pièces esquillées & & & 185 & 74 & & $259(38,9 \%)$ \\
\hline Total & $\mathbf{1 0}$ & $\mathbf{8 1}$ & $\mathbf{4 1 3}$ & $\mathbf{1 3 9}$ & $\mathbf{2 3}$ & $\mathbf{6 6 6 ( 1 0 0 \% )}$ \\
\hline
\end{tabular}

Tableau 7. Les chaînes opératoires d'où proviennent les supports d'outils sur éclats en chert Touladi. Table 7. The chaînes opératoires from which the flake tools made with Touladi chert come from.

\begin{tabular}{ll}
\hline Chaîne opératoire & Total \\
\hline Chaîne opératoire bifaciale & $84(67,7 \%)$ \\
Chaîne opératoire des nucléus & $2(1,6 \%)$ \\
Chaîne opératoire des pièces esquillées & $18(14,5 \%)$ \\
Depuis une matrice brute (bloc, plaquette, galet) & $20(16,1 \%)$ \\
\hline Total & $\mathbf{1 2 4 ( 1 0 0 \% )}$ \\
\hline
\end{tabular}

\subsection{Schèmes techno-économiques des industries en chert Touladi}

Nos données tendent à révéler le rôle prépondérant du processus bifacial dans la production de l'outillage en chert Touladi. Cette modalité de production illustre l'existence d'un modèle économique principalement orienté vers une chaîne opératoire de type intégré (Perlès 1991a) (Figure 25). La fabrication de l'outillage est ainsi orientée vers une production principale (chaîne opératoire bifaciale) à laquelle s'intègre la conception de la plupart des autres outils via les sous-produits qu'elle engendre (Boëda 1991; Brenet 2011: 26-28; Perlès 1991a). L'industrie bifaciale serait donc l'élément central des industries lithiques en chert Touladi. En comparaison des deux autres industries, le processus bifacial est de loin celui qui 
offre la plus grande standardisation dans la méthode et les techniques de taille, ainsi que dans les sous-produits engendrés à chaque phase. Les éclats de chaque étape n'étaient cependant pas tous propices à la confection d'outils. Les tailleurs ont en effet sélectionné de manière préférentielle ceux provenant des phases d'ébauchage avancé (phase 1b), de préformage (phase 2) et de façonnage initial (phase 3). Les éclats issus de ces trois étapes du processus bifacial étaient ceux ayant apparemment les caractéristiques morphométriques les plus appropriées pour les outils sur éclat. Les trois phases privilégiées, même si elles engendrent des supports légèrement différenciés, ont plutôt été utilisées invariablement pour tous les types d'outils sur éclats. Cela s'explique probablement par le fait que ces outils sont peu ou pas formalisés et que les tailleurs se contentaient d'un éventail morphométrique assez large. Cette flexibilité dans le choix des supports avait tout de même ses limites et ce serait pour cela que les sous-produits de plusieurs phases de production bifaciale auraient été délaissés.

\section{Schématisation techno-économique - chaîne opératoire bifaciale intégrée}

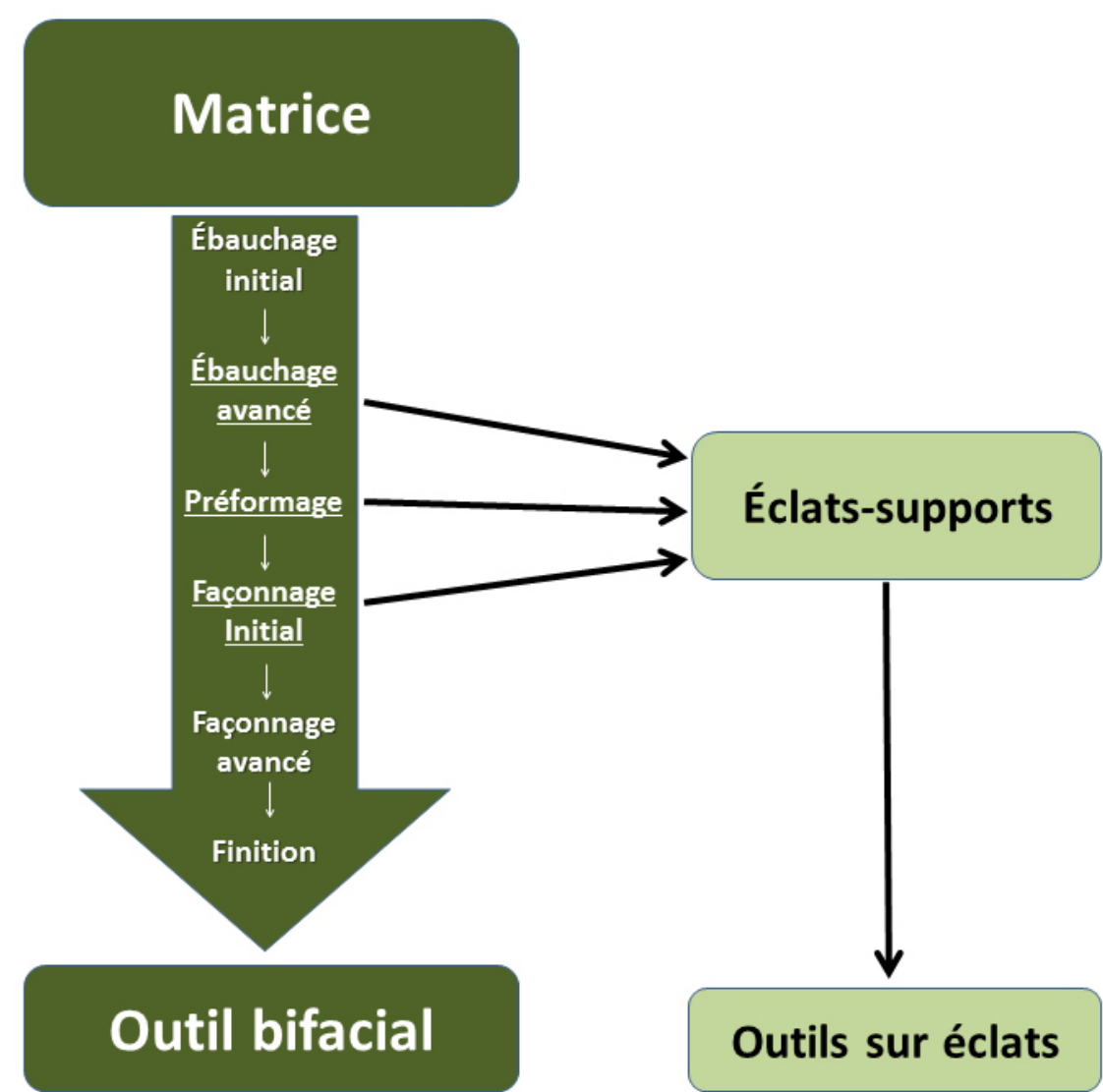

Figure 25. Schématisation techno-économique de la chaîne opératoire bifaciale intégrée.

Figure 25. Techno-economic schematization of the "integrated” bifacial chaîne opératoire.

La segmentation de la chaîne opératoire bifaciale dans le temps et dans l'espace montre que dans plusieurs cas, les tailleurs ont exporté des pièces bifaciales dans un état inachevé (ébauches ou préformes). Même si ce comportement peut s'expliquer par différentes raisons qui ne sont pas mutuellement exclusives, nous croyons que le principal avantage était d'utiliser ces objets pour la production de supports à une échelle territoriale. Les bifaces auraient donc eu une fonction de "nucléus » non seulement près des carrières lithiques du Témiscouata, mais également lorsque les groupes s'en éloignaient. La notion de «bifacenucléus » a été souvent avancée comme modèle organisationnel des industries lithiques nordaméricaines, mais plus rarement cette hypothèse a été supportée par des données 
technologiques tangibles (Bamforth 1991: 230; 2002: 58, 66 et 90; 2003: 210; Hofman 2003: 229; Kelly 1988: 718-719; Lhomme \& Connet 2001; Moncel 2001: 171; Odell 2001: 63; Parry \& Kelly 1987: 298; Soressi 2002: 6, 125-126,157 et 158; Turq 2001: 143).

La grande majorité des nucléus présente pour leur part les caractéristiques de chaînes opératoires indépendantes, c'est-à-dire un débitage ayant comme unique fonction la production de supports d'outils sur éclats, même si cette finalité est souvent difficile à percevoir dans nos assemblages. Toutefois, dans le cas des pièces bifaciales réalisées sur un éclat taillé depuis un nucléus, on aurait alors plutôt affaire à une chaîne opératoire dite « ramifiée mixte » (Figure 26). Il s'agit là d'une production où le débitage d'une matrice mène d'une part à la production de supports pouvant directement être employés comme outils (ad hoc, grattoirs, pièces esquillées) et qui engendre, d'autre part, des supports qui seront intégrés dans un processus de façonnage (bifacial) (Brenet 2011: 26-27). Enfin, les sousproduits de ce dernier processus pourront éventuellement à leur tour être transformés en outils. Ce type d'agencement de productions semble, rappelons-le, d'importance secondaire dans les industries du Témiscouata et n'est perceptible que par la découverte de quelques pièces bifaciales façonnées sur éclats. Qui plus est, l’absence de rapprochements entre ces outils et les nucléus de nos collections laisse croire que la phase de débitage de ces supports a pu se dérouler principalement à l'extérieur des sites analysés, possiblement à proximité des carrières de chert Touladi qui comptent plusieurs ateliers de taille.

\section{Schématisation techno-économique - chaîne opératoire des nucléus}
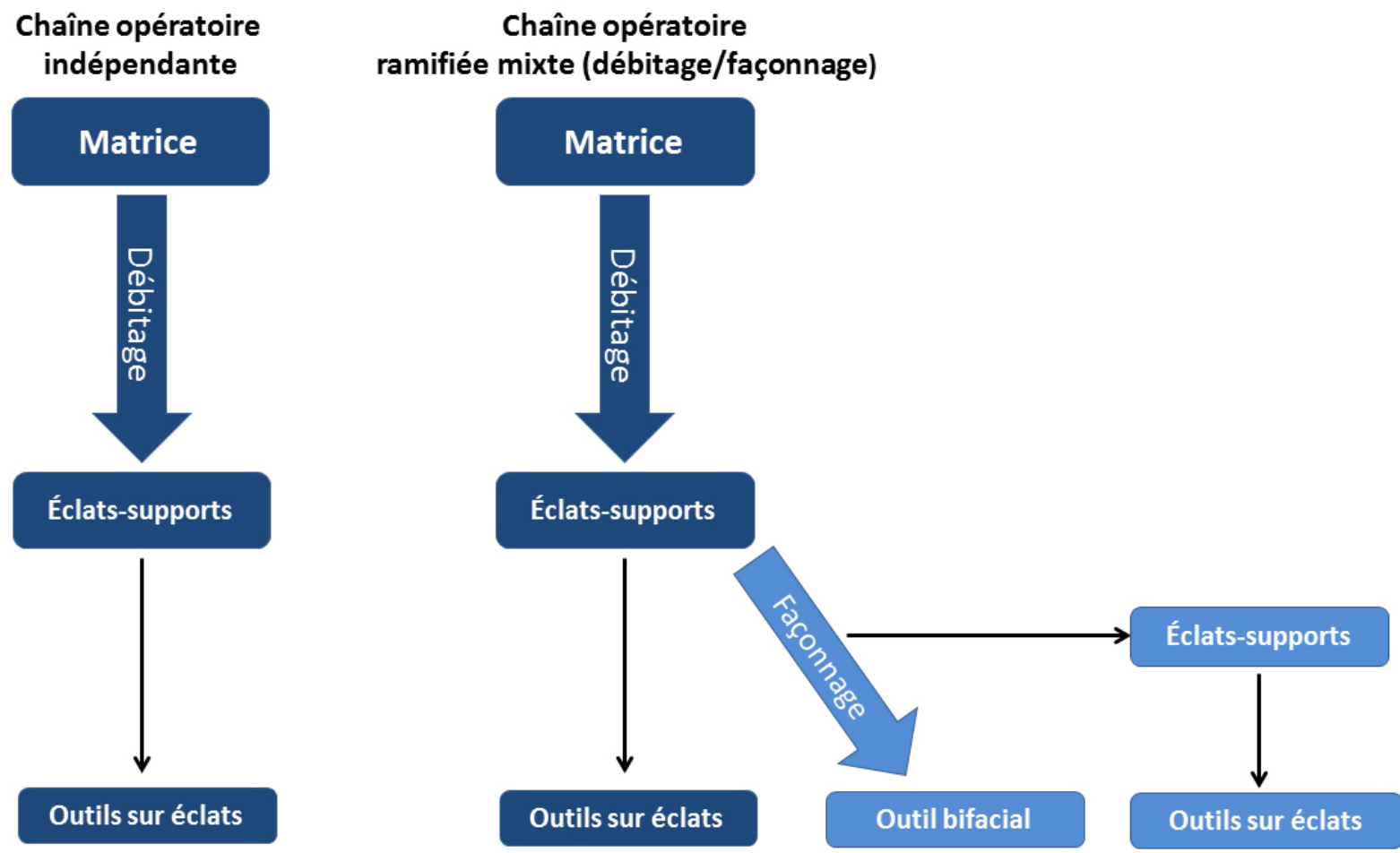

Figure 26. Schématisation techno-économique de la chaîne opératoire de débitage des nucléus. Figure 26. Techno-economic schematization of the flake cores chaîne opératoire.

En comparaison de la prépondérance de la chaîne opératoire bifaciale, celle des nucléus en chert Touladi aurait eu un rôle très limité dans la production d'outils. Le peu de soin apporté aux débitages, le faible rendement des nucléus, le peu d'outils qu'ils semblent avoir produits et le fait qu'ils engendrent des éclats relativement similaires à ceux issus du processus bifacial amènent à s'interroger sur leur fonction réelle au sein du système technique. 
Cela nous incite nécessairement à explorer d'autres avenues interprétatives pour cette classe d’objets. Outre la fonction de nucléus, des éléments observés sur plusieurs spécimens comme la morphologie de certains plans de frappe, la présence de traces d'abrasion, de retouches ou d'esquillements laissent croire qu'ils pourraient être en fait des outils sur blocs ou plaquettes de différentes natures (encoches, becs, grattoirs carénés, percuteur, etc.). Également, la piètre qualité de certains débitages peut rendre attrayante l'idée qu'ils aient été l'œuvre de débutants s'exerçant à la taille. Aucune de ces deux hypothèses n’a été formellement démontrée et, même si elles s'avéraient fondées, il est probable qu'elles ne concernent que certaines pièces de l'assemblage. Quoi qu'il en soit, elles nous amènent à penser qu'il ne faut peut-être pas considérer les artefacts associés traditionnellement à cette chaîne opératoire comme faisant partie d'un ensemble homogène. Il n'en demeure pas moins qu'à l'heure actuelle, un mystère persiste toujours sur cette industrie et nous n'arrivons pas à déterminer clairement son ou ses rôles fondamentaux dans les schèmes techno-économiques.

Quant aux pièces esquillées, elles ont aussi participé à la production de supports d'outils selon une stratégie de chaîne opératoire intégrée (Figure 27). Or, contrairement à la production bifaciale, les pièces esquillées occupent une place plus marginale dans les industries du Témiscouata et l'emploi de leurs sous-produits a possiblement été fait de manière plus opportuniste. Les tailleurs ont probablement puisé de temps en temps dans la masse d'éclats produits par l'utilisation de ces outils ceux convenant à leur besoin du moment en supports. À l'inverse des résidus de taille bifaciale qui font l'objet d'une certaine standardisation, ceux des pièces esquillées présentent des morphologies beaucoup plus variables, ce qui aurait probablement limité leur attrait auprès des tailleurs de pierre.

\section{Schématisation techno-économique - chaîne opératoire des pièces esquillées}

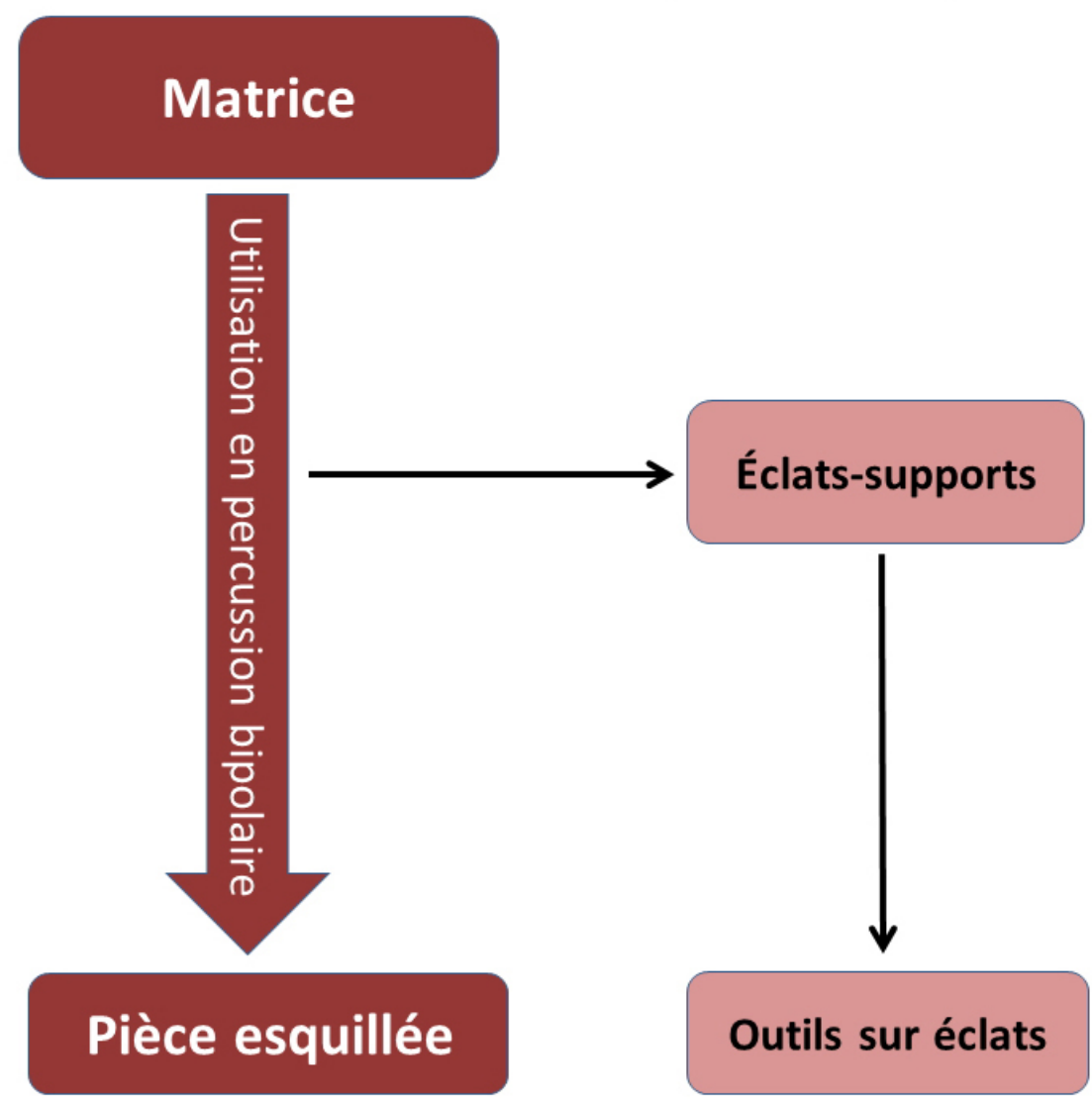

Figure 27. Schématisation techno-économique de la chaîne opératoire d'utilisation des pièces esquillées. Figure 27. Techno-economic schematization of the chaîne opératoire associated to the use of pieces esquillées. 


\section{Les chaînes opératoires en matières exogènes}

Les matières premières exogènes mises au jour sur les sites du Témiscouata sont variées, mais proviennent majoritairement des sources du bassin versant de la rivière Saint-Jean (cherts Tobique, Munsungun et Washademoak), mais également d'autres gisements du Québec, du Nouveau-Brunswick, de la Nouvelle-Écosse et de l'État du Maine (Figure 2) (Burke 2000; 2001; Chalifoux et al. 1998: 135-143). Même s’il existait plusieurs sources de pierres siliceuses de bonne qualité, accessibles directement ou indirectement par échanges, elles n’en étaient pas moins disséminées sur le territoire et séparées les unes des autres par d'assez grandes distances. Les groupes de chasseurs-cueilleurs étaient donc souvent confrontés à des contextes occupationnels où ils ne disposaient pas d'un accès direct à une source de matière lithique de bonne qualité. Afin de surmonter cette contrainte, il leur était nécessaire d'adopter des stratégies techno-économiques leur permettant de disposer des outils nécessaires dans de tels contextes. Les industries sur le chert Touladi nous ont montré que l'industrie bifaciale était l'élément central structurant la production de l'outillage à l'intérieur du Témiscouata et vraisemblablement aussi à l'extérieur, si on en croit les évidences d'exportation d'ébauches et de préformes. Or, comme tous les sites de notre corpus concernent des établissements ayant un accès direct aux carrières lithiques, les industries en chert Touladi ne peuvent offrir qu'une vision partielle des stratégies économiques qui ont prévalu en dehors de la région. Les artefacts en matériaux importés contribuent ainsi à jeter un peu plus de lumière sur les modalités de gestion des chaînes opératoires ayant eu cours avant d'atteindre le Témiscouata.

\subsection{Pièces bifaciales en matières exogènes}

Sur les cinq collections étudiées, seulement treize pièces bifaciales en matières exogènes ont été mises au jour, ce qui est fort peu considérant l'importance de cette chaîne opératoire pour les schèmes techno-économiques relatifs au chert Touladi. On les retrouve selon tous les stades d'avancement, même s'il y a une légère prépondérance pour les bifaces de phase 3 (Tableau 8) (Figures 28 à 31). Il n'en demeure pas moins que le tiers de ces artefacts ont été introduits dans un stade préliminaire (ébauches et préformes) révélant là aussi que ces groupes de chasseurs-cueilleurs ne transportaient pas que des spécimens achevés.

Tableau 8. Les types de pièces bifaciales en matières exogènes.

Table 8. Bifacial tool types made from exotic materials.

\begin{tabular}{lllllll}
\hline Types de pièces bifaciales & CkEe-12 & CkEe-22 & CkEe-9 & CkEe-2 & CjEd-5 & Total \\
\hline Ébauche & & 2 & & & & $2(15,4 \%)$ \\
$\begin{array}{l}\text { Préforme } \\
\text { Biface phase 3 }\end{array}$ & 1 & 1 & & & $2(15,4 \%)$ \\
$\begin{array}{l}\text { Biface phase 4 (mais introduit } \\
\text { dans une phase 3) }\end{array}$ & & 4 & & 1 & $5(38,4 \%)$ \\
$\begin{array}{l}\text { Pointe de projectile } \\
\text { Total }\end{array}$ & & & & 2 & $2(15,4 \%)$ \\
\hline
\end{tabular}

Le nombre restreint de pièces bifaciales importées laisse d'emblée croire que ces objets ne représentent pas la totalité de ceux qui ont été introduits au Témiscouata et que seule une partie d'entre eux a été rejetée in situ par les groupes nomades. Cela est d'autant plus probable lorsqu'on examine les causes d'abandon de ces artefacts et que l'on constate que neuf cas sur treize $(69,2 \%)$ ont été rejetés suite à une cassure. Cela ne traduirait pas ici une stratégie de remplacement massif de cet outillage (gearing up strategy) (Andrefsky 1994b; Binford 1979; Kuhn 1989; Sellet 1999: 55-61), mais plutôt un rejet des spécimens qui n’étaient plus 
fonctionnels ou pour lesquels on jugeait économiquement peu rentable de les réparer dans un contexte où il était facile de les remplacer.

Des travaux de raffutage de pièces bifaciales importées sont perceptibles par des éclats abandonnés in situ, démontrant ici aussi que les groupes préféraient probablement, lorsque possible, conserver et entretenir leurs outils bifaciaux importés. Le cas le plus éloquent de la volonté d'entretien de cette classe d'outil concerne un biface de phase 3 en rhyolite retrouvé sur CjEd-5 (Figure 28). Grâce aux remontages de deux segments de l'outil et de quelques éclats, ce spécimen révèle de manière explicite qu’il a été réparé sur place. Il semble d'ailleurs avoir été fracturé à deux reprises durant les activités de réparation si on en croit les segments jointifs qui présentent des dimensions différentes. Malgré ces accidents, il est probable que l'artisan-tailleur ait remis en état le biface, car la portion résiduelle n’a pas été retrouvée.

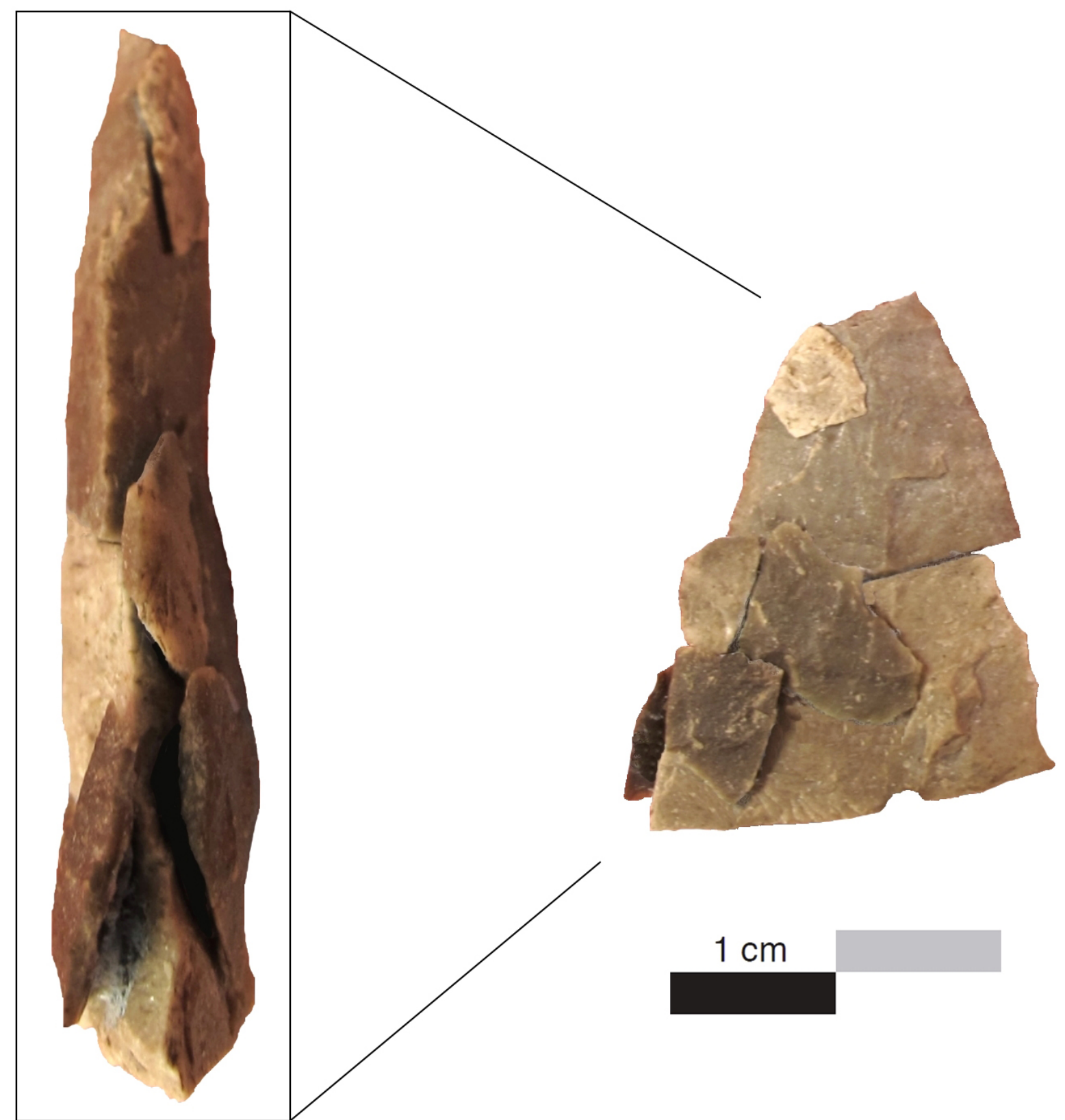

Figure 28. Biface en rhyolite partiellement remonté avec quatre éclats. Les deux segments du biface montrent plusieurs épisodes de cassures et de réparations (CjEd-5.27).

Figure 28. Partially refitted biface made from rhyolite. The two segments of the biface show several episodes of breaks and repairs (CjEd-5.27). 


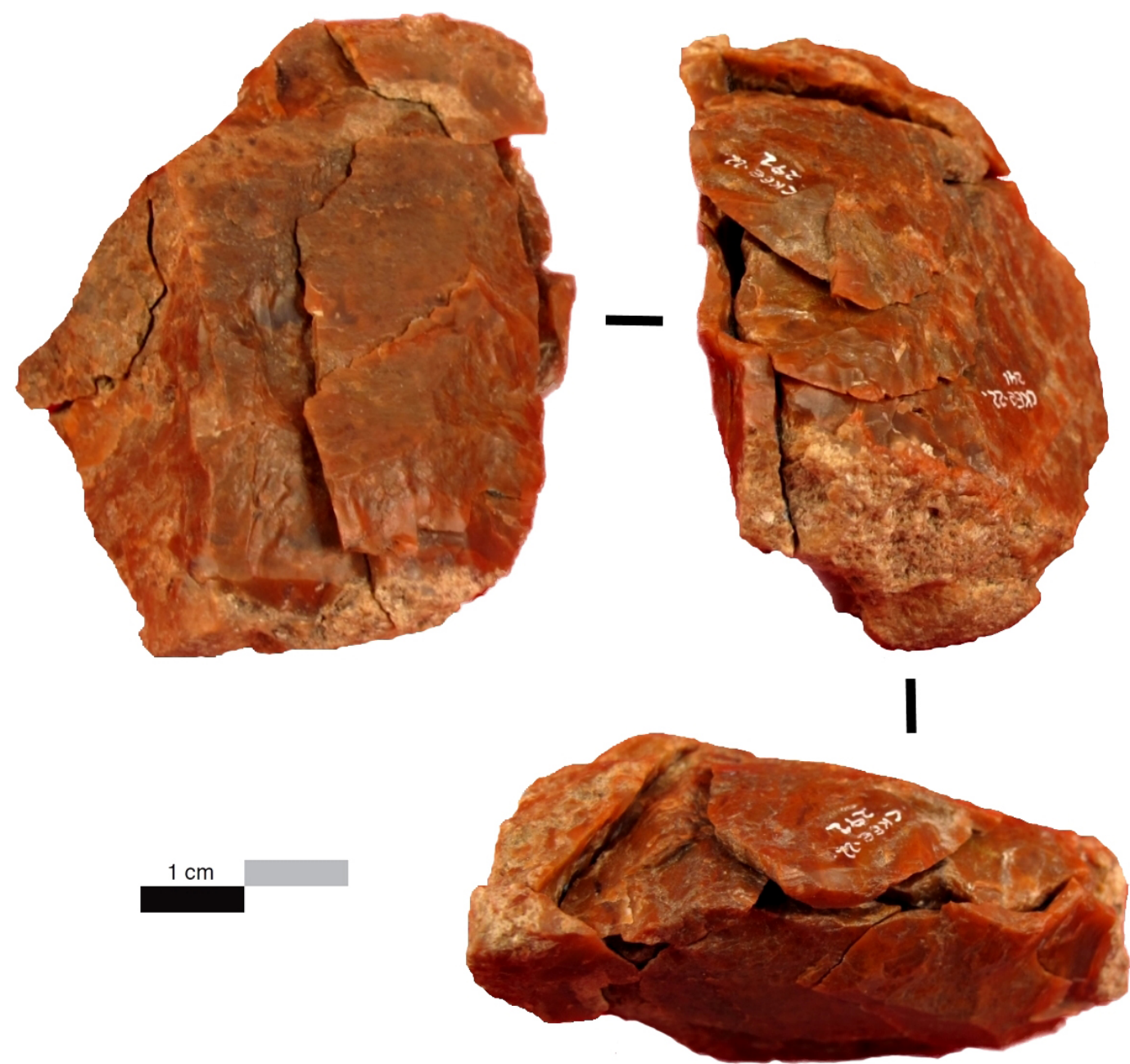

Figure 29. Ébauche bifaciale en chert Tobique partiellement remontée (CkEe-22.241).

Figure 29. Partially refitted bifacial rough-out made from Tobique chert (CkEe-22.241).

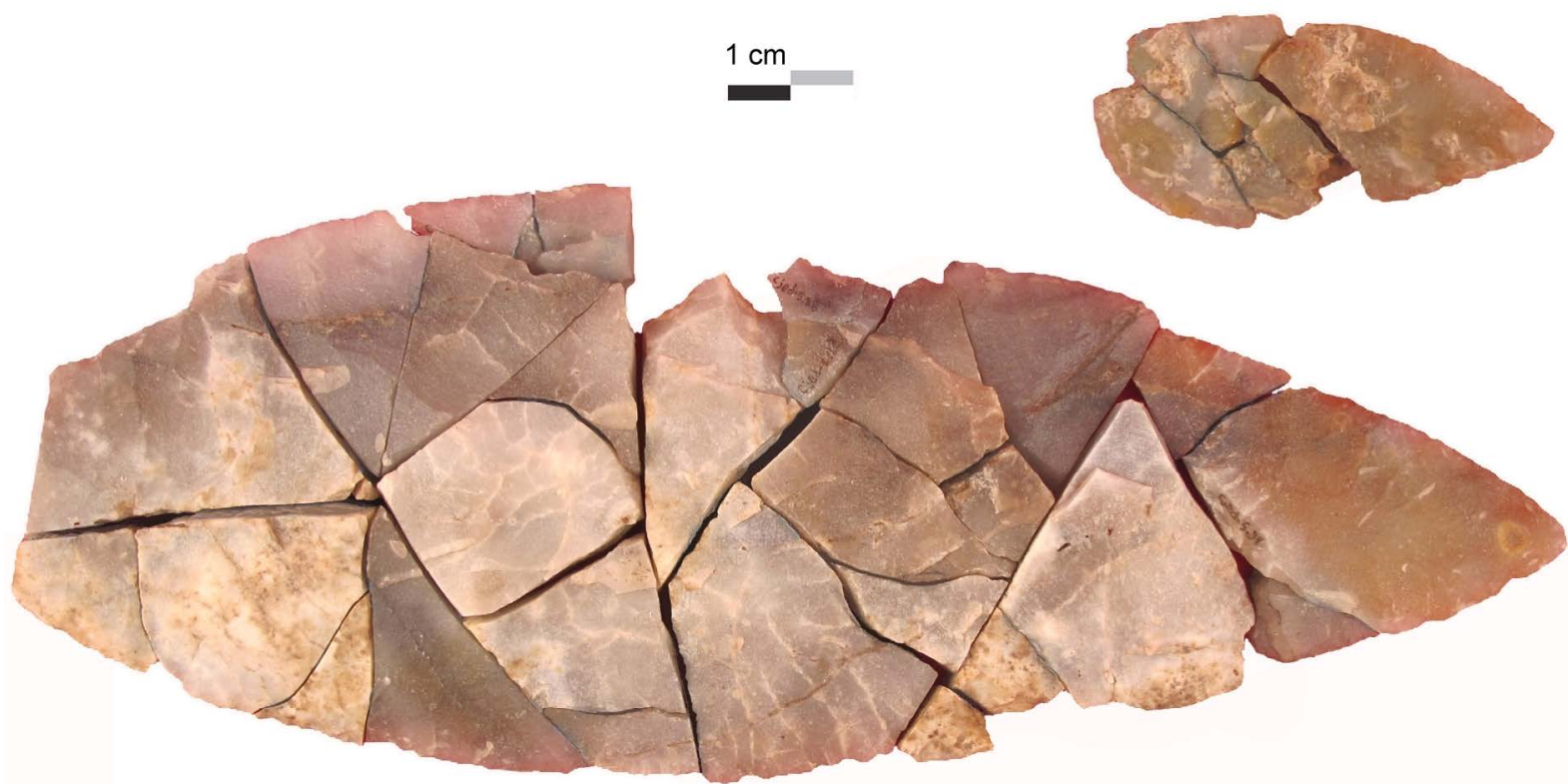

Figure 30. Deux bifaces en quartzite de Ramah fracturés intentionnellement et remontés (CjEd-5.34 et CjEd5.57).

Figure 30. Two refitted bifaces deliberately fractured and made from Ramah quartzite (CjEd-5.34 et CjEd-5.57). 

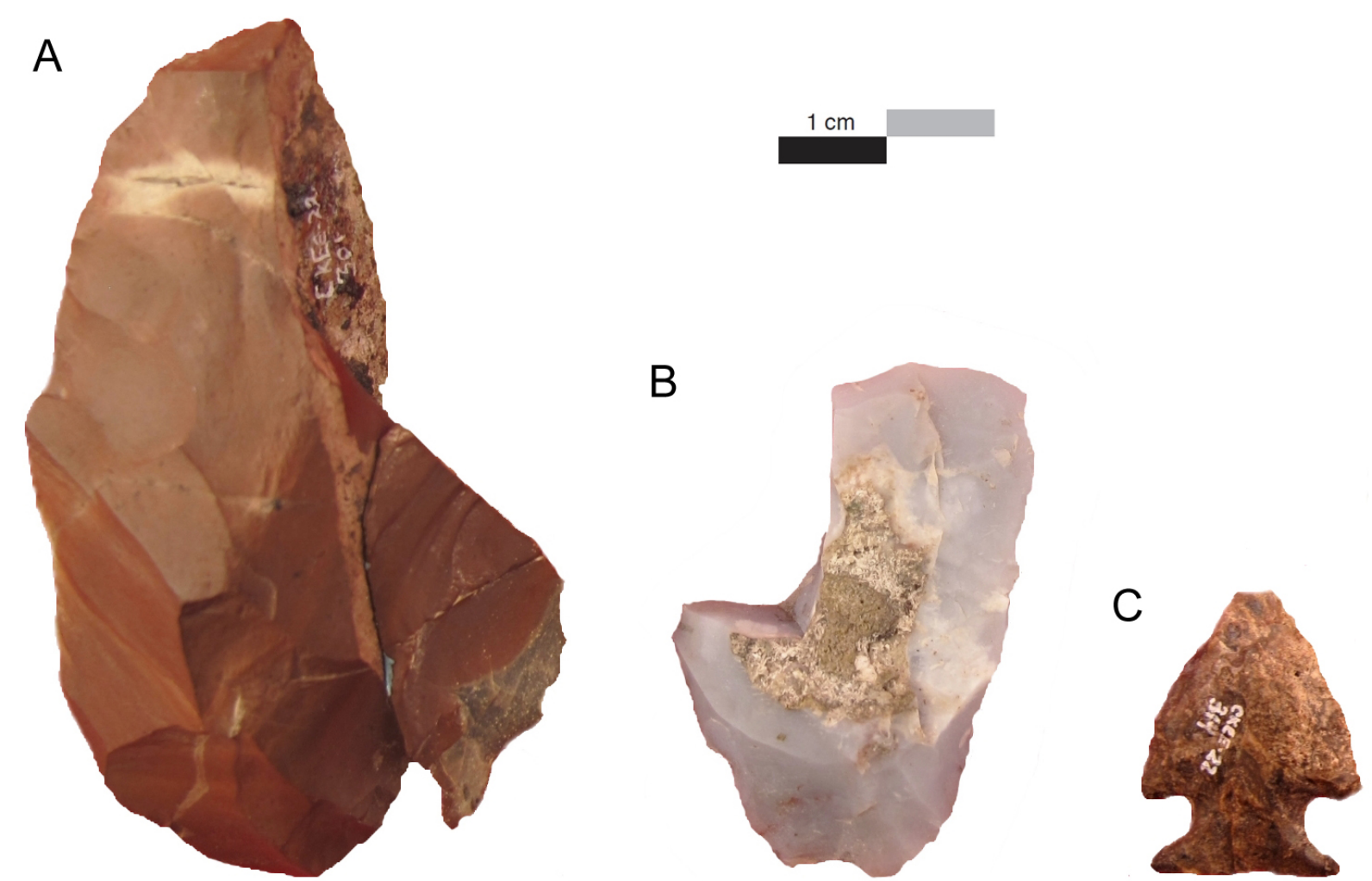

Figure 31. Trois pièces bifaciales en matériaux exogènes : A - chert Munsungun (CkEe-22.301-114); B - matière de Minas Bassin (CkEe-22.315); C - chert Tobique (CkEe-22.314).

Figure 31. Three bifacial tools made from exotic materials: A - Munsungun chert (CkEe-22.301-114); B - Minas Bassin material (CkEe-22.315); C - Tobique chert (CkEe-22.314).

La taille in situ de pièces bifaciales importées ne concerne toutefois pas que les activités d'entretien et de réparation. Le cas du site CkEe-22 est intéressant, car les tailleurs y ont importé deux galets de chert Tobique dans un état plus ou moins brut et c'est seulement une fois sur ce site qu'ils les ont transformés en pièces bifaciales (Figure 29). L'une a été abandonnée au stade d'ébauche, alors que l'autre a été terminée et probablement emportée hors du site. C'est donc seulement par l'analyse des éclats laissés par ce travail qu'il a été possible de reconnaître ce second spécimen. Sur CjEd-5, deux bifaces en quartzite de Ramah ont été introduits dans une phase 3 et ont été abandonnés dans une phase 4 suite à un travail de finition ayant précédé leur destruction intentionnelle, vraisemblablement faite dans un contexte rituelle (Figure 30). La source du quartzite de Ramah se retrouve au Labrador (TerreNeuve) à 1350 km à vol d'oiseau au nord du site CjEd-5 (Burke 2005; 2006).

Les quelques exemples mentionnés précédemment illustrent donc que les pièces bifaciales en matériaux exogènes auraient souvent été considérées comme ayant assez de valeur pour être conservées, même s’il était possible de les remplacer par des spécimens neufs en chert Touladi. Il semble aussi que les tailleurs aient généralement privilégié l'entretien et la réparation des pièces bifaciales importées sauf en certaines circonstances, notamment lorsque ces objets étaient trop abîmés.

\subsection{Les nucléus en matières exogènes}

On ne rencontre que trois nucléus formels en matières exogènes (CkEe-12 et CjEd-5) et ces derniers ont révélé une technologie très différente de leurs homologues en chert Touladi. Le premier spécimen (CkEe-12.320) correspond à un petit nucléus discoïde en chert Washademoak débité de manière bifaciale selon une progression tournante et centripète (Figure 32). Ses deux faces sont entièrement taillées et elles sont à la fois surface débitée et 
plan de frappe. Sept éclats et un grattoir, vraisemblablement taillés in situ, ont été remontés sur ce nucléus. Le second spécimen (CjEd-5.449) est fait sur un petit galet de chert dont l'origine est inconnue et qui a été taillé par percussion bipolaire sur enclume (Figure 33). Le troisième nucléus (CjEd-5.408) est quant à lui trop fragmentaire pour que l'on puisse préciser ses techniques et méthodes de taille.
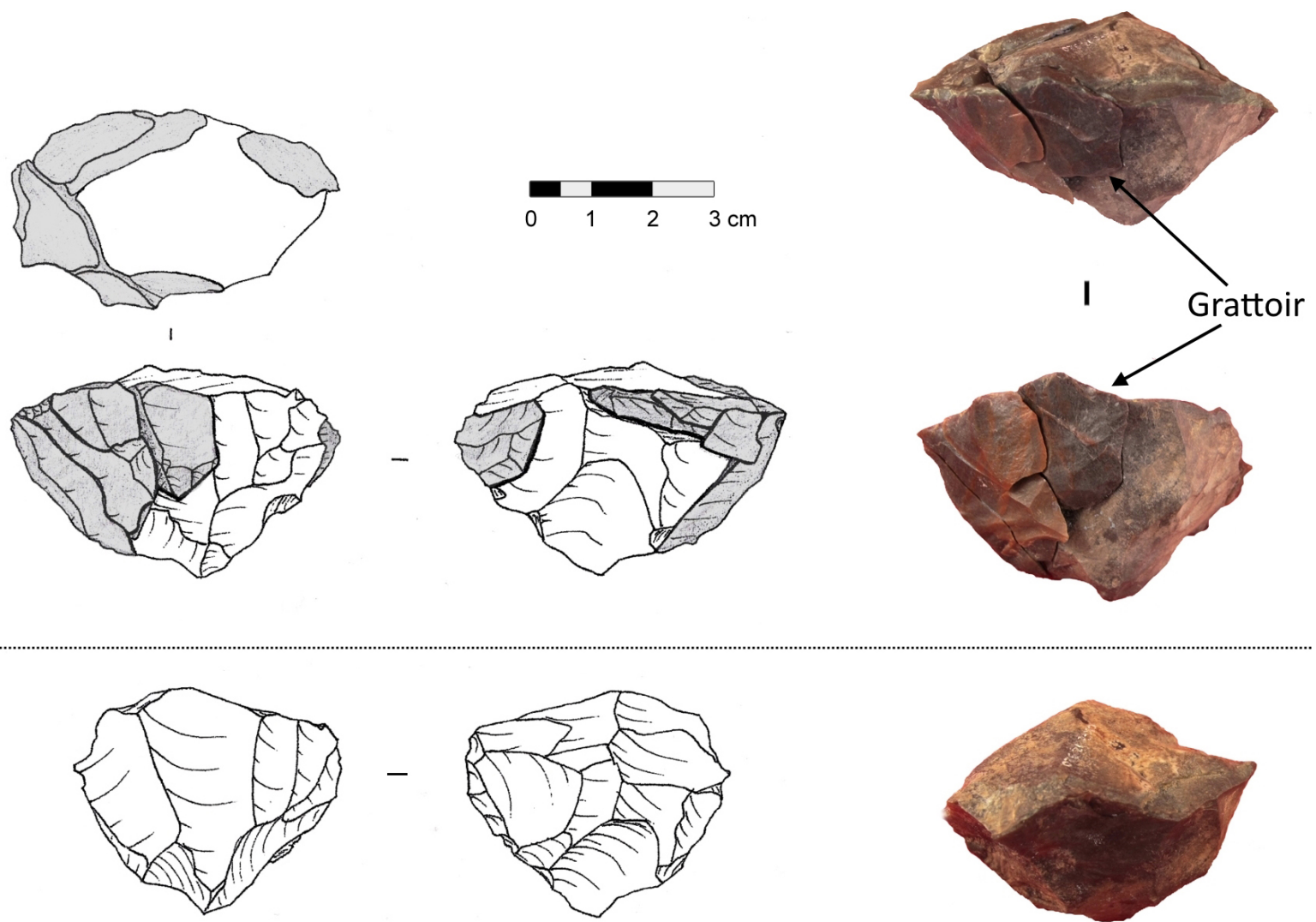

Figure 32. Nucléus discoïde en chert Washademoak partiellement remonté (en haut) et sans remontages (en bas). Les remontages sur le dessin sont représentés par les zones ombragées (CkEe-12.320; dessin : Julie Leclerc).

Figure 32. Discoidal core made from Washademoak chert. Upper view shows the core partially refitted with flakes and a single endscraper (CkEe-12.320; drawing: Julie Leclerc).

En plus de ces spécimens, notons aussi la présence d'un fragment de préforme bifaciale vraisemblablement recyclé en nucléus (CkEe-9.602), ainsi que les deux galets en chert Tobique susmentionnés et qui ont été transformés en pièces bifaciales sur CkEe-22. Or, avant d'atteindre ce site, ces galets étaient transportés dans un état plus ou moins brut ce qui indique peut-être que leur finalité n’était pas scellée à l'avance. Cela reste à démontrer, mais on peut proposer l'idée d'un emploi assez flexible de ces matrices brutes, s'adaptant en fonction des besoins et des contextes. Cette hypothèse est également avancée en regard des contraintes inhérentes au chert Tobique qui se rencontre essentiellement sous la forme de petits galets fréquemment parsemés d'impuretés et de failles. En raison de ces limitations, ce matériau est surtout connu pour le débitage de supports servant à la production de petits outils sur éclats (Burke 2000: 204-205).

Ces spécimens importés, bien qu'en nombre restreint, nous permettent d'avance l'idée que les tailleurs ont adapté la technologie de leurs nucléus en fonction du contexte et des matériaux lithiques utilisés. Loin des sources lithiques, elle tendrait à se complexifier et à maximiser la volumétrie des matrices, alors que près des carrières, elle serait plus simple et moins productive en supports. Le nucléus discoïde a généré beaucoup plus d'éclats que la 
plupart de ceux en chert Touladi, même si ses dimensions sont de loin inférieures. Comme le chert Washademoak n'est disponible qu'en petits galets souvent parsemés de failles (Burke 2000: 220), l'adoption d'une méthode de taille permettant d'exploiter au maximum la faible volumétrie de cette matière première semble avoir été privilégiée. Quant au nucléus bipolaire, même si la technique de taille a été probablement imposée par la matière première se présentant sous la forme d'un petit galet arrondi, on dénote tout de même un souci de maximiser la production d'éclats. L’investissement technique différentiel observé entre les nucléus locaux et importés au Témiscouata pourrait donc s'expliquer en partie par la proximité des sources de chert Touladi et en partie par les propriétés inhérentes des matériaux taillés. Quoi qu'il en soit, il semble cependant évident que la méthode de taille très peu élaborée observée sur le chert Touladi ait été un choix adopté parmi une gamme d'alternatives connues et maîtrisées par les tailleurs.
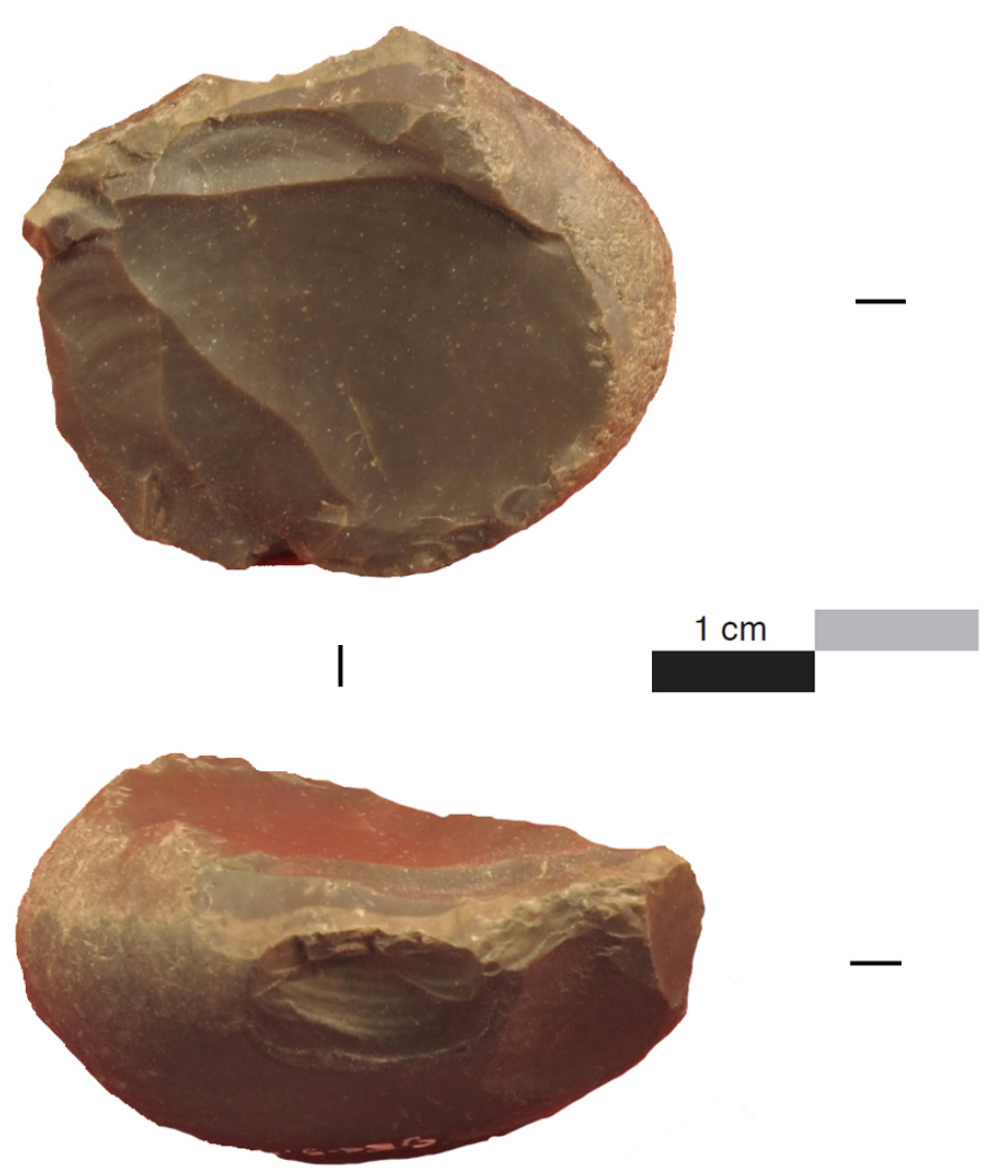

Figure 33. Nucléus bipolaire en matière exogène (CjEd-5.449).

Figure 33. Bipolar core made from exotic material (CjEd-5.449).
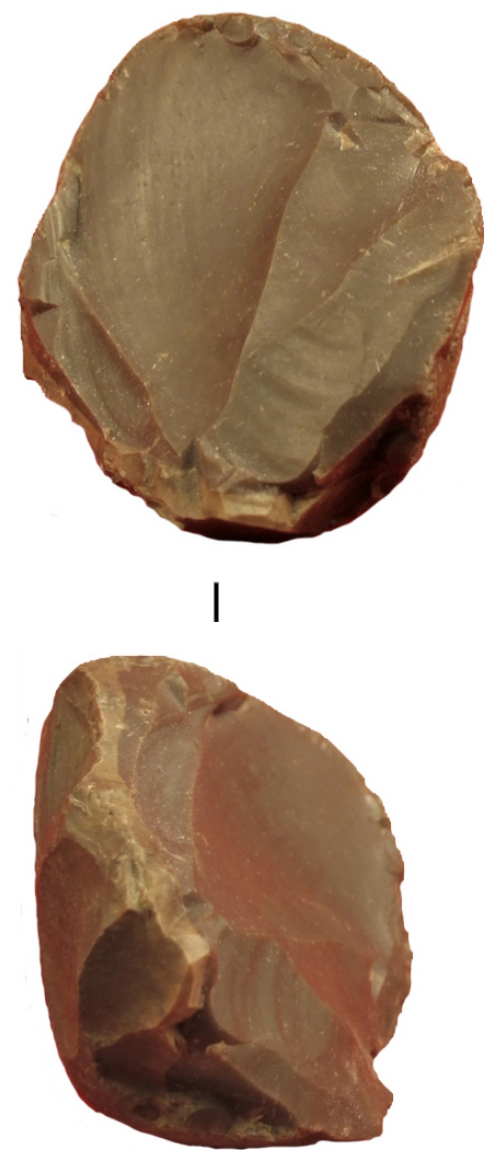

Dans la même perspective, nos données tendent aussi à révéler que la taille bifaciale avait tendance à être privilégiée par rapport au débitage de nucléus lorsque les matériaux importés favorisaient cette chaîne opératoire. Ce serait le cas notamment du chert Munsungun (Maine), matière qui n'offre pas de contrainte à la production de bifaces et pour laquelle peu de nucléus auraient été exportés en dehors des régions limitrophes à sa source (Burke 2000: 179-183 et 193-196). Cette hypothèse est notamment suggérée par le fait que les quelques nucléus en matériaux exogènes mis au jour ont été faits à partir de galets naturellement peu propices à la production bifaciale. 


\subsection{Pièces esquillées en matières exogènes}

À travers les cinq collections étudiées, on ne rencontre que six spécimens de pièces esquillées fabriquées sur des matériaux importés. De plus, seulement deux éclats issus de ces outils ont été dénombrés et dont l'un d'entre eux a été transformé en outil. L'emploi des pièces esquillées pour la production de supports semble avoir été un phénomène plus marginal sur les matières exogènes que sur le chert Touladi. L'apparente rareté de ces outils en est probablement l'explication première. Également, la grande variabilité morphométrique des résidus détachés durant l'utilisation de ces outils (éclats, esquilles, quartiers, bâtonnets) ne permettait probablement pas d'en faire un élément important des stratégies technoéconomiques. Pour ces raisons, ce mode de production d'éclats n'aurait été utilisé que de manière occasionnelle et opportuniste en contexte de pauvreté en ressources lithiques.

\subsection{L'outillage sur éclats en matières exogènes}

L'assemblage d'outils sur éclats importés comporte 75 spécimens se déclinant entre les trois principales classes : grattoirs $(n=45)$, outils ad hoc $(n=24)$ et pièces esquillées $(n=6)$ (Tableau 9). On note d'abord que la proportion de chaque catégorie est différente par rapport à celle observée sur le chert Touladi. En effet, les grattoirs forment la classe dominante chez les matières allochtones, alors que les outils ad hoc et les pièces esquillées sont prépondérants sur le chert local, et ce, même si ces dernières ne sont présentes que sur deux des cinq sites de l'étude.

Tableau 9. Les différentes classes d’outils sur éclats en matières exogènes. Table 9. The various classes of flake tools made from exotic materials.

\begin{tabular}{lllllll}
\hline Classe d'outil & CkEe-12 & CkEe-22 & CkEe-9 & CkEe-2 & CjEd-5 & Total \\
\hline Outils ad hoc & & 4 & 11 & 3 & 6 & $24(32,0 \%)$ \\
Grattoirs & 3 & 10 & 22 & 7 & 3 & $45(60,0 \%)$ \\
Pièces esquillées & & & 1 & 5 & & $6(8,0 \%)$ \\
\hline Total & 3 & 14 & 34 & 15 & 9 & $75(100 \%)$ \\
\hline
\end{tabular}

Lorsqu'on examine l'affiliation technologique des outils importés, on constate qu'une minorité d'entre eux a pu être rattachée à l'une des trois chaînes opératoires. Cela s'explique du fait que la lecture technologique a été restreinte par plusieurs motifs, dont de l'état fragmentaire de plusieurs spécimens et la modification des supports d'origine (retouches, esquillements) (Tableau 10). Même si les données sont plus limitées ici, on en vient cependant au même constat que sur les outils en chert local. La chaîne opératoire bifaciale a produit les supports pour la majorité des spécimens diagnostiqués et ce sont alors toujours les éclats des phases préliminaires (phases $1 b$ et 2) et intermédiaire (phase 3a) qui ont été privilégiés par les tailleurs. Seul un outil a été produit à partir d'un nucléus (le grattoir en chert Washademoak remontant sur le nucléus discoïde) (Figure 32) et un autre a été fait à partir d'un éclat détaché d'une pièce esquillée. Si nos résultats sont représentatifs, les tailleurs ne semblent donc pas avoir dévié ici de la tendance observée au Témiscouata.

Bien que la plupart des outils sur éclats en matières exogènes paraissent avoir été taillés en dehors des sites étudiés (ex situ), de rares spécimens auraient néanmoins été produits sur place. Ce serait entre autres le cas du grattoir remonté sur le nucléus discoïde en chert Washademoak (CkEe-12) (Figure 32) et d'un éclat retouché se raccordant à l'ébauche bifaciale en chert Tobique (CkEe-22) (Figure 29). Quant au reste de l'assemblage d'outils sur éclats en matériaux allochtones, on n'observe aucune évidence permettant de croire qu'ils ont pu être le résultat d'une taille in situ. La proximité des carrières de chert Touladi explique 
probablement pourquoi ici la taille d'outils à partir de matrices en matériaux exogènes ne serait qu'anecdotique.

Tableau 10. Les chaînes opératoires d’où proviennent les outils sur éclats en matières exogènes.

Table 10. The chaînes opératoires from which the flake tools made from exotic materials come from.

\begin{tabular}{lllllll}
\hline Origine technologique & CkEe-12 & CkEe-22 & CkEe-9 & CkEe-2 & CjEd-5 & Total \\
\hline $\begin{array}{l}\text { Chaîne opératoire } \\
\text { bifaciale }\end{array}$ & & 1 & 6 & 1 & 1 & $9(12,0 \%)$ \\
$\begin{array}{l}\text { Chaîne opératoire des } \\
\text { nucléus }\end{array}$ & 1 & & & & & $1(1,3 \%)$ \\
$\begin{array}{l}\text { Chaîne opératoire des } \\
\text { pièces esquillées }\end{array}$ & & & & 1 & & $1(1,3 \%)$ \\
$\begin{array}{l}\text { Indéterminée } \\
\text { Total }\end{array}$ & $\mathbf{3}$ & 13 & 28 & 13 & 8 & $64(85,3 \%)$ \\
\hline
\end{tabular}

Par ailleurs, on peut aussi s'interroger sur le contexte de production des outils sur éclats importés au Témiscouata. Trois scénarios possibles peuvent être à l'origine de ces outils :

1) Ils ont été manufacturés à l'avance dans un contexte d'accès direct à une source lithique.

2) Des éclats ont été taillés à proximité de sources lithiques et c'est une fois en retrait de celles-ci que ces supports bruts ont été transformés en outils.

3) Les outils et leurs supports ont été produits entièrement dans un contexte d'éloignement des sources lithiques, à partir de pièces bifaciales, de nucléus ou de pièces esquillées transportés par le groupe.

Ces trois cas de figure ont probablement coexisté à différents degrés, mais il est exceptionnel qu'on puisse associer un outil particulier à un de ces scénarios de production ex situ. Étant donné la découverte de plusieurs artefacts en matériaux importés agissants vraisemblablement comme matrices pourvoyeuses de supports, il semble toutefois fondé de croire que le troisième scénario n’était pas rare.

\subsection{Les supports bruts matières exogènes}

La question du transport d'éclats-supports bruts n’a que rarement été abordée par les archéologues nord-américains, surtout dans les contextes d'ateliers de taille où ils sont habituellement relégués au rang de "déchets de fabrication " au même titre que ceux des matières locales. Or, cela a pour effet de masquer un pan important de la gestion de l'outillage en situation d'éloignement des ressources lithiques. Pour aborder cette stratégie technoéconomique, il faut dans un premier temps départager les éclats réellement taillés et abandonnés in situ, résidus de productions ponctuelles faites à partir de matériaux importés (finition et réparation d'outils, utilisation de pièces esquillées, etc.), de ceux ayant été préalablement produits ex situ et transportés comme supports. Les critères diagnostics pour déterminer ces deux catégories d'éclats en matières exogènes peuvent varier en fonction des schèmes techno-économiques privilégiés par les tailleurs et doivent donc être évalués pour chaque contexte. Dans le cas du Témiscouata, les critères de sélection des supports produits ex situ peuvent se résumer ainsi :

- Ils sont habituellement retrouvés de manière isolée ou en petit nombre. Ceux retrouvés en grand nombre pour une même matière première sont plus susceptibles d'avoir été taillés in situ. Cela l'est d'autant plus s'ils témoignent d'une succession logique de plusieurs étapes d'une même chaîne opératoire. 
- Les éclats associés à la chaîne opératoire bifaciale devraient provenir surtout des phases préliminaires et intermédiaires de cette industrie. Les éclats issus des phases de finition relèvent donc probablement plus d'une taille in situ.

- Ils doivent répondre aux critères morphométriques des outils sur éclats en chert Touladi et ceux en matières exogènes. Leurs dimensions doivent ici être minimalement supérieures à 1 $\mathrm{cm}^{2}$.

En appliquant ces critères de sélection, on a pu déterminer que parmi les 818 éclats en matériaux allochtones, 736 auraient été taillés in situ contre 82 produits ex situ (Tableau 11). Les résidus de fabrication vraisemblablement générés sur place correspondent surtout à de la taille bifaciale, que ce soit lors d'activités de réparation et de raffutage ou, dans quelques cas, de projets de taille plus exhaustifs comme le façonnage des deux galets en chert Tobique mentionnés plus haut (Figure 29). On retrouve aussi le cas du débitage du nucléus discoïde en chert Washademoak dont les derniers supports auraient été détachés sur CkEe-12 (Figure 32), ainsi que l'utilisation ponctuelle de pièces esquillées. Quant aux supports qui auraient été importés au Témiscouata, on constate là également la prépondérance du processus bifacial pour leur confection. Ces éclats ont pu être produits à l'avance dans un contexte d'abondance lithique ou dans une situation de rareté à partir des pièces bifaciales inachevées que le groupe emportait avec lui.

Tableau 11. Les chaînes opératoires d’où proviennent les éclats bruts en matières exogènes en fonction du lieu de leur production (in situ ou ex situ).

Table 11. The chaînes opératoires from which the unused flake blanks made from exotic materials come from according to the location of their production (on site or off site).

\begin{tabular}{|c|c|c|c|c|c|c|c|}
\hline $\begin{array}{l}\text { Lieux de } \\
\text { taille }\end{array}$ & $\begin{array}{l}\text { Affiliations } \\
\text { technologiques }\end{array}$ & $\begin{array}{l}\text { CkEe- } \\
12\end{array}$ & $\begin{array}{l}\text { CkEe- } \\
22\end{array}$ & $\begin{array}{l}\text { CkEe- } \\
9\end{array}$ & $\begin{array}{l}\text { CkEe- } \\
2\end{array}$ & $\begin{array}{l}\text { CjEd- } \\
5\end{array}$ & Total \\
\hline \multirow{4}{*}{$\begin{array}{l}\text { Ex situ } \\
\text { (extérieur au } \\
\text { Témiscouata) }\end{array}$} & $\begin{array}{l}\text { Chaîne opératoire } \\
\text { bifaciale }\end{array}$ & 2 & 2 & 7 & 10 & 4 & $25(3,1 \%)$ \\
\hline & $\begin{array}{l}\text { Chaîne opératoire des } \\
\text { nucléus }\end{array}$ & & & & & & 0 \\
\hline & $\begin{array}{l}\text { Chaîne opératoire des } \\
\text { pièces esquillées }\end{array}$ & & & 1 & & & $1(0,1 \%)$ \\
\hline & Indéterminée & 1 & 1 & 25 & 13 & 16 & $56(6,8 \%)$ \\
\hline Total Ex situ & & 3 & 3 & 33 & 23 & 20 & $82(10,0 \%)$ \\
\hline $\begin{array}{l}\text { In situ } \\
\text { (au }\end{array}$ & $\begin{array}{l}\text { Chaîne opératoire } \\
\text { bifaciale }\end{array}$ & & 38 & 2 & 1 & 120 & $161(19,7 \%)$ \\
\hline \multirow[t]{3}{*}{ Témiscouata) } & $\begin{array}{l}\text { Chaîne opératoire des } \\
\text { nucléus }\end{array}$ & 7 & & & & & $7(0,9 \%)$ \\
\hline & $\begin{array}{l}\text { Chaîne opératoire des } \\
\text { pièces esquillées }\end{array}$ & & & & 2 & & $2(0,2 \%)$ \\
\hline & Indéterminée & & 423 & 3 & & 140 & $566(69,2 \%)$ \\
\hline Total In situ & & 7 & 461 & 5 & 3 & 260 & $736(90,0 \%)$ \\
\hline Total & & 10 & 464 & 38 & 26 & 280 & $818(100 \%)$ \\
\hline
\end{tabular}

On retrouve aussi plusieurs exemples d'éclats taillés ex situ qui, par la similitude de leur matière première et de leurs attributs morphotechnologiques, ont pu être rapprochés de pièces bifaciales en matières allochtones retrouvées sur les mêmes établissements. Relatons ici les cas les plus probants qui proviennent des deux bifaces en quartzite de Ramah (Figure 30) et de celui en rhyolite retrouvé sur CjEd-5 (Figure 28). On a vu plus haut que ces outils ont été respectivement finis et réparés sur place, mais outre les résidus produits par ces activités de 
taille, on retrouve aussi quelques intrus. Trois éclats en quartzite de Ramah et un en rhyolite sont associés à des phases préliminaires et intermédiaires qui ne concordent pas avec l'état dans lequel ces bifaces auraient été introduits. Ils auraient donc été produits ex situ, aux moments où les bifaces étaient apparemment aux stades d'ébauches et de préformes. Un des éclats en quartzite a été transformé en outil (éclat retouché), alors que les autres ont été abandonnés sans traces macroscopiques d'utilisation. Quant à la rhyolite, un seul éclat provenant d'une phase de préformage a été retrouvé et ne peut être associé avec ceux des activités de réparation réalisées sur place. Nous croyons qu'il aurait lui aussi été conçu à un moment où le biface de la même matière n'était qu'une préforme. La décision de rejeter ces éclats bruts s'explique probablement par la proximité des carrières de chert Touladi, lesquelles pouvaient alors répondre à tous les besoins en outils, ce qui contribuait à rendre obsolètes les réserves transportées jusque-là.

La quantité d'éclats bruts produits ex situ peut être indicative des réserves d'outils que les groupes transportaient avec eux lorsque leur mode de vie nomade les entraînait loin des gisements de pierres siliceuses. Le fait d'en retrouver sur chacun des sites, et souvent même en assez grande quantité, montre que ces communautés de chasseurs-cueilleurs n'étaient généralement pas en pénurie d'outils sur éclats à leur arrivée au Témiscouata. Au contraire, si nos interprétations sont justes, ils semblent en avoir eu en suffisance et même au-delà de leurs besoins si autant de supports ont été abandonnés inutilisés. L'absence d'utilisation est ici interprétée par l'absence de traces macroscopiques d'usures et non par l'entremise d'une analyse tracéologique. Contrairement aux outils bifaciaux importés, qui semblent avoir été conservés tant qu'on les jugeait économiquement rentables, les outils sur éclats et les supports bruts auraient plutôt été massivement rejetés pour être remplacés par des spécimens neufs en chert Touladi (gearing up strategy) (Andrefsky 1994b; Binford 1979; Kuhn 1989; Sellet 1999: 55-61).

\subsection{La prépondérance des grattoirs en matières exogènes}

On a vu plus haut que les trois classes d'outils en chert Touladi ne se rencontrent pas dans les mêmes proportions que celles en matières exogènes. À cet égard, ce sont les grattoirs qui présentent la disparité la plus marquante parmi tous les outils importés au Témiscouata. Ceux en matières allochtones sont en effet représentés dans une proportion beaucoup plus forte que les autres classes d'outils. Le phénomène se rencontre dans notre échantillon de sites étudiés, mais aussi dans la plupart des établissements situés à moins de $2 \mathrm{~km}$ des carrières de chert Touladi (Burke 2007: 74). Sur cette matière locale, les outils ad hoc sont habituellement plus nombreux que les grattoirs et il en va de même aussi pour les pièces esquillées sur CkEe-2 et CkEe-9. Comment alors expliquer que c'est l'image inverse qui apparaît lorsqu'on s'attarde aux matériaux exogènes? Voyons comment l'angle de la techno-économie peut apporter ici des éléments de réponse en puisant dans la gestion différentielle des différentes classes d'outils.

Tout d'abord, en considérant les supports bruts acheminés jusqu'au Témiscouata comme des outils potentiel plutôt que des résidus de taille produits in situ, cela remet en perspective la prépondérance numérale des grattoirs importés. En effet, ces supports en matières exogènes sont en nombre supérieur aux grattoirs sur les sites CkEe-9, CkEe-2 et CjEd-5, alors qu'ils sont en quantité égale sur CkEe-12. Seul CkEe-22 contient plus de grattoirs exogènes que d'éclats bruts produits ex situ.

En second lieu, nous devons considérer que tous les indices accumulés tendent à démontrer que les outils ad hoc et les pièces esquillées, peu importe leurs matières premières, auraient eu une durée de vie utile généralement assez courte. En effet, les outils ad hoc ne montrent pas d'indices d'entretien, l'emploi de tranchants bruts a été privilégié et les 
retouches, lorsque présentes, semblent la plupart du temps être le résultat de l'utilisation que d'un aménagement intentionnel. Qui plus est, le grand nombre d'outils ad hoc en chert Touladi abandonné indiquerait qu'ils étaient probablement remplacés rapidement lorsque leur rendement baissait. Conséquemment, ces outils devaient généralement être abandonnés sur le lieu même où ils étaient produits, ou du moins, ils ne devaient pas avoir tendance à être transportés sur de longues distances.

Quant aux pièces esquillées, par la manière dont elles sont utilisées en percussion bipolaire, elles s'épuisaient aussi vraisemblablement rapidement. Les expérimentations de Lucas et Hays (2004: 117) ont révélé que leurs pièces esquillées ont perdu environ $20 \%$ de leur volume dans l'axe dans lequel elles étaient percutées. Cela est présenté ici à titre indicatif, car la réduction de ces outils peut varier notamment en fonction de la matière travaillée et celle de la pièce esquillée, du type de percuteur, de la durée d'utilisation, du nombre d'axes de percussion et de la force déployée. Il devait ainsi être nécessaire de remplacer celles du Témiscouata assez régulièrement, lorsque leurs attributs morphométriques les rendaient contraignants ou impropres à leur utilisation.

En revanche, les grattoirs, peu importe leur matière première, montrent des indices d'entretien de leur front et ils constituent la classe d'outils sur éclats la plus susceptible à avoir été emmanchée (Hottin 2008: 36-49). Ces modalités d'utilisation témoignent vraisemblablement d'un usage plus intensif des grattoirs favorisant une plus longue durée de vie. Conséquemment, il parait logique de proposer que ces outils accompagnaient les groupes sur une plus longue période de temps, tandis que les autres outils sur éclats devaient être davantage abandonnés au fur et à mesure des multiples haltes parsemant leur cycle de nomadisme. Dans cette perspective, les grattoirs produits et utilisés ex situ avaient plus de chance que les autres classes d'outils sur éclats d'atteindre le Témiscouata.

Les nombreux supports bruts emportés par les groupes nomades constituent ici un facteur important à considérer, car on a vu qu'ils en auraient eu plus que leurs besoins ne le nécessitaient. À cela s’ajoute aussi le transport de matrices (pièces bifaciales, nucléus, pièces esquillées, matrices brutes) aptes à produire de nouveaux supports en cours de route. Ces stratégies techno-économiques faisaient en sorte que les groupes du Sylvicole et de la période de Contact pouvaient disposer d'un nombre important d'éclats-supports, peu importe leur éloignement des sources lithiques. Conséquemment, cela leur permettait probablement d'adopter des modalités d'utilisation similaires en contexte d'abondance et de rareté en pierres siliceuses. Les tailleurs n'auraient donc pas cherché à rendre les outils sur éclats plus durables ou plus performants loin des sources lithiques. Peu importe le contexte, l'abandon rapide des outils ad hoc et des pièces esquillées était possible sans risquer d'épuiser les réserves du groupe. Selon cette logique, toutes les classes d'outils n'auraient donc pas été sujettes aux mêmes schémas de mobilité et il semble donc logique qu'un plus haut taux de grattoirs ait atteint le Témiscouata. Si notre raisonnement est juste, l'apparente dominance des grattoirs exogènes pourrait donc n’être en fait qu'une image déformée par la gestion différentielle des trois classes d'outils sur éclats.

Quant aux outils bifaciaux importés, ils ne font que pousser encore un peu plus loin le principe observé chez les grattoirs : ils sont encore plus entretenus et sont conservés plus longtemps. Contrairement aux grattoirs cependant, ils ne seraient pas abandonnés massivement sur les sites du Témiscouata et la plupart de ceux fonctionnels seraient demeurés dans l'équipement des groupes après leur départ du Témiscouata, restreignant du même coup leur visibilité archéologique.

La dynamique de formation des assemblages archéologiques parait donc fortement influencée par la gestion différentielle de ces classes d'objets où certains répondent davantage à un usage local (outils ad hoc et pièces esquillées) et d'autres à un usage territorial sur de 
moyenne (grattoirs et supports bruts) et grande (pièces bifaciales) distances (Ploux et al. 1992; Porraz 2005: 19-20; Sellet 1999: 64) (Tableau 12 et Figure 34).

Tableau 12. Modalités de gestion différentielles des classes d’objets en matériaux exogènes.

Table 12. The management patterns proper to each class of artifacts made with exotic materials.

\begin{tabular}{|c|c|c|c|}
\hline Classes d'objets & $\begin{array}{l}\text { Distances de } \\
\text { déplacement des } \\
\text { objets }\end{array}$ & $\begin{array}{l}\text { Indices } \\
\text { d'entretien }\end{array}$ & $\begin{array}{l}\text { Visibilité sur les sites du } \\
\text { Témiscouata (matières exogènes) }\end{array}$ \\
\hline Outils ad hoc & Courtes distances & $\begin{array}{l}\text { Aucun à } \\
\text { faible }\end{array}$ & $\begin{array}{l}\text { Faible à modérée } \\
\text { (abandon ex situ et in situ) }\end{array}$ \\
\hline $\begin{array}{l}\text { Pièces } \\
\text { esquillées }\end{array}$ & Courtes distances & Aucun & $\begin{array}{l}\text { Faible } \\
\text { (abandon ex situ dominant) }\end{array}$ \\
\hline Grattoirs & Moyennes distances & $\begin{array}{l}\text { Modéré à } \\
\text { fort }\end{array}$ & $\begin{array}{l}\text { Forte } \\
\text { (abandon in situ dominant) }\end{array}$ \\
\hline Supports bruts & Moyennes distances & - & $\begin{array}{l}\text { Forte } \\
\text { (abandon in situ dominant) }\end{array}$ \\
\hline Pièces bifaciales & Longues distances & $\begin{array}{l}\text { Fort à très } \\
\text { fort }\end{array}$ & $\begin{array}{l}\text { Très faible } \\
\text { (abandon ex situ dominant, mais } \\
\text { après l'occupation du Témiscouata) }\end{array}$ \\
\hline
\end{tabular}

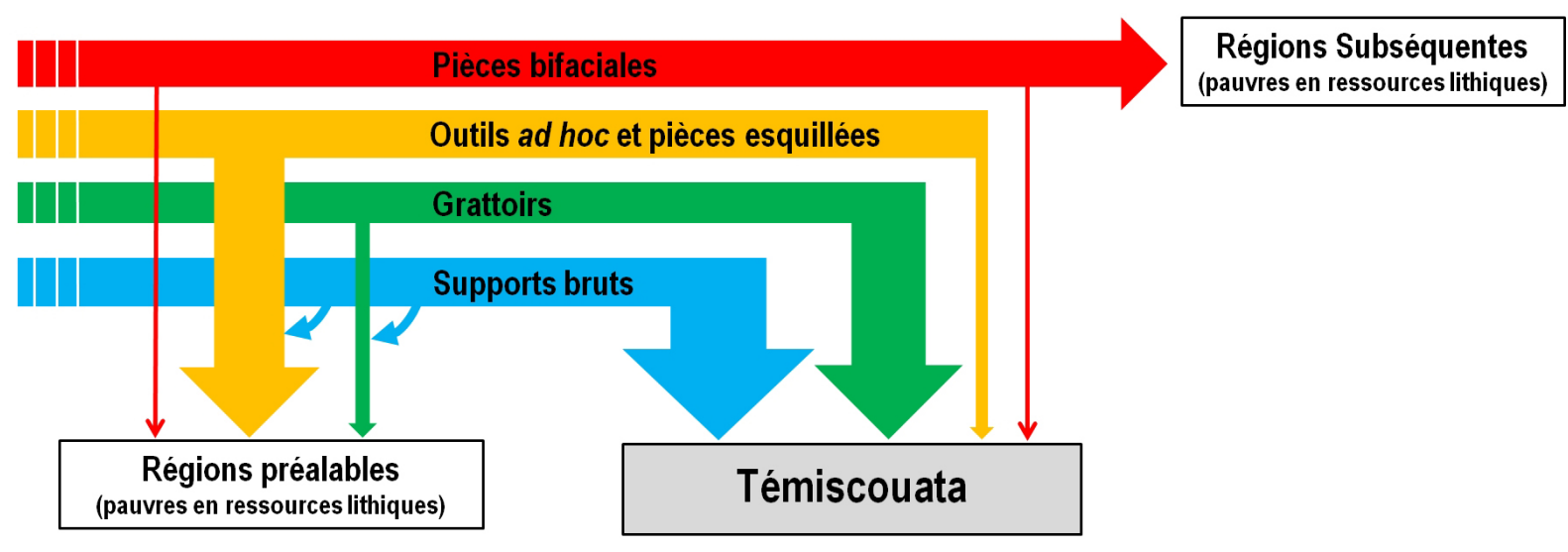

Figure 34. Schéma illustrant les modalités de gestion différentielles des classes d’objets en matériaux exogènes. Les flèches symbolisent par leur épaisseur la proportion approximative de chaque classe d’objets abandonnée dans trois contextes : les régions préalablement occupées et pauvres en ressources lithiques, le Témiscouata et les régions subséquemment occupées et aussi pauvres en ressources lithiques.

Figure 34. Diagram illustrating the management patterns proper to each class of artifacts made with exotic materials. The arrows symbolize, by their thickness, the approximate proportion of each class of objects discarded in three contexts: the previously occupied regions scarce in lithic resources, the Témiscouata and the regions subsequently occupied and also poor in lithic resources.

Malgré ces explications d'ordre techno-économique, d'autres motifs, plus difficilement perceptibles, ont pu agir de manière concomitante pour accentuer la fréquence des grattoirs exogènes au Témiscouata. Burke (2007) propose que la prépondérance des grattoirs en matières importées puisse s'expliquer du fait qu'ils auraient eu un rôle particulier, peut-être comme outils essentiellement réservés au travail des femmes, ce qui aurait influencé leur gestion au sein des industries lithiques. Cette hypothèse reste à démontrer et les données tracéologiques actuelles, bien qu'encore minces, tendent plutôt à indiquer que les grattoirs auraient pu servir autant sur de la matière organique dure (os, andouiller, bois) que souple (peaux sèches et crues), ce qui appuie moins l'idée d'une spécialisation de cette classe d'outils (Hottin 2008: 92-97). Or, cette hypothèse n’est pas forcément en contradiction avec la nôtre et 
comme elle explique la situation des grattoirs par leur gestion différentielle, elle témoigne d'une logique similaire à celle que nous proposons.

Andrefsky (1994a) avance quant à lui que certaines matières premières pouvaient avoir des propriétés qui les rendaient plus propices à certaines fonctions ou à la fabrication de certains types d'outils. Le chert Touladi présente un grain relativement fin, mais les matières exogènes observées dans les collections sont souvent de qualité supérieure. Est-ce que cela pourrait expliquer aussi le plus grand nombre de grattoirs importés sur les sites du Témiscouata? Nous jugeons cette hypothèse peu probable dans ce contexte en raison du rejet important de supports bruts en matériaux exogènes, autant ceux produits sur place que ceux importés. En effet, si la plus grande finesse des éclats en pierres allochtones avait été un facteur sélectif crucial pour fabriquer les grattoirs, il semble probable que les tailleurs les auraient préférés au chert Touladi et ne les auraient donc pas abandonnés en si grand nombre.

\section{Bilan et conclusion}

Cet article a mis l'accent sur un élément particulier d'une recherche beaucoup plus large, en s'intéressant aux schèmes techno-économiques des matières premières exogènes dans un contexte riche en pierre siliceuse (chert Touladi). Ces matériaux importés au Témiscouata portent en eux des informations inédites sur la manière dont les chasseurs-cueilleurs du Sylvicole et de la période de Contact ont organisé leurs technologies lithiques préalablement à leur occupation de la région. Les données demeurent certes partielles, puisque cette étude ne se base que sur des sites du Témiscouata, tous situés à proximité de la même source lithique. Néanmoins, l'exercice s'est montré intéressant et a permis de jeter un regard neuf sur un élément de ces assemblages lithiques moins abordé par les chercheurs du Nord-est américain.

Dans un premier temps, nos données tendent à constater que les chasseurs-cueilleurs du Sylvicole adaptaient les modalités de gestion de leurs chaînes opératoires en fonction de la disponibilité des matières premières, sans toutefois dévier beaucoup des stratégies adoptées en contexte d'abondance en ressources lithiques. À l'extérieur du Témiscouata, la taille de pièces bifaciales semble toujours être le processus dominant et celui le plus susceptible d'engendrer des supports d'outils sur éclats. La réutilisation des sous-produits de la fabrication des bifaces aurait là aussi été réalisée selon une stratégie de chaîne opératoire intégrée et en privilégiant les éclats issus de certaines phases de production.

Si au Témiscouata les nucléus étaient frustes et généralement peu exploités, leurs méthodes de taille avaient cependant tendance à se complexifier ou à être plus " rentables » en situation de rareté en matériaux lithiques. Si nos interprétations sont justes, ce comportement différentiel s'expliquerait avant tout par l'intérêt d'exploiter des matières premières disponibles sous la forme de petits galets. Cependant, lorsque les matériaux étaient disponibles en plus grands modules, nous croyons que les pièces bifaciales avaient alors tendance à être préférées aux nucléus pour la production de supports.

À l'instar de celles du Témiscouata, les pièces esquillées importées pouvaient à l'occasion être utilisées comme matrices pourvoyeuses de supports, mais de manière vraisemblablement plus opportuniste que pour l'industrie bifaciale. Cet outil est habituellement absent des assemblages du Témiscouata et il semble en avoir été de même pour les sites en dehors de la région. Cela contribue à démontrer que les schèmes technoéconomiques ne reposaient habituellement pas sur les supports générés par l'utilisation des pièces esquillées.

Sur le chert Touladi comme sur les matériaux exogènes, les tailleurs ont conservé la même gamme d'outils sur éclats, lesquels sont assez simples et pouvaient s'accommoder de supports de dimensions et de formes variables. Si les groupes du Témiscouata ont transporté avec eux des matrices pour la production de supports, ils ont également transporté des éclats 
bruts prêts à être transformés en outils. Ces deux stratégies auraient entraîné une certaine abondance de supports permettant de remplacer régulièrement l'outillage sur éclats, même en situation d'éloignement des sources lithiques. Cet élément apporte une perspective nouvelle sur les réserves d'outils que ces chasseurs-cueilleurs transportaient avec eux et le fait que leurs visites aux carrières de chert Touladi n'étaient pas nécessairement corrélées avec une pénurie en outillage sur éclats. Pour cette raison notamment, nous croyons que les tailleurs n’ont pas réellement modifié leurs modalités d'utilisation des différentes classes d'outils lorsqu'ils s'éloignaient des carrières de chert du Témiscouata. L'outillage ad hoc et les pièces esquillées auraient continué à avoir une durée de vie relativement courte, alors que les grattoirs auraient toujours été utilisés plus longtemps, ce qui aurait favorisé leur plus grande représentativité au Témiscouata. Quant aux pièces bifaciales, elles semblent avoir fait l'objet d'un soin et d'un entretien supérieur aux grattoirs. Ainsi, l'outillage sur éclats et les supports bruts importés auraient été rejetés préférentiellement sur les sites du Témiscouata pour être remplacés par des spécimens neufs en chert Touladi. À l'inverse, les pièces bifaciales auraient été préférentiellement conservées, voire réparées lorsque possible, minimisant ainsi leur rejet sur les sites de la région.

Si nos analyses apportent de nouvelles données sur la manière dont les chasseurscueilleurs du Témiscouata ont organisé leurs chaînes opératoires lithiques avant d’occuper la région, il reste à interpréter pourquoi ils ont adopté de tels choix. Cet aspect est certes complexe, car les facteurs pouvant influencer les choix techno-économiques d'un groupe sont multiples et intimement liés à leurs modes de vie (organisation sociale, politique, mobilité, commerce, économie de subsistance, croyances, etc.) et aux contextes dans lesquels ils évoluent (environnements, matières premières, distribution des ressources, saisonnalité, relations avec les groupes voisins, etc.) (Bamforth 1991: 217; Burke 2007: 64-66; Sellet 2006: 223; Straus 1991: 170-171). Évidemment, on ne peut isoler tous les facteurs ayant influencé les stratégies techno-économiques adoptées, mais ils forment néanmoins le cadre général sur lequel on peut explorer des pistes d'interprétations. Durant le Sylvicole et la période de Contact, le Témiscouata était fréquenté par des groupes de chasseurs-cueilleurs très mobiles et dont le territoire d'occupation et les liens de parenté étaient principalement axés vers le bassin de la rivière Saint-Jean. Cette vaste région leur offrait diverses sources lithiques, ainsi qu'une faune et une flore abondante et diversifiée. La plupart des archéologues s'entendent pour dire que leur économie de subsistance n'était pas tournée vers l'exploitation intensive d'un nombre restreint de ressources, mais plutôt vers une économie généraliste basée sur une multitude de ressources dont l'accessibilité n'était assurée qu'à certaines périodes de l'année. Ce mode de vie amenait ces communautés à varier leurs schèmes de mobilité et à devoir s'adapter à un environnement changeant grandement chaque saison. S'ils pouvaient se regrouper en de plus grandes agglomérations durant les mois plus chauds, il leur était toutefois nécessaire de fractionner leurs groupes durant l'hiver et d'accroître leur mobilité pour pallier la baisse de productivité alimentaire du territoire. Les nombreux et fréquents déplacements les entraînaient souvent loin des sources de matières premières et il leur fallait alors posséder l'outillage nécessaire pour affronter leurs besoins multiples, variés et changeants (Burke 2000: 58-64, 72-89, 94-100, 333-340; 2009; Chalifoux et al. 1998).

Il est tentant de faire le rapprochement entre le mode de vie " généraliste » des groupes du Témiscouata et leur technologie basée sur des stratégies de production simples, flexibles, mais néanmoins efficaces. Les schèmes techno-économiques observés semblent avoir été élaborés de manière à ce qu'ils puissent s'adapter facilement, et avec un minimum de déviations, aux multiples contextes et matières premières rencontrés au cours de leurs cycles de nomadisme. Sans être l'unique facteur, nous croyons que le contexte socio-économique spécifique à ces communautés serait un élément fondamental dans la manière dont elles ont 
choisi d'organiser l'acquisition, la production, l'utilisation, l'entretien et l'abandon de leurs outils, autant à l'échelle locale que territoriale.

Enfin, en regard de l'approche conceptuelle de notre recherche, soulignons qu'il s'agit d'un des rares exemples d'analyses technologiques (de tradition française) réalisées sur des contextes archéologiques nord-américains. C'est aussi la première étude du genre à être entreprise sur des sites du Témiscouata et de la vallée de la rivière Saint-Jean (Québec, Maine, Nouveau-Brunswick). En considérant le cadre dans lequel cette étude a été menée, il était difficile, voire souvent impossible, de comparer nos résultats avec ceux de recherches équivalentes pour des contextes similaires ou comparables. Même si le portrait dressé dans cet article demeure incomplet, l'objectif initial était de voir dans quelle mesure il était possible de reconnaître des éléments de techno-économie extérieurs au Témiscouata à partir seulement d'évidences archéologiques prélevées sur les sites de cette région. Il est bien certain dans un tel contexte que plusieurs pièces du puzzle demeurent manquantes et que ce dernier ne pourra être complété avant l'étude de collections issues de sites contemporains, mais positionnés en retrait de toutes sources lithiques.

\section{Remerciements}

Je tiens à remercier chaleureusement Adrian Burke, directeur de ma thèse doctorale, pour son encadrement et ses précieux conseils, ainsi que pour les cartes présentées dans cet article. J'exprime ma reconnaissance également à Jacques Chabot qui a codirigé ma thèse et qui a été d'un support non négligeable lors de mes analyses technologiques. Je remercie enfin toutes les personnes qui ont révisé et commenté la version préliminaire de ce texte ou qui ont contribué par leurs commentaires à enrichir mes réflexions.

\section{Références}

Andrefsky, W. 1994a, The Geological Occurrence of Lithic Material and Stone Tool Production Strategies. Geoarchaeology, 9(5): 375-391. (in English) ("L'occurrence géologique du matériel lithique et les stratégies de production des outils en pierre") doi:10.1002/gea.3340090503

Andrefsky, W. 1994b, Raw-Material Availability and the Organization of Technology. American Antiquity, 59(1): 21-34. (in English) ("La disponibilité en matière première et l'organisation de la technologie") doi:10.2307/3085499

Bamforth, D.B. 1991, Technological Organization and Hunter-Gatherer Land Use : A California Example. American Antiquity, 56(2): 216-234. (in English) ("L'organisation technologique et l'utilisation du territoire par les chasseurs-cueilleurs : un exemple de la Californie") doi:10.2307/281416

Bamforth, D.B. 2002, High-Tech Foragers? Folsom and Later Paleoindian Technology on the Great Plains. Journal of World Prehistory, 16(1): 55-98. (in English) ("'High-Tech Foragers"? La technologie des Paléoindiens Folsom et ceux des époques subséquentes des Grandes Plaines") doi:10.1023/A:1014567313865

Bamforth, D.B. 2003, Rethinking the Role of Bifacial Technology in Paleoindian Adaptations on the Great Plains. In: Multiple Approaches to the Study of Bifacial Technologies (Soressi, M. \& Dibble, H.L., Eds.), University of Pennsylvania Museum of Archaeology and Anthropology, Philadelphia: p. 209-228. (in English) ("Repenser le rôle de la technologie bifaciale dans les adaptations paléoindiennes des Grandes Plaines") 
Binford, L.R. 1979, Organization and Formation Processes: Looking At Curated Technologies. Journal of Anthropological Research, 35(3): 251-273. (in English) ("Les processus d'organisation et de formation : regard sur la technologie curated") doi:10.1086/jar.35.3.3629902

Bisson, D. 1990, Premier regard sur l'archéologie du Témiscouata: analyse du site Davidson. Mémoire de maîtrise thesis at the Département d'Anthropologie, Université de Montréal, Montréal, 366 p. (in French) ("First Look at the Archaeology of Témiscouata: The Davidson Site Analysis")

Boëda, É. 1991, Approche de la variabilité des systèmes de production lithique des industries du Paléolithique inférieur et moyen : Chronique d'une variabilité attendue. Techniques et culture, 17-18: 37-79. (in French) ("Approach of the Variability of the lithic production systems of the Lower and Middle Paleolithic industries:: Chronicle of an Expected variability ") doi:10.4000/tc.685

Boëda, É., Geneste, J.-M. \& Meignen, L. 1990, Identification de chaînes opératoires lithiques du Paléolithique ancien et moyen. Paléo 2: 43-79. (in French) ("Identification of Early and Middle Palaeolithic lithic chaînes opératoires") doi:10.3406/pal.1990.988

Brenet, M. 2011, Variabilité et signification des productions lithiques au Paléolithique moyen ancien. L'exemple de trois gisements de plein-air du Bergeracois (Dordogne, France). $\mathrm{PhD}$ thesis at Université Bordeaux 1, Bordeaux, 482 p. (in French) ("Variability and significance of lithic productions in the Early Middle Paleolithic : an analysis of three open-air sites in the Bergeracois region (Dordogne, France)")

Burke, A.L. 1993, The Pelletier Site (CkEe-9), Témiscouata: A Lithic Workshop and Habitation Site. Master thesis at the Département d'Anthropologie, Université de Montréal, Montréal, 120 p. (in English) ("Le site Pelletier (CkEe-9) au Témiscouata: un atelier lithique et un site d'habitation")

Burke, A.L. 2000, Lithic Procurement and the Ceramic Period Occupation of the Interior of the Maritime Peninsula. Thèse de doctorat thesis at the Department of Anthropology, University at Albany - SUNY, Albany, 478 p. (in English) ("L'acquisition du matériel lithique et l'occupation de l'intérieur de la Péninsule Maritime durant la Période Céramique ")

Burke, A.L. 2001, Témiscouata: Traditional Maliseet Territory and Connections between the St.-Lawrence Valley and the St. John River Valley. In: Actes du trente-deuxième congrès des algonquinistes (Ogg, A.C., Ed.), Université du Manitoba, Winnipeg: p. 6173. (in English) ("Témiscouata: territoire malécite traditionnel et les liens entre la vallée du Saint-Laurent et la vallée de la rivière Saint-Jean")

URL: https://ojs.library.carleton.ca/index.php/ALGQP/article/view/420

Burke, A.L. 2003, Archetypal Landscapes and Seascapes: Coastal versus Interior in the Archaeology of the Maritime Peninsula. Northeast Anthropology, 66: 41-55. (in English) ("Paysages terrestres et marins archétypaux: La côte par rapport à l'intérieur dans l'archéologie de la Péninsule Maritime")

Burke, A.L. 2005, Interventions archéologiques menées sur le site CjEd-5 dans la vallée de la rivière Madawaska, Ville de Dégelis, MRC Témiscouata, juillet-août 2004. (Rapport inédit). Université de Montréal, Montréal, 16 p.

Burke, A.L. 2006, Le site CjEd-5 : Lieu d'habitation coutumier et lieu de rituel dans le BasSaint-Laurent. Recherches amérindiennes au Québec, 36(1): 23-36. (in French) ("The 
CjEd-5 site : Customary Place of Residence and Place of Ritual in the Bas-SaintLaurent region")

Burke, A.L. 2007, Quarry Source Areas and the Organization of Stone Tool Technology : A View From Quebec. Archaeology of Eastern North America, 35: 63-80. (in English) ("Les zones de carrières et l'organisation de la technologie des outils en pierre : une perspective du Québec") URL: http://www.jstor.org/stable/40914510

Burke, A.L. 2009, L’archéologie des Malécites : passé, présent et futur. Recherches amérindiennes au Québec, 39(3): 7-24. (in French) ("Maliseet Archeology: Past, Present and Future") doi:10.7202/045799ar

Burke, A.L. \& Chalifoux, É. 1998, Stratégie d'acquisition du chert Touladi et production lithique durant la période du Sylvicole au Témiscouata. In: L'éveilleur et l'ambassadeur: Essais archéologiques et ethnohistoriques en hommage à Charles A. Martijn (Tremblay, R., Ed.), Recherches amérindiennes au Québec, Montréal: p. 33-51. (in French) ("Strategy for the Procurement of Chert Touladi and Lithic Production During the Woodland period in Témiscouata")

Burke, A.L. \& Richard, P.J.H. 2010, L'occupation du Témiscouata pendant l'Archaïque. La comparaison du registre archéologique et du registre paléoenvironnemental. Chapter 5. In: De l'archéologie analytique à l'archéologie sociale (Loewen, B., Chapdelaine, C. \& Burke, A.L., Eds.), Paléo-Québec Vol. 34, Recherches amérindiennes au Québec, Montréal: p. 103-127. (in French) ("The Occupation of Témiscouata During the Archaic. Comparison of the Archaeological record and the Palaeoenvironmental Record")

Chalifoux, É. \& Burke, A. 1995, L'occupation préhistorique du Témiscouata (est du Québec), un lieu de portage entre deux grandes voies de circulation. In: Archéologies québécoises (Balac, A.-M., Chapdelaine, C., Clermont, N. \& Duguay, F., Eds.), Paléo-Québec Vol. 23, Recherches amérindiennes au Québec, Montréal: p. 237-270. (in French) ("The Prehistoric Occupation of Témiscouata (Eastern Quebec), A Portage Between Two Main thoroughfares")

Chalifoux, É., Burke, A.L. \& Chapdelaine, C. 1998, La préhistoire du Témiscouata: Occupations amérindiennes dans la haute vallée de Wolastokuk. Paléo-Québec Vol. 26. Recherches amérindiennes au Québec, Montréal, 155 p. (in French) ("Prehistory of Témiscouata: Native American Occupations in the Upper Wolastokuk Valley")

Chapdelaine, C. 1991, Le site Morin-Martijn (CkEe-26), une carrière de chert au Témiscouata. (Rapport inédit). Département d'anthropologie, Université de Montréal, Montréal, 13 p.

Delmas, V. 2016, Beads and Trade Routes: Tracing Sixteenth-Century Beads around the Gulf and into the Saint Lawrence Valley. Chapter 4. In: Contact in the 16th Century. Networks Among Fishers, Foragers and Farmers (Loewen, B. \& Chapdelaine, C., Eds.), Mercury Series, Archaeology Paper 176, Canadian Museum of History et University of Ottawa Press, Altona: p. 77-115. (in English) ("Perles et routes commerciales: Répertorier les perles du seizième siècle autour du Golfe et de la vallée du Saint-Laurent")

Dumais, P., Poirier, J. \& Rousseau, G. 1998, La préhistoire du Témiscouata, trente ans plus tard. In: L'éveilleur et l'ambassadeur: Essais archéologiques et ethnohistoriques en hommage à Charles A. Martijn (Tremblay, R., Ed.), Paléo-Québec Vol. 27, Recherches 
amérindiennes au Québec, Montréal: p. 53-80. (in French) ("The Prehistory of Témiscouata, Thirty Years Later")

Dumais, P. \& Rousseau, G. 2002, De limon et de sable : Une occupation paléoindienne du début de l'Holocène à Squatec (ClEe-9), au Témiscouata. Recherches amérindiennes au Québec, 32(3): 55-75. (in French) ("From Silt and Sand: Early Paleoindian Occupation of the Holocene at Squatec (ClEe-9), Témiscouata")

Eid, P. 2017, Analyse techno-économique des chaînes opératoires lithiques du Témiscouata (Québec), durant le Sylvicole et la période de Contact. PhD thesis at the Département d'Anthropologie, Université de Montréal, 471 p. (in French) ("Techno-economic analysis of the lithic chaînes opératoires of Témiscouata (Quebec), during the Woodland and the Early Historic period")

Gauthier, G., Burke, A.L. \& Leclerc, M. 2012, Assessing XRF for the geochemical characterization of radiolarian chert artifacts from northeastern North America. Journal of Archaeological Science, 39: 2436-2451. (in English) ("Évaluation du XRF pour la caractérisation géochimique des artefacts en chert à radiolaires du Nord-est de l'Amérique du Nord") doi:10.1016/j.jas.2012.02.019

Geneste, J.-M. 2010, Systèmes techniques de production lithique. Variations technoéconomiques dans les processus de réalisation des outillages paléolithiques. Techniques et culture, 54-55: 419-449. (in French) ("Technical systems of lithic production. Techno-economic variations in the process of Paleolithic tools manufacturing") doi:10.4000/tc.5013

Hofman, J.L. 2003, Tethered to Stone of Freedom to Move: Folsom Biface Technology in Regional Perspective. In: Multiple Approaches to the Study of Bifacial Technologies (Soressi, M. \& Dibble, H.L., Eds.), University of Pennsylvania Museum of Archaeology and Anthropology, Philadelphia: p. 229-249. (in English) ("La technologie bifaciale Folsom dans une perspective régionale")

Hottin, F. 2008, Analyse fonctionnelle des grattoirs du Témiscouata : Tracéologie, morphologie et expérimentation. Master thesis at the Département d'Anthropologie, Université de Montréal, Montréal, 118 p. (in French) ("Use-wear analysis of Temiscouata endscrapers: Traceology, morphology and experimentation")

Inizan, M.-L. 1976, Nouvelle étude d'industries lithiques du Capsien. PhD thesis at Université de Paris X, Paris, 328 p. (in French) ("New Study of Lithic Industries of the Capsian")

Inizan, M.-L. 1980, Série ancienne et économie du débitage. In: Préhistoire et Technologie Lithique (Tixier, J., Ed.), Cahier de l'URA (Unité de Recherche Archéologique) 28, $\mathrm{n}^{0}$ 1, Centre national de la recherche scientifique (CNRS), Paris: p. 28-30. (in French) ("Old collections and economy of the debitage")

Jost, I. 1995, Le site CkEe-12 au Témiscouata: Paléoethnographie d'un atelier de taille. Master thesis at the Département d'Anthropologie, Université de Montréal, Montréal, 250 p. (in French) ("The CkEe-12 Site in Témiscouata: Paleoethnography of a Knapping Workshop")

Kelly, R.L. 1988, The Three Sides of a Biface. American Antiquity, 53(4): 717-734. (in English) ("Les trois côtés d'un biface") doi:10.2307/281115

Kuhn, S.L. 1989, Hunter-Gatherer Foraging Organization and Strategies of Artifact Replacement and Discard. In: Experiments in Lithic Technology (Amick, D.S. \& 
Mauldin, R.P., Eds.), BAR International Series Vol. 528, British Archaeological Reports, Oxford: p. 33-47. (in English) ("Organisation des chasseurs-cueilleurs et stratégies de remplacement et d'abandon des artefacts")

Leclerc, M. 2009, La caractérisation chimique de cherts du Bas-Saint-Laurent et de la Gaspésie : vers le développement d'une méthode d'analyse non destructrice. Mémoire de maîtrise thesis at the Département d'Anthropologie, Université de Montréal, Montréal, 192 p. (in French) ("Chemical Characterization of Cherts from Bas-SaintLaurent and Gaspésie: Towards the Development of a Non-Destructive Method of Analysis")

Lemonnier, P. 1986, The Study of Material Culture Today: Toward an Anthropology of Technical Systems. Journal of Anthropological Archaeology, 5: 147-186. (in English) ("L'étude de la culture matérielle aujourd'hui: vers une anthropologie des systèmes techniques") doi:10.1016/0278-4165(86)90012-7

Lhomme, V. \& Connet, N. 2001, Observations sur les pièces bifaciales et les chaînes opératoires de façonnage dans les sites du Pléistocène moyen de Soucy (Yonne). In: Les industries à outils bifaciaux du Paléolithique moyen d'Europe occidentale. Actes de la table ronde internationale organisée à Caen (Basse-Normandie-France) 14 et 15 octobre 1999 (Cliquet, D., Ed.), Études et Recherches Archéologiques de l'Université de Liège (ERAUL) 98, Liège: p. 43-50. (in French) ("Observations on the Bifacial Artifacts and the Shaping Chaîne Opératoire in the Middle Pleistocene Sites of Soucy (Yonne)")

Loewen, B. 2016, Sixteenth-Century Beads: New Data, New Directions. Chapter 12. In: Contact in the 16th Century. Networks Among Fishers, Foragers and Farmers (Loewen, B. \& Chapdelaine, C., Eds.), Mercury Series, Archaeology Paper 176, Canadian Museum of History et University of Ottawa Press, Altona: p. 269-286. (in English) ("Perles du XVIe siècle : nouvelles données, nouvelles directions")

Lucas, G. \& Hays, M.A. 2004, Les pièces esquillées du site paléolithique du Flageolet I (Dordogne) : outils ou nucléus ? In: Approches fonctionnelles en Préhistoire (Bodu, P. \& Constantin, C., Eds.), XXVème Congrès Préhistorique de France (24-26 novembre 2000), Société Préhistorique Française, Nanterre: p. 107-120. (in French) ("The Pièces Esquillées of the Paleolithic Site of Flageolet I (Dordogne): Tools or Core?")

Marie-Victorin, F.n.C.K. 1918, Le portage du Témiscouata: Notes critiques et documents pour servir à l'histoire d'une vieille route coloniale. Mémoires et comptes rendus de la Societé Royale du Canada, $3^{e}$ série, 12(1): 55-93. (in French) ("The Portage of Témiscouata: Critical Notes and Documents to Serve the History of an Old Colonial Road")

Moncel, M.-H. 2001, Le Paléolithique moyen à outils bifaciaux du sud-est de la France : Réflexion sur un phénomène marginal. In: Les industries à outils bifaciaux du Paléolithique moyen d'Europe occidentale. Actes de la table ronde internationale organisée à Caen (Basse-Normandie-France) 14 et 15 octobre 1999 (Cliquet, D., Ed.), Études et Recherches Archéologiques de l'Université de Liège (ERAUL) 98, Liège: p. 163-172. (in French) ("The Middle Paleolithic Bifacial Tools of South-East France: Reflection on a Marginal Phenomenon")

Morin, J. 1988, Carrière de chert au Témiscouata, rapport d'activités, été 1987. (Rapport inédit). Ministère des Affaires culturelles du Québec, 8 p. 
Odell, G.H. 2001, Stone Tool Research at the End of the Millenium: Classification, Fuction, ans Behavior. Journal of Archaeological Research, 9(1): 45-100. (in English)

("Recherche sur les outils en pierre à la fin du millénaire : classification, fonction et comportement") doi:10.1023/A:1009445104085

Parry, W.J. \& Kelly, R.L. 1987, Expedient core technology and the organization of technology. In: The organization of core technology (Johnson, J.K. \& Morrow, C.A., Eds.), Westview Press, Boulder et London: p. 285-369. (in English) ("Technologie sur nucléus informels et l'organisation de la technologie")

Perlès, C. 1980, Économie de la matière première et économie du débitage : deux exemples grecs. In: Préhistoire et Technologie lithique (Tixier, J., Ed.), Cahier de l'URA (Unité de Recherche Archéologique) 28, $n^{0} 1$, Centre national de la recherche scientifique (CNRS), Paris: p. 37-41. (in French) ("Raw Material Economy and Debitage Economy: Two Greek Examples")

Perlès, C. 1991a, Économie des matières premières et économie du débitage : deux conceptions opposées ? In: 25 ans d'études technologiques en préhistoire. XIe Rencontre Internationales d'Archéologie et d'Histoire d'Antibes, Association pour la promotion et la diffusion des connaissances archéologiques (Éditions APDCA), Juanles-Pins: p. 35-45. (in French) ("Economy of Raw Materials and Economy of Debitage: Two Opposing Conceptions?")

Perlès, C. 1991b, Introduction. In: 25 ans d'études technologiques en préhistoire. XIe Rencontres Internationales d'Histoire et d'Archéologie d'Antibes, Association pour la promotion et la diffusion des connaissances archéologiques (Éditions APDCA), Juanles-Pins: p. 7-10. (in French) ("Introduction")

Ploux, S., Karlin, C. \& Bodu, P. 1992, D'une chaîne l'autre : Norme et variations dans le débitage laminaire magdalénien. Techniques et culture, 17-18: 81-114. (in French) ("From a Chain to Another: Standard and Variations in Magdalenian Blade Debitage")

Porraz, G. 2005, En marge du milieu alpin - Dynamique de formation des ensembles lithiques et modes d'occupation des territoires au Paléolithique moyen. Thèse de doctorat thesis at Université de la Méditerranée - Aix-Marseille II, Aix-en-Provence, 386 p. (in French) ("In the margin of the Alp's environment: Dynamics of lithic assemblages formation and middle palaeolithic settlement patterns") URL: https://tel.archivesouvertes.fr/tel-00078239/

Robitaille, A. \& Saucier, J.-P. 1998, Paysages régionaux du Québec méridional. Les publications du Québec, Sainte-Foy, 213 p. (in French) ("Regional Landscapes of Southern Quebec")

Sanger, D. 2008, Discerning Regional Variation: The Terminal Archaic Period in the Quoddy Region of the Maritime Peninsula Canadian Journal of Archaeology/Journal Canadien d’Archéologie, 32(1): 1-42. ("Discerner les variations régionales : La période de l'Archaïque terminal de la région de Quoddy dans la péninsule maritime") URL: http://www.jstor.org/stable/41103603

Sellet, F. 1999, A Dynamic View of Paleoindian Assemblages at the Hell Gap Site, Wyoming : Reconstructing Lithic Technological Systems Thèse de doctorat thesis at Dedman College, Southern Methodist University, Dallas, 273 p. (in English) ("Une vision dynamique des assemblages paléoindiens du site Hell Gap, Wyoming : reconstruction des systèmes technologiques lithiques") 
Sellet, F. 2006, Two Steps Forward, One Step Back. The Inference of Mobility Patterns from Stone Tools. In: Archaeology and Ethnoarchaeology of Mobility (Sellet, F., greaves, R. \& Yu, P.-L., Eds.), University Press of Florida, Gainesville: p. 221-239. (in English) ("Deux pas en avant, un pas en arrière. L'inférence des modèles de mobilité à partir des outils en pierre")

Soressi, M. 2002, Le Moustérien de tradition acheuléenne du sud-ouest de la France. Discussion sur la signification du faciès à partir de l'étude comparée de quatre sites :Pech-de-l'Azé I, Le Moustier, La Rochette et la Grotte XVI. Thèse de doctorat thesis at the École doctorale des Sciences du vivant - Géoscience, Sciences de l'environnement, Université Bordeaux I, Bordeaux, 330 p. (in French) ("The Mousterian of Acheulean Tradition From Southwestern France. Discussion on the Significance of the Facies From the Comparative Study of Four Sites: Pech-de-l'Azé I, Le Moustier, La Rochette and Grotte XVI") URL: https://tel.archives-ouvertes.fr/tel-00573675/

Straus, L.G. 1991, The Role of Raw Materials in Upper Paleolithic and Mesolithic Stone Artifact Assemblage Variability in Southwest Europe. In: Raw Material Economies among Hunter-Gatherers (Montet-White, A. \& Holen, S., Eds.), University of Kansas Publications in Anthropology Vol. 19, Department of Anthropology, University of Kansas, Lawrence, Kansas: p. 169-185. (in French) ("Le rôle des matières premières dans la variabilité des assemblages d'artefacts en pierre du Paléolithique supérieur et du Mésolithique en Europe du Sud-Ouest")

Turq, A. 2001, Réflexions sur le biface dans quelques sites du Paléolithique ancien-moyen en grotte ou abris du Nord-Est du Bassin Aquitain. In: Les industries à outils bifaciaux du Paléolithique moyen d'Europe occidentale, Actes de la table ronde internationale organisée à Caen (Basse-Normandie-France) 14 et 15 octobre 1999 (Cliquet, D., Ed.), Études et Recherches Archéologiques de l'Université de Liège (ERAUL) 98, Liège: p. 141-149. (in French) ("Reflections on the Biface in Some Ancient-Middle Paleolithic Cave Sites or Shelters in the North-East of the Aquitaine Basin") 


\title{
Imported stone artifacts in a quarry context: the techno- economy of lithic industries from the Temiscouata (Québec) during the Woodland and the early historic period
}

\author{
Patrick Eid \\ Université de Montréal, Montréal, Canada. Email: patrick.eid@artefactuel.ca
}

\begin{abstract}
:
This article presents data on chipped stone techno-economic patterns of nomadic huntersgatherers at a quarry source area in the Témiscouata region (Québec, Canada) during the Middle late Woodland (1500-1000 BP) and the Late Woodland (1000-450 BP) and also the early historic period (450-250 BP). Located in the hinterland of the Bas-Saint-Laurent, in the upper St-John river drainage, the Témiscouata region is rich of many common natural resources, but also by the presence of an important chert outcrop. The Touladi chert is present in two main quarries and is also found in pebbles forms scattered in the vicinity of the surrounding lakes and rivers. We applied a technological analysis, from the technological approach in the French tradition, on five lithic collections in the objectives to reconstruct the chaîne opératoires and their economic management patterns (technoeconomy). This methodology was first applied on the local chert material and afterward on the exotic chipped stone artifacts in order to study the patterns that prevailed while hunters-gatherers were outside the quarries zone and also to understand the influence of the outcrops in the economics patterns.
\end{abstract}

The most prominent artifacts found is of course the numerous flakes which can be derive from three different chaînes opératoires: the bifacial process, the multidirectional (ad hoc) core reduction and the use of pièces esquillées. The production of bifacial tools is the most important process in Témiscouata lithic industries and is the one who produce most of the flakes found on prehistoric settlements. Core reduction sequence is unstandardized and is responsible for just a small part of the flakes product. The pièces esquillées process is only found on two sites and the flakes are generated unintentionally during the used of these artifacts. The tools assemblage is first characterized by the bifacial tools which are mostly manufactured on raw tabular blocks of chert. As for the flake tools, they are mostly represented by informal (ad hoc) tool (retouched and used flakes), endscrapers and pièces esquillées.

Techno-economics patterns on Touladi chert have demonstrated that most of the flake tools were made on flake blanks derived from the bifacial process, mostly from the early and middle stages of this chaîne opératoire. Bifacial process was also fractioned in time and space and we found that bifacial blanks and preforms were carried throughout the territory to be used as "cores". The two other productions are quite secondary in respect of the small amount of tools manufactured and they are far less mobile than the first one.

Exotic materials show similar and different patterns than those observed on local chert. The bifacial process is still the dominant one and the most prominent way to make flake tools when the quarries are remote. Even then, they still use mostly flakes derived from early and intermediate stages of reduction. Core reduction is interesting because it shows different techno-economic patterns. Reduction sequences are more formal or at least more efficient than those observed on Touladi chert. For example, a small discoid core demonstrate a more complex reduction method which allows a greater ratio of flakes production compared to the multidirectional core processes used in the 
Témiscouta region. This is partly a consequence of the exotic raw materials used for cores, which is in the form of small pebbles. But it is also probably an adaptation of the core technology in the purpose of making it more efficient and more productive when knappers were away from lithic sources. However, the use of core technologies was probably a second choice, mostly adopted when the raw material did not allow the manufacture of bifacial tools. Bifaces used as cores seem to have prevailed when it was possible to do so. As for the pièces esquillées, they do not seem to have played an important part in tool fabrication in context of raw material scarcity.

Another interesting aspect of tools manufacturing with exotic materials is the behavior of carrying flake blanks. Every site shows numerous flake blanks, imported and discarded unused, a behavior which reveals that the prehistoric groups were carrying more flakes than their real needs. Conversely of the curated bifacial tools, which were discarded in quarry zone only if their economic threshold was reach (fractures, size too small, inadequate morphology, knapping accidents, etc.), flake tools and flake blanks were mostly discarded at workshop sites in a gearing up strategy. The results demonstrate also that all the flake tools were not managed in the same ways. Endscrappers, unlike the other flake tools, show some evidences of curation, but not as important as bifacial tools. Since they are discarded less quickly than the ad hoc tool and pièces esquillées, this behavior explain probably why the imported endscrappers are found in greater amount at the Témiscouata sites.

The technological analysis shows empiric evidences that hunter-gatherers of the Témiscouata adopted flexible and simple, yet very efficient, techno-economical strategies. These management schemes, which use bifacial chaîne opératoire as the central element of the tool manufacturing, seem well adapted to their way of life based on a generalist, seasonal and flexible subsistence economy. Exotic artifacts, even if they represent a small part of the archaeological record, can reveal important aspects of the organization of past stone tool technologies.

Keywords: lithic technology; techno-economy; chaîne opératoire; exotic materials; Québec; First Nations; prehistory; archaeology 